\title{
Hard to get, hard to keep : dissemination of and exposure to Internet-delivered health behaviour change interventions aimed at adolescents
}

Citation for published version (APA):

Crutzen, R. M. M. (2009). Hard to get, hard to keep : dissemination of and exposure to Internet-delivered health behaviour change interventions aimed at adolescents. [Doctoral Thesis, Maastricht University]. Datawyse / Universitaire Pers Maastricht. https://doi.org/10.26481/dis.20090219rc

Document status and date:

Published: 01/01/2009

DOI:

10.26481/dis.20090219rc

Document Version:

Publisher's PDF, also known as Version of record

Please check the document version of this publication:

- A submitted manuscript is the version of the article upon submission and before peer-review. There can be important differences between the submitted version and the official published version of record.

People interested in the research are advised to contact the author for the final version of the publication, or visit the DOI to the publisher's website.

- The final author version and the galley proof are versions of the publication after peer review.

- The final published version features the final layout of the paper including the volume, issue and page numbers.

Link to publication

\footnotetext{
General rights rights.

- You may freely distribute the URL identifying the publication in the public portal. please follow below link for the End User Agreement:

www.umlib.nl/taverne-license

Take down policy

If you believe that this document breaches copyright please contact us at:

repository@maastrichtuniversity.nl

providing details and we will investigate your claim.
}

Copyright and moral rights for the publications made accessible in the public portal are retained by the authors and/or other copyright owners and it is a condition of accessing publications that users recognise and abide by the legal requirements associated with these

- Users may download and print one copy of any publication from the public portal for the purpose of private study or research.

- You may not further distribute the material or use it for any profit-making activity or commercial gain

If the publication is distributed under the terms of Article 25fa of the Dutch Copyright Act, indicated by the "Taverne" license above, 


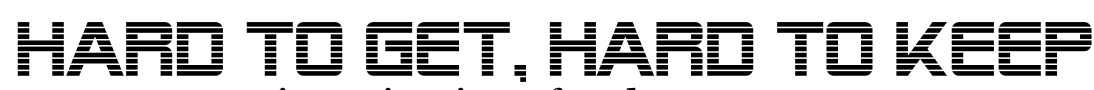

Dissemination of and exposure to

Internet-delivered health behaviour change interventions aimed at adolescents

\section{PROEFSCHRIFT}

ter verkrijging van de graad van doctor aan de Universiteit Maastricht, op gezag van de Rector Magnificus, Prof. mr. G.P.M.F. Mols, volgens het besluit van het College van Decanen,

in het openbaar te verdedigen op donderdag 19 februari 2009 om 12.00 uur

door

RIK CRUTZEN

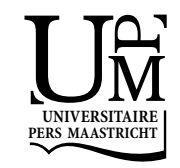




\section{Promotor}

Prof. dr. N.K. de Vries

\section{Copromotor}

Dr. J. de Nooijer

\section{Beoordelingscommissie}

Prof. dr. G.J. Kok (voorzitter)

Prof. dr. R.A. Knibbe

Prof. dr. H. de Vries

Dr. M.C. Willemsen (STIVORO)

Omslagontwerp: Bilbo Schickenberg

Druk: Datawyse / Universitaire Pers Maastricht

(C) Rik Crutzen, Etenaken, 2009

ISBN 978-90-5278-800-5

The studies presented in this dissertation were conducted under the auspices of the school for Public Health and Primary Care (Caphri) at Maastricht University, The Netherlands. The school for Public Health and Primary Care (Caphri) is part of the Netherlands School of Primary Care Research (CaRe), which has been acknowledged since 1995 by The Royal Netherlands Academy of Art en Sciences (KNAW).

This studies presented in this dissertation were supported by a grant from ZonMw - the Netherlands Organization for Health Research and Development (grant 4016.0017). 


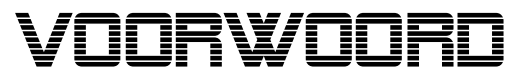

Mijn dank aan eenieder die inhoudelijk dan wel ondersteunend heeft bijgedragen aan deze dissertatie is immens groot. Bij dezen wil ik echter enkele personen in het bijzonder bedanken.

Jascha. De (illusie van) vrijheid die je me gaf, was voor mij de best denkbare begeleidingsvorm.

Nanne. De manier waarop je (ogenschijnlijk) à l'improviste wijze dingen in en over kan brengen, blijft indrukwekkend.

Pap, mam, Mick. Wat zijn wij toch een ideaal gezinnetje. Ongenormaald, doch prettig.

Nico. Laten we de hele wereld rondhuppelen en dansen... tot aon 't morregeleech! 



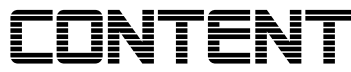

$\begin{array}{ll}\text { General introduction } & 7\end{array}$

Chapter 1 How to facilitate exposure to Internet-delivered 13 health behaviour change interventions aimed at adolescents or young adults? A systematic review on methods, strategies and outcomes

Chapter 2 Internet-delivered interventions aimed at adolescents: a Delphi study on dissemination and exposure

Chapter 3 Qualitative assessment of adolescents' views about improving exposure to Internet-delivered interventions

Chapter 4 A conceptual framework for understanding and improving adolescents' exposure to Internetdelivered interventions

Chapter 5 Effectiveness of online word of mouth on exposure to an Internet-delivered intervention

Chapter 6 Adolescents who intend to change multiple health behaviours choose greater exposure to an Internetdelivered intervention

Chapter 7 Utilising exposure measures of Internet-delivered interventions: a commendable example on smoking behaviour

General discussion

References

Summary

Samenvatting 


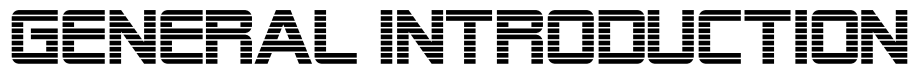




\section{Once upon a time...}

...there was the Internet. This dissertation starts as a fairy tale, since this is in accordance with the way people used to talk about the Internet and its possibilities during the feast days of its growth (in the late nineties of the $20^{\text {th }}$ century). This fairy tale turned out to be true, insofar as the growth of the Internet has been enormous. Recent figures show a worldwide usage acceleration of $291.3 \%$ between 2000 and 2008 (Internet World Stats, 2008b). The Internet penetration rate is $90.1 \%$ in the Netherlands and penetration rates are also high in other countries in western Europe, North America and Australia (Internet World Stats, 2008a).

The Internet is an open medium which is accessible 24/7. It is frequently used as an information source, for information ranging from international news affairs to very specific information about leisure activities. The Internet is also used for entertainment purposes, both active (e.g. gaming) and passive (e.g. video clips). Furthermore, companies use the Internet to offer facilities to their customers, such as online banking and shopping. Moreover, the Internet is being used as a communication channel, both synchronous (instant messaging) and asynchronous (e-mail, discussion boards). Retrieving information, enjoying entertainment, using facilities and communicating with each other are all ways to give Internet users gratification to some extent (McQuail, 1994; Ruggiero, 2000). The Internet, however, can also be used to proffer certain facilities which are not directly related to Internet users' gratification (i.e. health promotion).

Through its interactive character, for example, the Internet is thought to have great potential as a communication channel that can combine a high reach with tailored or targeted health promotion (Brug, Oenema, Kroeze, \& Raat, 2005). The huge increase in possibilities of and access to the Internet has initiated an expansion of Internet-delivered health behaviour change interventions. It has been proven that Internetdelivered interventions can be effective in changing behaviour (De Nooijer, Oenema, Kloek, Brug, De Vries, \& De Vries, 2005; Van den Berg, Schoones, \& Vliet Vlieland, 2007; Vandelanotte, Spathonis, Eakin, \& Owen, 2007), but evidence from efficacy trials indicates that exposure rates are low (De Nooijer et al., 2005). Exposure rates may be even lower when these interventions are implemented in real life rather than in a research setting (Evers, Cummins, Prochaska, \& Prochaska, 2005), since participants tend to spend only a limited amount of time assessing an intervention (Eysenbach, 2005). These findings touch upon critical issues regarding Internet-delivered interventions: How could behaviour change ever be established if people are not or only limitedly exposed to the intervention itself? Prior to this question, it is important to know more about how to attract people to an Internet-delivered intervention among innumerable other websites that probably serve their gratification to a larger extent. These issues pertain to the concepts of dissemination and exposure. 
Successful dissemination of an Internet-delivered intervention is required before participants can be exposed to the intervention content and use its components. Successful dissemination depends on (1) the target population, (2) the source and (3) the intervention itself (Rogers, 2003). This distinction is taken into account in the studies presented in this dissertation. Throughout this dissertation, dissemination means the distribution of the intervention among the target population, including bringing the intervention to the attention of the target population. Exposure comprises paying attention to the intervention content as well as use of the intervention and elaboration to some extent. In terms of Internet-delivered interventions, three different aspects of exposure can be distinguished: (1) accessing the intervention website, i.e. a first visit, (2) staying on the intervention website long enough to use and process the information and (3) revisiting the intervention website. The latter only applies to interventions which are developed to be visited multiple times. There is a possible dose-response relationship between the number of visits and behaviour change outcomes (Lenert et al., 2003; Verheijden, Jans, Hildebrandt, \& Hopman-Rock, 2007; Zebrack, Mitchell, Davids, \& Simpson, 2005).

The studies presented in this dissertation aim to better understand dissemination of and exposure to Internet-delivered behaviour change interventions and therewith providing opportunities to improve this. For feasibility purposes, the focus was only on Internetdelivered health behaviour change interventions which aim to promote healthy behaviour related to the primary prevention of physical chronic diseases. Those physical chronic diseases, especially, have a significant impact on public health in the Netherlands, e.g. cancer, cardiovascular diseases, diabetes mellitus, obesity and HIV/AIDS. Multiple health risk behaviours were addressed in the studies presented, to acquire more general insight into dissemination of and exposure to Internet-delivered interventions.

The presented studies were conducted within the framework of a collaborative project of the Department of Health Promotion at Maastricht University and the Department of Public Health at the Erasmus University Medical Centre. Both research groups addressed different age groups, but the studies presented in this dissertation focus only on adolescents. There were several reasons to make a distinction between adults and adolescents. First, while many health risk behaviours (such as lack of physical activity, low consumption of fruit, cigarettesmoking, unprotected sex and excessive alcohol consumption) are acquired during adolescence, they track into adulthood, thereby affecting not only current health but also health in later life (Kelder, Perry, Klepp, \& Lytle, 1994; Perry, 2000). Second, the current generation of adolescents grew up with the Internet (Tapscott, 1998) and is more open towards new possibilities offered by this medium than today's adults (Leung, 2003). They use the Internet differently than adults (Fox, 2006; Gross, 2004; Hansen, Derry, Resnick, \& Richardson, 2003) and their 
main online activities are instant messaging, gaming, downloading and visiting social-networking websites (Gross, 2004; Van den Eijnden \& Vermulst, 2006) while adults use the Internet mainly for e-mail and information seeking (De Haan, Van 't Hof, \& Van Est, 2006; Jackson, Von Eye, Biocca, Barbatsis, Zhao, \& Fitzgerald, 2005; Van den Eijnden \& Vermulst, 2006). The expectation is therefore that adolescents are susceptible to other factors associated with dissemination of and exposure to Internet-delivered interventions. Third, this age group also poses specific challenges to health promoters. Although they might be interested in feedback on lifestyle behaviours (De Nooijer, Veling, Ton, De Vries, \& De Vries, 2008), this age group is, in contrast to older people who are more often confronted with chronic diseases, not likely to be internally motivated to invest time in behaviour change interventions in the domain of health promotion (De Nooijer et al., 2005). With hindsight, the distinction made in this project between adults and adolescents appeared to be valid, since results differed for both age groups (Crutzen, Brouwer, Brug, De Vries, Oenema, \& De Nooijer, 2008).

Within this project, several existing Internet-delivered interventions were used to conduct applied research on dissemination of and exposure to these interventions. The opportunity to use these interventions resulted from collaborations with other research groups and health promotion institutions. Besides the logistic issue that the intervention needed to be available during the course of this project, the most important criterion was that the intervention consisted of a website offered in a non-controlled setting or a controlled setting (e.g. class period) with freedom to navigate. The latter criterion was added since an intervention consisting of a website without freedom to navigate (i.e. a linear intervention) offered in a controlled setting would guarantee exposure, but also make it impossible to study differences regarding exposure.

\section{Outline of the dissertation}

A systematic approach was used to reach the aim of this dissertation to better understand dissemination of and exposure to Internet-delivered behaviour change intervention and therewith offering opportunities to improve this. The departure point in this dissertation, as well as in the empirical cycle which is often employed in science, is the observation of certain patterns. In this case, the observed pattern which served as departure point was the low exposure rates to Internet-delivered behaviour change interventions aimed at adolescents. Inductive reasoning moves from observations to theory and inductive research is therefore exploratory in nature (Chalmers, 1999). As a consequence, Chapters 1, 2 and 3 describe explorative research regarding dissemination of and exposure to Internet-delivered interventions. This explorative research consists of three studies, covering the literature, experts, and potential users of Internet-delivered interventions. 
Chapter 1 (Crutzen, De Nooijer, Brouwer, Oenema, Brug, \& De Vries, submitted-b) describes a systematic review to determine which methods and strategies are reported to be effective in facilitating exposure.

Chapter 2 (Crutzen, De Nooijer, Brouwer, Oenema, Brug, \& De Vries, 2008a) describes a Delphi study which aims to identify factors, from the point of view of experts in different areas, that are associated with dissemination and exposure and the extent to which experts agree on the importance of these factors. Chapter 3 (Crutzen, De Nooijer, Brouwer, Oenema, Brug, \& De Vries, 2008b) describes focus group interviews with adolescents to gain insight into factors which they consider associated with exposure to Internet-delivered interventions. In Chapter 4 (Crutzen, De Nooijer, Brouwer, Oenema, Brug, \& De Vries, submitted-a) a conceptual framework is proposed for understanding and improving adolescents' exposure to Internet-delivered interventions. Although this framework relates to website design in general, it is applied to Internetdelivered health behaviour change interventions and results from Chapters 2 and 3 will be contextualised. The framework can serve as a tool for health promoters on the one hand, and technical and design staff on the other hand. Furthermore, it can be seen as a theoretical framework to specify hypotheses, after which data (observations) need to be gathered in future research to test these hypotheses and to move forward on the empirical cycle.

Chapters 5, 6 and 7 describe research regarding dissemination of and exposure to Internet-delivered interventions which are applied in real-life settings. In Chapter 5 (Crutzen, De Nooijer, Brouwer, Oenema, Brug, \& De Vries, e-pub ahead of print), an Internet-delivered intervention aimed at changing implicit attitudes related to alcohol was used as an experimental playground to investigate the effect of online word of mouth on exposure. This strategy was derived from the explorative research (Chapters 2 and 3). Chapter 6 (Crutzen, De Nooijer, Candel, \& De Vries, 2008) focuses on the relationship between adolescents' intention to change their behaviour and the use of an Internet-delivered lifestyle intervention aimed at multiple health risk behaviours. This intervention also provided the opportunity to test whether results can be generalised, since multiple health risk behaviours were addressed. In Chapter 7 (Crutzen et al., submitted), the potential of tracking multiple exposure measures and linking them to variables at the individual level was explored, using an Internet-delivered intervention aimed at smoking behaviour as an example.

The results of the presented studies are discussed and integrated in the general discussion, which also offers implications for practice and future research (Crutzen, De Nooijer, \& De Vries, 2008). 


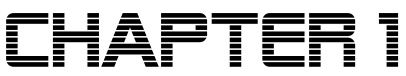

This chapter has been submitted for publication as Crutzen, R., De Nooijer, J., Brouwer, W., Oenema, A., Brug, J., \& De Vries, N. K. How to facilitate exposure to Internet-delivered health behavior change interventions aimed at adolescents or young adults? A systematic review on methods, strategies and outcomes. 


\begin{abstract}
Purpose - The Internet is considered to be a promising delivery channel of interventions aimed at promoting healthful behaviours, especially for adolescents and young adults. It appears, however, that participation or exposure rates are generally low. A more extensive exploration of methods, strategies and their effectiveness with regard to facilitating exposure is therefore timely, since this knowledge is crucial to improve the use of such interventions and subsequently, to increase behavioural change.

Methods - A systematic review of the literature was conducted to identify methods, strategies and their effectiveness with regard to facilitating exposure.

Results - Approximately 12,000 titles were initially identified, of which 26 studies met the eligibility criteria. The systematic review resulted in an overview of methods and strategies which have been used to facilitate exposure

Conclusions - Patterns of effective strategies could be observed, such as the combination of tailored communication and the use of reminders and incentives. Nevertheless, more attention should be paid to the development of theories regarding exposure. Finally, methods and strategies which are used need to be linked to exposure measures and, in the end, to intervention outcome measures, to study potentially mediating effects of exposure on interventions outcomes.
\end{abstract}




\section{Introduction}

The Internet holds the promise of reaching large numbers op people and is very suitable to deliver interventions aimed at primary prevention of physical chronic diseases through health behaviour change (Bernhardt \& Hubley, 2001; De Nooijer \& De Vries, 2006). Internet-delivered interventions may be particularly suitable to reach the current generation of adolescents and young adults, since they grew up with the Internet (Tapscott, 1998) and are probably more open towards new possibilities offered by this medium than today's adults (Leung, 2003). Although this age group might be interested in feedback on lifestyle behaviours (De Nooijer et al., 2008), they are, in contrast to older people who are more often confronted with chronic diseases, not likely to be internally motivated to invest time in health behaviour change interventions (De Nooijer et al., 2005). This age group is, however, an important target group for health promotion, since many health risk behaviours are acquired during this period in life and may track to a certain extend into adulthood, thereby affecting not only current health but also health in later life (Kelder et al., 1994; Perry, 2000; Te Velde, Twisk, \& Brug, 2007). Hence, the focus of this study will be on Internet-delivered interventions aimed at adolescents or young adults.

Research indicates that Internet-delivered interventions can be effective in changing behaviour (De Nooijer et al., 2005; Oenema, Brug, Dijkstra, De Weerdt, \& De Vries, 2008; Van den Berg et al., 2007; Vandelanotte et al., 2007), but evidence from efficacy trials indicates that participation or exposure rates are generally low (De Nooijer et al., 2005). Exposure rates may even be lower when these interventions are implemented in real life (Evers et al., 2005), since participants tend to spend only a limited amount of time at an intervention (Eysenbach, 2005). True exposure, that is accessing the intervention as well as paying attention to the intervention content and active use and elaboration of the intervention components, is necessary for an intervention to induce behaviour changes (McGuire, 1985). For Internet-delivered interventions, at least three different aspects of exposure can be distinguished: (1) accessing the intervention website, i.e. a first visit, (2) staying on the intervention website long enough to use and process the information and (3) revisiting the intervention website. The latter only applies to interventions which are developed to be visited multiple times. A systematic review of the literature was conducted to gain insight into the potential effects of methods and strategies aimed at improving exposure to Internet-delivered interventions. A more extensive exploration is timely, since this knowledge is crucial to improve the use of such interventions and consequently, to increase behavioural change.

Whereas a method is a theory-based technique, a strategy is a way of organising, operationalising, and delivering the method (Bartholomew, Parcel, Kok, \& Gottlieb, 2006). For example, sending email messages to encourage participants to visit the intervention and set goals for reducing and eliminating cigarette use (An et al., 2006) would 
be a practical strategy based on the theory-based technique of goal setting. We expect that methods and strategies that facilitate exposure can vary in effectiveness for different target groups, since these groups can differ in online experience and motivation to change behaviour. Our aim was to gain insight into which methods and strategies are effective in facilitating exposure to Internet-delivered interventions aimed at primary prevention of physical chronic diseases through behaviour change and aimed at adolescents or young adults. Several research questions (RQ) were answered to reach this aim:

- $R Q 1$ Which methods and strategies are used to facilitate exposure to existing Internet-delivered interventions?

- $R Q 2$ Which theories or empirical data are used to base these methods and strategies on?

- $R Q 3$ Which outcomes are used to measure exposure to Internetdelivered interventions and how are they linked to strategies used in Internet-delivered interventions?

- RQ4 How does exposure to Internet-delivered interventions relate to strategies used and theories or empirical data on which these strategies are based?

- RQ5 How does exposure relate to actual outcome measures of the interventions?

\section{Methods}

A systematic review was conducted, according to the Cochrane guidelines (Higgins \& Green, 2006), to answer these questions.

\section{Search strategy}

We searched (February 18, 2008) the PubMED, PsycINFO and Web of Science databases using the following query: (Internet* OR web* OR online*) AND (prevention OR intervention OR "health promotion" OR "health education" OR "health communication" OR (behav* AND change)). The search was limited to the time period January 1, $1995-$ January 1, 2008 and to literature in English. We deliberately used a very broad search strategy to firstly include as much literature as possible and reduce the possibility of omissions.

\section{Selection criteria}

A study was eligible (see Table 1.1 for criteria) for inclusion when describing an Internet-delivered intervention aimed at the primary prevention of physical chronic diseases through behaviour change, targeted at adolescents or young adults (aged 12-25) and which consisted of a website offered in a non-controlled setting or a controlled setting (e.g. class period) with freedom to navigate. The latter restriction was added since an intervention consisting of a website without freedom to navigate (i.e. linear) offered in a controlled setting would guarantee full exposure, but would make it impossible to study the effectiveness of methods and strategies used to facilitate exposure. 
Table 1.1 Inclusion and exclusion criteria used to identify relevant studies

\begin{tabular}{ll}
\hline Inclusion criteria & Exclusion criteria \\
\hline Original articles published in & Editorials, commentaries, book \\
peer-reviewed journals. & reviews, bibliographies, (systematic) \\
& reviews, meta-analyses, handbooks, \\
& abstracts, errata or conference \\
& proceedings.
\end{tabular}

Studies describing interventions aimed at the primary prevention of physical chronic diseases by changing determinants or healthrelated behaviour.

Studies describing interventions targeted at participants between 12 and 25 years.

Studies describing interventions, at least partly, targeted at end users.

Studies describing interventions which, at least partly, consist of a website targeted at the general public between 12 and 25 years.

Website offered in a noncontrolled setting or a controlled setting (e.g. class period) with freedom to navigate.

Studies that describe evaluation of the intervention.
Studies describing interventions aimed at secondary or tertiary prevention, therapy or treatment of physical chronic diseases or interventions aimed at mental disorders or non-chronic diseases.

Studies describing...

- interventions (partly) targeted at participants younger than 12 years or older than 25 years (e.g. all people above 18 years).

- interventions targeted at patients.

- interventions targeted at institutionalised participants.

Studies describing interventions targeted at intermediaries (e.g. doctor, nurse, dietician, parent, or teacher) only.

Studies describing interventions which do not consist of a website targeted at the general public between 12 and 25 years.

Website offered in a controlled setting (e.g. class period) without freedom to navigate.

Studies that do not describe evaluation of the intervention. 


\section{Review procedure}

The review procedure comprised three phases to identify relevant studies and was performed independently by two reviewers. During the first phase, studies were reviewed based on title only. If in doubt, studies were included for the second phase during which they were reviewed based on their abstract. If still in doubt, we included the study for the third phase during which the full article was reviewed. After this phase, both reviewers ( $\mathrm{RC}$ and $\mathrm{JdN}$ ) discussed whether studies met the inclusion criteria until agreement was reached. To identify more eligible studies, the same procedure was repeated for articles in reference lists of included studies.

\section{Data abstraction}

A standardised extraction form was used to summarise intervention and sample characteristics, methods and strategies which could facilitate exposure, theories or empirical data on which they were based, and exposure measures. Two reviewers ( $\mathrm{RC}$ and $\mathrm{JdN}$ ) independently gathered the relevant information and discussed this afterwards to improve the reliability of their data abstraction. Methods and strategies were labelled for the sake of clarity and both reviewers fully agreed on this labelling. Corresponding authors of included studies were contacted by e-mail (April, 2008) to complete the extraction forms (if insufficient information was found in the article). Initially, the authors had three weeks to respond, but we sent a reminder by e-mail after three weeks to increase the response rate (May, 2008).

\section{Results}

Over 12,00o titles were initially identified, of which 26 studies met the eligibility criteria. There was full agreement between the two reviewers, although it is possible that there were multiple and different reasons why a study could be excluded. Figure 1.1 gives an overview of the different phases of the review procedure.

These 26 studies described 22 interventions which were related to smoking cessation (8), sexual behaviour (4), alcohol use (4), physical activity (2), nutrition (1), physical activity and nutrition (1), health and lifestyles in general (1) and weight loss (1). Table 1.2 provides an overview of the interventions that were included and their sample characteristics.

All corresponding authors $(N=21)$ were contacted of whom fourteen (67\%) responded to our request to complete the extraction forms. Table 1.3 summarises all data abstracted from the articles and information provided by the corresponding authors and was used to answer our research questions. Six interventions were excluded from this table, since information regarding methods and strategies used to facilitate exposure (Gilbert, Temby, \& Rogers, 2005) or exposure measures (Chen, Yeh, \& 
Chao, 2006; Chiauzzi, Green, Lord, Thum, \& Goldstein, 2005; Evers \& Carol, 2007; Obermayer, Riley, Asif, \& Jean-Mary, 2004; Walters, Vader, $\&$ Harris, 2007) was unavailable, resulting in data from sixteen interventions for the present review.

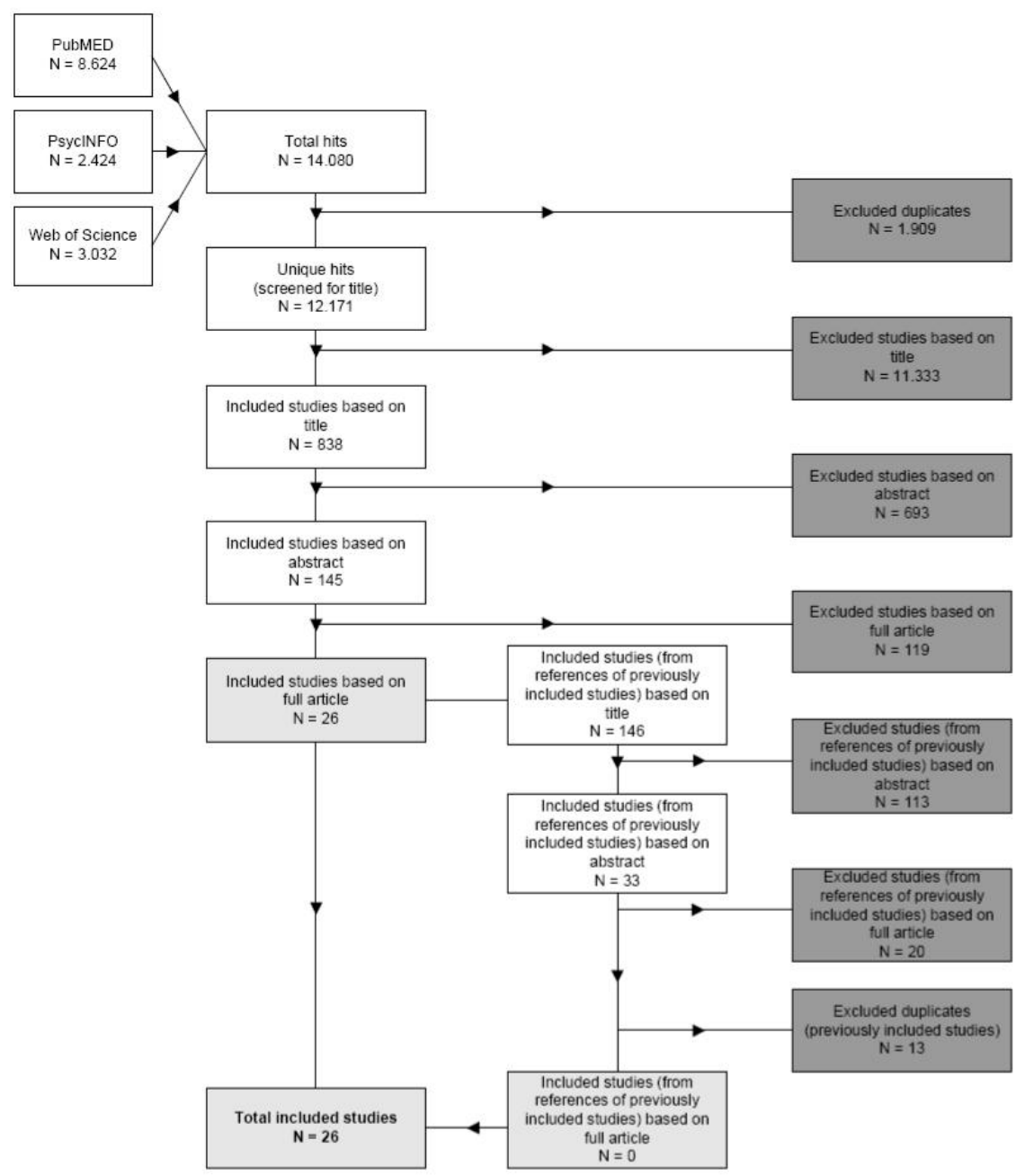

Figure 1.1 Flow-chart review procedure 
Table 1.2 Intervention and sample characteristics

\begin{tabular}{|c|c|c|c|c|c|}
\hline \multirow[t]{2}{*}{ Study } & \multirow{2}{*}{$\begin{array}{l}\text { Topic } \\
\text { (Name): } \\
\text { Description }\end{array}$} & \multirow{2}{*}{$\begin{array}{l}\text { Target } \\
\text { group } \\
\text { (Country) }\end{array}$} & \multicolumn{3}{|c|}{ Participants ${ }^{1}$} \\
\hline & & & $N$ & Age & $\begin{array}{l}\text { p } \\
\text { (\%) }\end{array}$ \\
\hline $\begin{array}{l}\text { An et al. } \\
\text { (2006) }\end{array}$ & $\begin{array}{l}\text { smoking } \\
\text { cessation } \\
\text { (RealU): } \\
\text { college life } \\
\text { magazine }\end{array}$ & $\begin{array}{l}\text { college } \\
\text { smokers } \\
\text { (USA) }\end{array}$ & 257 & $\begin{array}{l}\mathrm{M}=20.1 \\
(\mathrm{SD}=1.6)\end{array}$ & 70.4 \\
\hline $\begin{array}{l}\text { Barak and } \\
\text { Fisher } \\
\text { (2003) }\end{array}$ & $\begin{array}{l}\text { sexual } \\
\text { behaviour } \\
\text { (Sexuality } \\
\text { and u / Ma } \\
\text { sexualité): } \\
\text { educational } \\
\text { resource }\end{array}$ & $\begin{array}{l}\text { adolescents } \\
\text { (Canada) }\end{array}$ & N.A. & N.A. & N.A. \\
\hline $\begin{array}{l}\text { Chen and } \\
\text { Yeh (2006) }\end{array}$ & $\begin{array}{l}\text { smoking } \\
\text { cessation: } \\
\text { addition to } \\
\text { offline } \\
\text { intervention }\end{array}$ & $\begin{array}{l}\text { adolescent } \\
\text { smokers } \\
\text { (Taiwan) }\end{array}$ & 39 & $\begin{array}{l}\mathrm{M}=17(\mathrm{SD} \\
=0.68)\end{array}$ & N.A. \\
\hline $\begin{array}{l}\text { Chen et al. } \\
\text { (2006) }\end{array}$ & $\begin{array}{l}\text { smoking } \\
\text { cessation: } \\
\text { addition to } \\
\text { auricular } \\
\text { acupressure }\end{array}$ & $\begin{array}{l}\text { adolescent } \\
\text { smokers } \\
\text { (Taiwan) }\end{array}$ & 38 & N.A. & o \\
\hline $\begin{array}{l}\text { Chiauzzi et } \\
\text { al. (2005) }\end{array}$ & $\begin{array}{l}\text { alcohol use } \\
\text { (My Student } \\
\text { Body) }\end{array}$ & $\begin{array}{l}\text { college } \\
\text { students } \\
\text { (USA) }\end{array}$ & 131 & $\begin{array}{l}M=20.0 \\
(S D=1.7)\end{array}$ & 54.2 \\
\hline $\begin{array}{l}\text { Escoffery et } \\
\text { al. (2004) }\end{array}$ & $\begin{array}{l}\text { smoking } \\
\text { cessation } \\
\text { (Kick It!) }\end{array}$ & $\begin{array}{l}\text { college } \\
\text { smokers } \\
\text { (USA) }\end{array}$ & 35 & $M=21$ & 57.1 \\
\hline $\begin{array}{l}\text { Evers and } \\
\text { Carol (2007) }\end{array}$ & $\begin{array}{l}\text { nutrition and } \\
\text { physical } \\
\text { activity: } \\
\text { assessment } \\
\text { tool }\end{array}$ & $\begin{array}{l}\text { college } \\
\text { students } \\
\text { (USA) }\end{array}$ & 84 & N.A. & N.A. \\
\hline
\end{tabular}




\begin{tabular}{|c|c|c|c|c|c|}
\hline $\begin{array}{l}\text { Gilbert et al. } \\
(2005)\end{array}$ & $\begin{array}{l}\text { sexual } \\
\text { behaviour } \\
\text { (I wanna } \\
\text { know): open } \\
\text { access }\end{array}$ & $\begin{array}{l}\text { adolescents } \\
\text { (USA) }\end{array}$ & 1242 & $\begin{array}{l}13: 11.7 \% \\
14: 16.9 \% \\
15: 24.4 \% \\
16: 25.2 \% \\
17: 21.8 \%\end{array}$ & 73.8 \\
\hline $\begin{array}{l}\text { Long et al. } \\
(2006)\end{array}$ & $\begin{array}{l}\text { nutrition: } \\
\text { interactive } \\
\text { educational } \\
\text { website }\end{array}$ & $\begin{array}{l}\text { minority } \\
\text { adolescents } \\
\text { (USA) }\end{array}$ & 21 & $M=13$ & 42.9 \\
\hline $\begin{array}{l}\text { Lou et al. } \\
\text { (2006) }\end{array}$ & $\begin{array}{l}\text { sexual } \\
\text { behaviour } \\
\text { (Youthhood) }\end{array}$ & $\begin{array}{l}\text { adolescents } \\
\text { and } \\
\text { unmarried } \\
\text { youth } \\
\text { (China) }\end{array}$ & 624 & $\begin{array}{l}\leq 15: 20.7 \% \\
16: 22.9 \% \\
17: 2.6 \% \\
18: 20.2 \% \\
\geq 19: 33.6 \%\end{array}$ & 39.7 \\
\hline $\begin{array}{l}\text { Marks et al. } \\
(2006)\end{array}$ & $\begin{array}{l}\text { physical } \\
\text { activity } \\
\text { (LifeBytes) }\end{array}$ & $\begin{array}{l}\text { adolescent } \\
\text { girls (USA) }\end{array}$ & 181 & $\begin{array}{l}\mathrm{M}=12.2 \\
(\mathrm{SD}=1.0)\end{array}$ & 100 \\
\hline $\begin{array}{l}\text { Mermelstein } \\
\text { and Turner } \\
\text { (2006) }\end{array}$ & $\begin{array}{l}\text { smoking } \\
\text { cessation } \\
\text { (NOT Plus): } \\
\text { addition to } \\
\text { Not on } \\
\text { Tobacco } \\
\text { intervention }\end{array}$ & $\begin{array}{l}\text { adolescent } \\
\text { smokers } \\
\text { (USA) }\end{array}$ & 181 & $\begin{array}{l}M=16.3 \\
(1.04)\end{array}$ & 55.2 \\
\hline $\begin{array}{l}\text { Michaud } \\
\text { and Colom } \\
(2003)\end{array}$ & $\begin{array}{l}\text { health and } \\
\text { lifestyles } \\
\text { (Ciao) }\end{array}$ & $\begin{array}{l}\text { adolescents } \\
\text { (Switzer- } \\
\text { land) }\end{array}$ & N.A. & N.A. & 63 \\
\hline $\begin{array}{l}\text { Obermayer } \\
\text { et al. (2004) }\end{array}$ & $\begin{array}{l}\text { smoking } \\
\text { cessation: } \\
\text { integrated } \\
\text { web and text- } \\
\text { messaging } \\
\text { intervention }\end{array}$ & $\begin{array}{l}\text { college } \\
\text { smokers } \\
\text { (USA) }\end{array}$ & 46 & $\begin{array}{l}M=19.9 \\
(S D=1.5)\end{array}$ & 46 \\
\hline $\begin{array}{l}\text { Patten et al. } \\
\text { (2006; } \\
2007)\end{array}$ & $\begin{array}{l}\text { smoking } \\
\text { cessation } \\
\text { (Stomp Out } \\
\text { Smokes) }\end{array}$ & $\begin{array}{l}\text { adolescent } \\
\text { smokers } \\
\text { (USA) }\end{array}$ & 70 & $\begin{array}{l}M=15.7 \\
(S D=1.3)\end{array}$ & 50 \\
\hline $\begin{array}{l}\text { Roberto et } \\
\text { al. (2007) }\end{array}$ & $\begin{array}{l}\text { sexual } \\
\text { behaviour }\end{array}$ & $\begin{array}{l}\text { rural } \\
\text { adolescents } \\
\text { (USA) }\end{array}$ & 139 & $\begin{array}{l}M=15.5 \\
(S D=0.6)\end{array}$ & 58.3 \\
\hline
\end{tabular}




\begin{tabular}{|c|c|c|c|c|c|}
\hline $\begin{array}{l}\text { Saitz et al. } \\
(2007)\end{array}$ & $\begin{array}{l}\text { alcohol use: } \\
\text { screening } \\
\text { and brief } \\
\text { intervention }\end{array}$ & $\begin{array}{l}\text { college } \\
\text { freshman } \\
\text { students } \\
\text { with } \\
\text { unhealthy } \\
\text { alcohol use } \\
\text { (USA) }\end{array}$ & 650 & $\begin{array}{l}M=18.14 \\
(\mathrm{SD}=0.42)\end{array}$ & 63.7 \\
\hline $\begin{array}{l}\text { Suminski } \\
\text { and Petosa } \\
(2006)\end{array}$ & $\begin{array}{l}\text { physical } \\
\text { activity: } \\
\text { addition to } \\
\text { offline } \\
\text { information }\end{array}$ & $\begin{array}{l}\text { college } \\
\text { students } \\
\text { (USA) }\end{array}$ & 127 & $\begin{array}{l}M=21.3 \\
(S D=5.5)\end{array}$ & 65.4 \\
\hline $\begin{array}{l}\text { Thombs et } \\
\text { al. (2007) }\end{array}$ & alcohol use & $\begin{array}{l}\text { college } \\
\text { freshman } \\
\text { students } \\
\text { (USA) }\end{array}$ & 192 & ca. $18-19$ & $\begin{array}{l}\text { ca. } \\
2 / 3\end{array}$ \\
\hline $\begin{array}{l}\text { Walters et } \\
\text { al. (2007) }\end{array}$ & alcohol use & $\begin{array}{l}\text { college } \\
\text { freshman } \\
\text { students } \\
\text { (USA) }\end{array}$ & 50 & $\begin{array}{l}M=18.24 \\
(\mathrm{SD}=.771)\end{array}$ & 50 \\
\hline $\begin{array}{l}\text { White et al. } \\
(2004) ; \\
\text { Williamson } \\
\text { et al. (2005; } \\
2006)\end{array}$ & $\begin{array}{l}\text { weight loss } \\
\text { (HIPTeens): } \\
\text { interactive } \\
\text { behaviour } \\
\text { therapy vs. } \\
\text { passive } \\
\text { health } \\
\text { education } \\
\text { group }\end{array}$ & $\begin{array}{l}\text { overweight } \\
\text { adolescent } \\
\text { African- } \\
\text { American } \\
\text { girls with at } \\
\text { least one } \\
\text { obese } \\
\text { biological } \\
\text { parent } \\
\text { (USA) }\end{array}$ & 57 & $\begin{array}{l}M=13.19 \\
(S D=1.37)\end{array}$ & 100 \\
\hline $\begin{array}{l}\text { Woodruff et } \\
\text { al. (2008; } \\
2007)\end{array}$ & $\begin{array}{l}\text { smoking } \\
\text { cessation } \\
\text { (Breathing } \\
\text { Room): } \\
\text { counselling } \\
\text { intervention } \\
\text { in virtual } \\
\text { world }\end{array}$ & $\begin{array}{l}\text { adolescent } \\
\text { smokers } \\
\text { (USA) }\end{array}$ & 77 & $\begin{array}{l}M=16.5 \\
\text { Range: } 14^{-} \\
19\end{array}$ & 49 \\
\hline
\end{tabular}


Table 1.3 Methods, strategies, foundation and outcomes regarding exposure to Internet-delivered interventions

\begin{tabular}{|c|c|c|}
\hline $\begin{array}{l}\text { Study / } \\
\text { Setting }\end{array}$ & Methods, strategies and foundation ${ }^{1}$ & Outcomes \\
\hline $\begin{array}{l}\text { An et al. } \\
\text { (2006) / } \\
\text { Twenty } \\
\text { weeks } \\
\text { during } \\
\text { which } \\
\text { participants } \\
\text { should visit } \\
\text { every week. }\end{array}$ & $\begin{array}{l}\text { Providing a broader focus on } \\
\text { college life to [S] maintain } \\
\text { engagement with our audience on } \\
\text { several fronts [M] that would } \\
\text { eventually link back to anti- } \\
\text { smoking messages [S]. (targeted } \\
\text { communication) } \\
\text { Linear structure, with participants } \\
\text { guided step-by-step through } \\
\text { specific weekly tasks [S]. The } \\
\text { benefits of a simple linear design } \\
\text { may be particularly pronounced } \\
\text { when a participant's investment in } \\
\text { a website is low [T]. (accessible } \\
\text { content) } \\
\text { Peer coaches who provided weekly } \\
\text { proactive personal e-mail support } \\
\text { [S]. E-mail messages encouraged } \\
\text { participants to set goals for } \\
\text { reducing or eliminating cigarette } \\
\text { use [M]. Peer support e-mails may } \\
\text { create a greater sense of connection } \\
\text { with the website [S]. (peer support) } \\
\text { The interactive quiz was the } \\
\text { primary mechanism for presenting } \\
\text { tailored messages [S]. (interactive } \\
\text { content; tailored communication) } \\
\text { Peer coaches provided follow-up e- } \\
\text { mail messages to individuals who } \\
\text { had not yet completed weekly tasks } \\
\text { [S]. (invitations/reminders) } \\
\text { US\$10 gifts for each week of } \\
\text { participation [S]. (incentives) }\end{array}$ & $\begin{array}{l}\text { Participation (= } \\
\text { return to website } \\
\text { and complete } \\
\text { weekly tracker and } \\
\text { interactive quiz): } \\
\mathrm{M}=95 \% \text {; range } \\
89 \%-98 \% \text {; no } \\
\text { decline over } 20 \\
\text { weeks. } \\
\text { No difference } \\
\text { between weekly } \\
\text { interactive quizzes } \\
\text { that addressed } \\
\text { smoking compared } \\
\text { with general } \\
\text { interest quizzes ( } p \\
=.90) \text {. }\end{array}$ \\
\hline $\begin{array}{l}\text { Barak and } \\
\text { Fisher } \\
(2003) /\end{array}$ & $\begin{array}{l}\text { Attractive, accessible, functional, } \\
\text { and conveying expert and up-to- } \\
\text { date content, in text and graphic }\end{array}$ & $\begin{array}{l}\text { Frequency: } \\
\text {-unique visitors: } \\
75869 / 79888\end{array}$ \\
\hline
\end{tabular}




\begin{tabular}{|c|c|c|}
\hline \multirow[t]{2}{*}{$\begin{array}{l}\text { Approx. } \\
\text { eight } \\
\text { months. }\end{array}$} & $\begin{array}{l}\text { form, and with as much } \\
\text { interactivity as possible [S]. } \\
\text { (interactive content) }\end{array}$ & $\begin{array}{l}\text { (English/French) } \\
\text {-visited more than } \\
\text { once: } 9821 / 11187\end{array}$ \\
\hline & $\begin{array}{l}\text { Guided by the Information- } \\
\text { Motivation-Behavioural skills } \\
\text { (IMB) model [T], information was } \\
\text { script-like in nature and could } \\
\text { easily be deployed [S]. (accessible } \\
\text { content) }\end{array}$ & $\begin{array}{l}\text { Duration: } \\
\text {-time per visit: } \mathrm{M} \\
\text { = 11:53/10:23 min. } \\
\text {-home: } \mathrm{M}= \\
\text { o:36/0:34 } \\
\text {-quiz: } \mathrm{M}= \\
\text { o:06/0:30 }\end{array}$ \\
\hline $\begin{array}{l}\text { Chen and } \\
\text { Yeh (2006) / } \\
\text { A six-week } \\
\text { intervention. }\end{array}$ & $\begin{array}{l}\text { A discussion forum was set up to } \\
\text { share thoughts and feelings during } \\
\text { the cessation process and to receive } \\
\text { peer-to-peer support [S], thereby } \\
\text { strengthening their willingness to } \\
\text { quit smoking [T]. (peer support; } \\
\text { discussion board) }\end{array}$ & $\begin{array}{l}\text { Frequency: } \\
\text {-use: } \mathrm{M}=14.7 \\
\text { range: } 0-197 \\
\text {-discussion } \\
\text { posted: } \mathrm{M}=3.6 ; \\
\text { range } 0-33\end{array}$ \\
\hline $\begin{array}{l}\text { Escoffery et } \\
\text { al. (2004) / } \\
\text { Four } \\
\text { sessions; } \\
\text { each } \\
\text { available for } \\
\text { two weeks. }\end{array}$ & $\begin{array}{l}\text { Four sessions applying the } \\
\text { Transtheoretical Model of Change } \\
\text { and the theory of social support [T]. } \\
\text { Tailored messages based on staging } \\
\text { question at each intervention } \\
\text { session [S]. Major steps for each } \\
\text { stage of change were outlined with } \\
\text { advanced organisers as headings to } \\
\text { serve as learning guides [S]. } \\
\text { Through personalised } \\
\text { assessments, smokers could enter } \\
\text { pros and cons of smoking, reasons } \\
\text { for quitting smoking, goals related } \\
\text { to quitting, and individuals who can } \\
\text { offer support in their decision to } \\
\text { quit. Afterwards they received } \\
\text { immediate feedback [S]. (tailored } \\
\text { communication) } \\
\text { Social support components: } \\
\text { opportunities to ask-the-expert } \\
\text { questions by e-mailing questions; } \\
\text { share stories through a personal } \\
\text { story area; talk to other participants } \\
\text { through stage-matched discussion } \\
\text { boards [S]. (professional support; } \\
\text { peer support; discussion board) }\end{array}$ & $\begin{array}{l}\text { Frequency (use): } \\
\text { (self-report) } \\
\text { 94\% all sessions } \\
\text {-text: } 94.1 \% \\
\text {-quizzes: 88.2\% } \\
\text {-quitting } \\
\text { resources: } 64.7 \% \\
\text {-personal stories: } \\
\text { 23.5\% } \\
\text {-ask-the-expert: } \\
\text { 5.9\% } \\
\text {-discussion } \\
\text { boards: } 23.5 \% \\
\text {-Q\&A: } 29.4 \% \\
\text {-top ten reasons } \\
\text { contest: 35.3\% } \\
\text { (tracking system) } \\
\text { 60\% all sessions } \rightarrow \\
\text { 82.4\% agreement } \\
\text { with self-report }\end{array}$ \\
\hline
\end{tabular}


The web architecture was created applying principles of web usability guidelines [S]. The design of the website also employed usability guidelines; use of consistent placement of the intervention logo and navigation, consistent layout throughout the whole website, short sentences, small graphic files, and concise, clearly labelled navigation buttons [S]. (accessible content)

Participants received US $\$ 5$ for each session [S]. (incentives)

Long et al. Website tailored to the social and (2006) / Three weeks. adolescents [S].

The nutrition education experience was designed to be age relevant, fun, and participatory [S] - capturing adolescent attention while allowing individual control over the pace of learning [T]. Website utilised an edutainment approach to learning by blending education and entertainment [S]. (targeted communication)

Intervention was delivered in the school's computer class-room 45 minutes before school began over a 3-week period [S]. (social context)

Incentives were provided to attend the sessions. Participants could select from an assortment of ageappropriate small, inexpensive items such as notebooks, pens, stickers, etc. for attending. One larger "grand prize" was given at the end of the 3 week period [S]. (incentives)
Duration (attendance): $\mathrm{M}=$ 5 hours 


\begin{tabular}{|c|c|c|}
\hline $\begin{array}{l}\text { (2006) / Ten } \\
\text { months } \\
\text { during } \\
\text { which the } \\
\text { website was } \\
\text { updated } \\
\text { every two } \\
\text { weeks. }\end{array}$ & $\begin{array}{l}\text { reproductive health knowledge and } \\
\text { services information by web pages; } \\
\text { (2) ten 10-minute educational } \\
\text { videos were posted; (3) professional } \\
\text { counselling by e-mail; (4) } \\
\text { discussion on the bulletin board } \\
\text { system [S]. At baseline, expert e- } \\
\text { mail was cited by 54\% as preferable } \\
\text { and online discussion by 30\% [E]. } \\
\text { (professional support; discussion } \\
\text { board) } \\
\text { Information of the website was } \\
\text { provided by writing " A letter to } \\
\text { adolescents" to students, "A letter } \\
\text { to adolescents' parents" to parents, } \\
\text { informing teachers of these } \\
\text { intervention schools/university } \\
\text { (who would inform the information } \\
\text { to their students), and } \\
\text { disseminating a small card (like a } \\
\text { name card) with the information of } \\
\text { the website to each student [S]. } \\
\text { (invitations/reminders) }\end{array}$ & $\begin{array}{l}\text { 15357 visits/10 } \\
\text { months } \\
\text { Per month (visits): } \\
\text { 0: } 6.3 \% \\
\text { < 1: } 26.9 \% \\
\text { 1-4: } 61.1 \% \\
\geq 5: 5.7 \% \\
\text { Per activity: } \\
\text {-e-mail } \\
\text { counselling: used } \\
\text { 11 times } \\
\text {-discussion on the } \\
\text { bulletin board } \\
\text { system: } 452 \\
\text { participants } \\
\text { registered; only a } \\
\text { few posted } \\
\text { comments } \\
\\
\text { Duration (in } \\
\text { minutes per visit): } \\
\text { < 10: } 16.3 \% \\
\text { 10-20: } 43.8 \% \\
\geq 20: 39.9 \%\end{array}$ \\
\hline $\begin{array}{l}\text { Marks et al. } \\
\text { (2006) / } \\
\text { Two-week } \\
\text { period in } \\
\text { which } \\
\text { participants } \\
\text { should } \\
\text { review the } \\
\text { materials at } \\
\text { least four } \\
\text { times. }\end{array}$ & $\begin{array}{l}\text { Website included interactive games, } \\
\text { a quiz, downloadable charts to plan } \\
\text { daily activities, and interactive } \\
\text { demonstrations of different types of } \\
\text { activities [S]. These addressed } \\
\text { barriers and benefits of physical } \\
\text { activity, goal setting, and social } \\
\text { support [T]. (interactive content) }\end{array}$ & $\begin{array}{l}\text { Frequency (views; } \\
\text { self-report): } \\
\text { 1-3: } 45 \% \\
\text { 4-6: } 25 \% \\
\text { 7-10: } 13 \% \\
>10: 16 \% \\
\text { Duration (in total; } \\
\text { self-report): } \\
M=89( \pm 64.8) \\
\text { minutes }\end{array}$ \\
\hline $\begin{array}{l}\text { Mermelstein } \\
\text { and Turner } \\
\text { (2006) / } \\
\text { Website } \\
\text { available } \\
\text { throughout } \\
\text { the whole } \\
\text { intervention. }\end{array}$ & $\begin{array}{l}\text { Website contained facts about } \\
\text { smoking and health; motivational } \\
\text { messages from teens who had quit; } \\
\text { strategies and tips for not smoking; } \\
\text { and access to incentive gear [S]. } \\
\text { (peer support; incentives) }\end{array}$ & $\begin{array}{l}\text { Frequency: } \\
\text {-Visiting: } 56.9 \% \\
\text { (self-report) } \\
\text {-Number of pages: } \\
\mathrm{M}=14.5 \text { (SD = } \\
12.8 \text { ) } \\
\text { Duration: } \\
\mathrm{M}=33.0 \text { (SD = } \\
\text { 32.3) minutes total }\end{array}$ \\
\hline
\end{tabular}


viewing time

Visitors were more

likely to be

abstinent at end-

of-treatment (OR

= 2.91; 95\% CI =

$1.07-7.93$ ) and

use of the website

predicted

cessation $(\mathrm{OR}=$

2.81; $95 \% \mathrm{CI}=$

$1.02-7.71$ )

Michaud and Colom (2003) /

Four months.

Patten et al. (2006; 2007) /

Twenty-four weeks; home-based.
Participants can ask personal questions using a pseudonym, which ensures complete anonymity [S]. (professional support)

Content was consistent with the USPHS clinical practice guidelines on effective tobacco use intervention and web architecture and design consistent with the National Cancer Institute web usability guidelines [S]. (accessible content)

Social learning (cognitive) theory, health communication and decision-making theories formed the conceptual basis for the intervention [T].

Interactive services provided opportunities for self-expression [M] including a private journaling service, quizzes, quit plan and quit notes, and an art gallery where participants could post their artwork [S]. A private e-mail service allowed participants to ask questions of an expert and receive confidential responses within $24 \mathrm{~h}$ [S]. A discussion support group consisted of an e-mail service,
Frequency (during year 2001): 181557 visits and 4382 questions

Frequency:

-Days of use: $\mathrm{M}=$ $6.8(\mathrm{SD}=7.1)$ -Logins: $\mathrm{M}=10.9$ $(\mathrm{SD}=15.3) ; 52 \%$ during the first 3 weeks -Page views: 6825 interactive pages $(\mathrm{Mdn}=65$, range o-848); 883 informational pages $(\mathrm{Mdn}=6$, range $0-86$ ).

$\%$ of total page views per component:

-Discussion support group: $35 \%$

-Quit plan: 30\%

-Quit notes: 10\% -My journal: 4\% -Ask an expert; Myth quizzes; Real time chat: $3 \%$ 


which posted messages and
responses to and from participants
[S]. (peer support; professional
support; discussion board)
Videos of personal stories; first
person accounts of teens who had
quit or were trying to quite,
representing various ethnic and
gender backgrounds [S]. These
stories addressed barriers to
quitting and how the barriers were
managed [T]. (targeted
communication)

Roberto et Six activities: (1) sensation-seeking al. (2007) /

Seven weeks: One activity $( \pm 15$ minutes) per week and a seventh "make-up week" in which all six activities were accessible. scale; (2) truth or myth; (3) impulsive decision-making scale; (4) risky behaviour; (5) choose your own adventure/refusal skill activity; (6) radio PSA contest [S]. Participants who completed a weekly activity were given an opportunity to enter a drawing for a gift card to a national retail store [S]. Teachers played a vital role in reminding students about the intervention and encouraging students to participate [S]. Each activity was put online for one week and all six activities were put online during week seven to encourage and enhance participation [S]. (incentives; invitations/reminders; social context; conditional progress)

To make the experience more interesting and realistic, images were randomly selected at various points so they would be different each time [S]. (variable content)
-Personal stories; Art gallery; Video: $2 \%$

Percentage of participants decreased over 24 weeks $(p<.001)$. $-7 \%$ never used $-86 \%$ used at least once after 3 weeks

212 postings to discussion support group; 28 postings to ask an expert

Frequency (use per activity):

(1) $60.4 \%$

(2) $62.6 \%$

(3) $46.0 \%$

(4) $52.5 \%$

(5) $41.0 \%$

(6) $18.0 \%$

88.5\% used at least one activity

Saitz et al. Minimal intervention: three No difference in (2007)/ One screens; comparison to local norms, completion rate by 


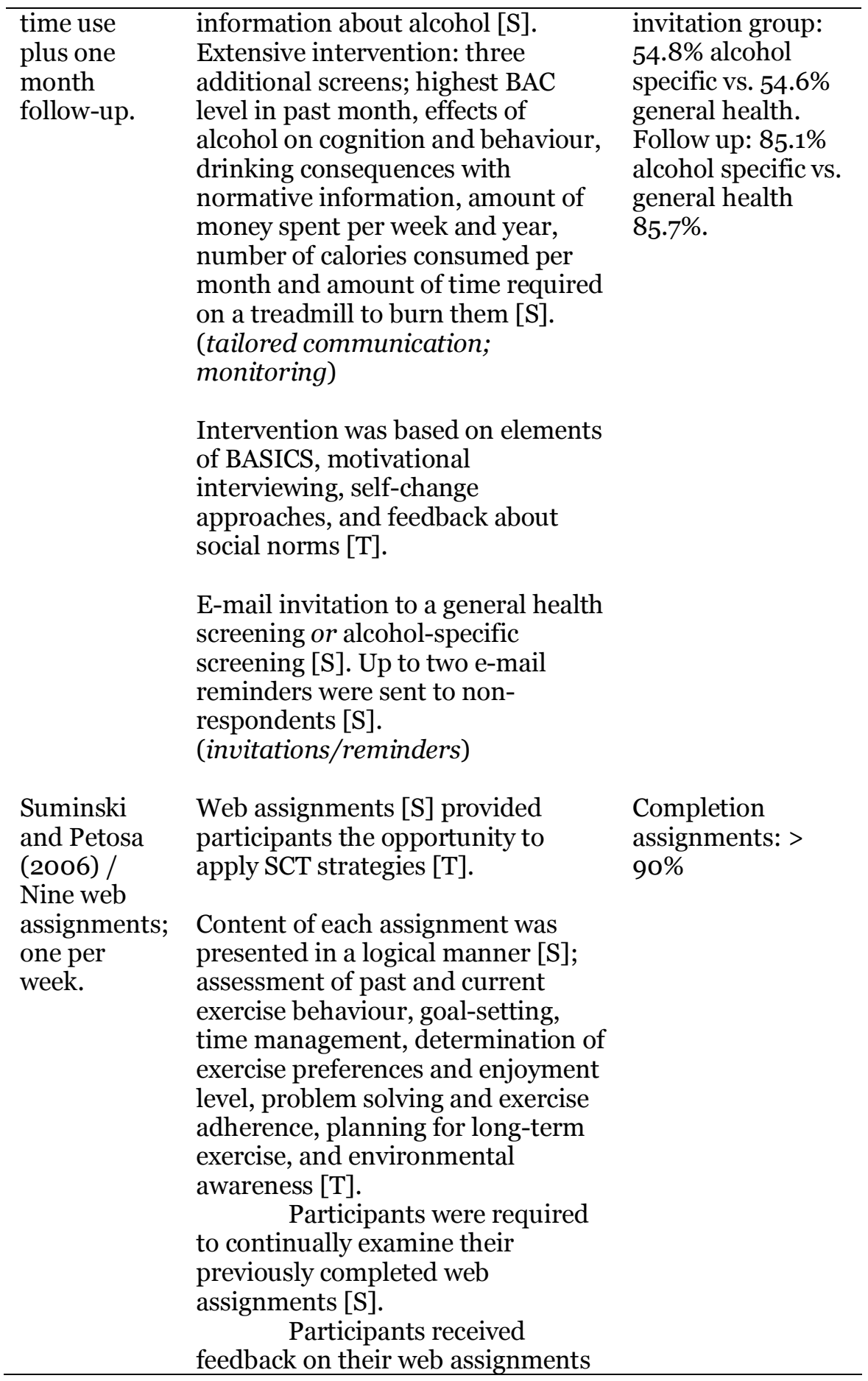




\begin{tabular}{|c|c|c|}
\hline \multirow[b]{2}{*}{$\begin{array}{l}\text { Thombs et } \\
\text { al. (2007) / } \\
\text { During one } \\
\text { academic } \\
\text { year in two } \\
\text { resident } \\
\text { halls from } 10 \\
\text { PM to } 3 \text { AM, } \\
\text { Wednesday } \\
\text { trough } \\
\text { Saturday. }\end{array}$} & $\begin{array}{l}\text { by e-mail [S]. (monitoring; tailored } \\
\text { communication) } \\
\text { Participants received a reminder e- } \\
\text { mail to address topics related to } \\
\text { each web assignment and a } \\
\text { refresher on the previous week's } \\
\text { web content [S]. } \\
\text { (invitations/reminders) }\end{array}$ & \\
\hline & $\begin{array}{l}\text { After a 3-minute interview, } \\
\text { participants received an } \\
\text { information sheet with the project's } \\
\text { website address and a space for } \\
\text { them to record their user-ID and } \\
\text { password [S]. The interviewer } \\
\text { instructed participants to visit and } \\
\text { register at the project website the } \\
\text { next day between noon and } 8 \text { PM } \\
\text { [S]. (invitations/reminders) } \\
\text { Participants received their own and } \\
\text { the average BAC of their entire hall } \\
\text { for the previous night (normative } \\
\text { feedback [M], based on Social } \\
\text { Norms Theory [T]); other alcohol } \\
\text { information about interpreting a } \\
\text { BAC reading an alcohol poisoning, } \\
\text { interactive assessment activities, } \\
\text { including motivation enhancement } \\
\text { pages for reluctant and ambivalent } \\
\text { high-risk drinkers; and links to } \\
\text { counselling services (anonymous, if } \\
\text { desired) [S]. (tailored } \\
\text { communication; interactive } \\
\text { content) } \\
\text { Participants enrolled into the } \\
\text { project's weekly lottery [S]. } \\
\text { (incentives) } \\
\text { Night time staff members reminded } \\
\text { each resident nightly to participate } \\
\text { the following day and provided } \\
\text { them with the hours the website } \\
\text { would be available to them [S]. } \\
\text { Furthermore, lollipops with }\end{array}$ & $\begin{array}{l}\text { Frequency: } \\
7087 \text { night time } \\
\text { interviews } \rightarrow 61 \% \\
\text { visited website } \\
\text { next day; } 55 \% \\
\text { from male- } \\
\text { population, } 71 \% \\
\text { female-population } \\
\text { Per activity: } \\
\text {-11 students } \\
\text { conduct an online } \\
\text { self-assessment of } \\
\text { their readiness to } \\
\text { change their } \\
\text { drinking } \\
\text { behaviours } \\
\text {-no one contacted } \\
\text { the clinician } \\
\text { involved }\end{array}$ \\
\hline
\end{tabular}


reminders tags taped to the stick

identifying the website were

distributed [S], flyers were posted

throughout each hall [S], and hand

stamps were used to identify the

website URL [S].

(invitations/reminders)

White et al. Passive condition: interactive graph

(2004);

Williamson

et al. (2005;

2006) / Two

years.

Outcomes, however, relate to the first six months.

to track weight loss; healthy menu

ideas; ability to e-mail case a quiz; interactive graph to track exercise; internet counselling; interactive food monitoring worksheets with instant feedback; treatment strategies; structured programs to increase physical manager. Interactive condition also: weekly treatment sessions including activity [S].

Participants were

encouraged to send e-mail weekly to their counsellor regarding their progress in the intervention. Each participant had their own e-mail account that could be accessed through the website. The e-mail communication also allowed counsellors to provide feedback on intervention components [S]. (interactive content; monitoring; professional support; tailored communication)

Websites were designed to present culturally specific information [M], including link to other websites containing culturally relevant diet and physical activity information, recipes for foods commonly eaten by African-Americans, and links to websites designed specifically for African-Americans as well as the inclusion of chat rooms for participants only [S]. (targeted communication)
Frequency:

-Visits: interactive condition > passive condition: $(t(55)=5.07, p<$ .001)

-Hits: interactive: $\mathrm{M}=624.9$ (444.1); passive: $\mathrm{M}=186.4$ (137.6)

Completed quizzes: $\mathrm{M}=9.75$

(8.17); score > 60\%: $\mathrm{M}=7.96$ (7.10); decrease over time $(t(27)=$ $5.37, p<.001$ )

$r_{\text {Weight graph, BMI change }}$ $=-0.55, p<.01$

$r_{\text {Weight graph, DXA change }}$ $=-0.43, p<.05$

$r_{\text {E-mails, DXA change }}=-$ $0.39, p<.05$

(BMI: $\mathrm{kg} / \mathrm{m}^{2}$; DXA: \% body fat) 

Each session was coordinated with
modules on the website that
corresponded to the same goals [S].
(conditional progress)

Woodruff et School liaisons [S] were an integral

al. (2008;

part of implementing the

2007) /

intervention on campus,

encouraging completion of

counselling sessions. (social

sessions

context)

$( \pm 45$

Frequency

(attendance):

$\mathrm{M}=3$ sessions

$19 \%$ no sessions

$9 \%$ all sessions

minutes),

over a seven- A sky mall was chosen as the virtual

week period, setting because malls frequently

in which serve as meeting places for teens

attendance $\quad[\mathrm{S}]$. (targeted communication)

was

recorded. Peer-to-peer interaction; real-time

discussion between four adolescent

smokers and counsellor [S] who

conducted motivational

interviewing $[\mathrm{M}]$. Nature and

content was somewhat fluid and

partly driven by the participants

[S]. (peer support; professional

support)

Labelling in italics is used for the sake of clarity.

${ }^{1} \mathrm{M}=$ method; $\mathrm{S}=$ strategy; $\mathrm{T}=$ theoretical foundation, $\mathrm{E}=$ empirical foundation 
$R Q 1$ Which methods and strategies are used to facilitate exposure to existing Internet-delivered interventions?

Nine interventions customised their information to a certain extent. According to the categorisation of Hawkins et al. (2008), five interventions used targeted communication (group targeted, e.g. appealing for African-American teenage girls) and six interventions used tailored communication (individually tailored, e.g. personal feedback). Three of those six interventions combined tailored communication with monitoring of health behaviour (change).

Nine interventions offered facilities to support their participants, either through professionals (e.g. ask-the-expert; six interventions) or peers (six interventions). Peer support was enabled through sharing of information (e.g. personal experiences with behaviour change) or direct communication with other peers. Four interventions offered a discussion board or forum to facilitate opportunities to support.

Several strategies have been used with regard to the delivery of the intervention's content. Five interventions provided content in an interactive way. Content was made easily accessible (for example through a simple linear design) by four interventions. Conditional progress, meaning that participants can only access certain modules or parts of a website once the previous are finished or during a certain time period, was used by two interventions.

Other strategies were to embed the Internet-delivered intervention in a social context (e.g. link it to school assignments; three interventions), the use of reminders to visit or revisit or invitations to participate (either physical or through e-mail; seven interventions), and the use of incentives (six interventions).

RQ2: Which theories or empirical data are used to base these methods and strategies on?

Social learning (cognitive) theory, the transtheoretical model of change, the information-motivation-behavioural skills model, self-regulation theory, and the theoretical fields of social support and social norms were described as the basis for methods and strategies. Although the aim of these theories is to explain behaviour or the process of behaviour change, the methods and strategies which are derived from these theories could also be used to facilitate exposure. Furthermore, some theoretical assumptions were described without explicitly mentioning an underlying theory. For example, one study (An et al., 2006) described that the benefits of a simple linear design may be particularly pronounced when a participant's investment in a website is low without referring to a theory or empirical data. Empirical data as a basis for methods and strategies was barely described. If so, participants' preferences (e.g. communication through e-mail or discussion board) were investigated during the development process (Lou et al., 2006). 
RQ3: Which outcomes are used to measure exposure to Internetdelivered interventions and how are they linked to strategies used in Internet-delivered interventions?

The number of (unique) visitors was mostly reported, but several other outcomes were also used to measure exposure, e.g. frequency of visiting, duration of visit and number of pages visited. Furthermore, whether or not certain tasks were conducted was also used as an exposure measure. For each intervention, however, only a few of these measures were reported, resulting in a heterogeneous description of exposure to intervention websites.

Twelve interventions used objectively tracked exposure measures, one intervention relied on self-reported exposure measures, and one intervention combined both methods (and reported $82.4 \%$ agreement). The remaining two interventions were session-based and only participants' attendance to these sessions was recorded.

Seven interventions reported these exposure measures for the intervention's website as a whole. Nine interventions, however, reported some exposure measures per component, which made it possible to link them to strategies used. Furthermore, two of those nine interventions made a distinction between interactive and non-interactive content.

RQ4: How does exposure to Internet-delivered interventions relate to strategies used and theories or empirical data on which they are based? Results of those interventions who reported exposure measures per component showed that discussion boards were only moderately used for peer support. Professional support (e.g. ask-the-expert), although often provided, was only limitedly used. From those interventions that made a distinction between interactive and non-interactive content, it appeared that providing content in a more interactive way resulted in higher exposure rates. In an Internet-based lifestyle behaviour modification intervention for weight management, participants in the interactive condition visited the website more often than participants in the passive condition $(t(55)=5.07, p<$.001) (White et al., 2004; Williamson et al., 2005; 2006). Descriptive statistics of a website for adolescent smoking cessation indicated more page views for interactive pages compared to informational pages (Mdn = 65 vs. $M d n=6$ ) (Patten et al., 2006; 2007). Other interventions used a combination of several methods and strategies, which complicates dismantling the effectiveness to single methods and strategies by looking at exposure measures with regard to the intervention's website as a whole. The combination of tailored communication, the use of reminders to visit or revisit or invitations to participate, and the use of incentives, however, resulted in high exposure rates to Internet-delivered interventions. In an online college life magazine targeting college smokers, for example, on average $95 \%$ of participants returned weekly to the website and completed a tracker and interactive quiz. Notably, there was no decline over 20 weeks (An et al., 2006). 
The use of strategies was inconsistently linked to exposure measures, yet effective patterns could be observed. It was hard, however, to relate effectiveness to theories or empirical data that served as the ground for the use of methods and strategies, since theories or empirical data were hardly linked to exposure measures.

\section{RQ5: How does exposure relate to actual outcome measures of the} interventions?

Only two interventions related exposure (strategies) to outcome measures of the interventions. In a web-based adjunct to the Not on Tobacco (NOT) intervention it appeared that website visitors were more likely to be abstinent at end-of-treatment compared to non-visitors (OR $=2.91 ; 95 \% \mathrm{CI}=1.07-7.93)$ and use of the website predicted cessation $(\mathrm{OR}=2.81 ; 95 \% \mathrm{CI}=1.02-7.71)$ (Mermelstein \& Turner, 2006). In an Internet-based lifestyle behaviour modification intervention for weight management, significant relations (not necessarily causal) were found between biomedical measures (BMI, DXA ${ }^{1}$ ) and the use of monitoring (weight graphs: $r_{\text {Weight graph, BMI change }}=-0.55, p<.01 ; r_{\text {Weight graph, DXA change }}=-$ $0.43, p<.05$ ) and professional support (through e-mail: $r_{\mathrm{E}-\mathrm{mails}}$, DXA change $=$ $-0.39, p<.05$ ) (White et al., 2004; Williamson et al., 2005; Williamson et al., 2006).

\section{Discussion}

This systematic review resulted in an overview of methods and strategies which have been used to facilitate exposure to Internet-delivered interventions aimed at adolescents or young adults. Certain patterns which effectively facilitated exposure could be observed. For example, the combination of tailored communication, the use of reminders to visit or revisit or invitations to participate, and the use of incentives.

This overview can be useful to choose potential strategies to be used in Internet-delivered interventions to improve exposure. It appeared that frequently used strategies (e.g. ask-the-expert, discussion boards) were moderately or even seldom utilised by adolescents or young adults, even though they were suggested by experts (Chapter 2) and the target group (Chapter 3) as factors which might be associated with exposure to Internet-delivered interventions in previous studies. Interventions which combined several strategies were most effective with regard to facilitating exposure. While most interventions used a combination of several strategies, it is hard to study the effectiveness of single strategies. It is recommended to conduct experimental research in more controlled settings to increase evidence-based insight into their effectiveness regarding exposure, before applying these strategies in practice.

It needs to be stressed, however, that methods and strategies which have been used to facilitate exposure do not need to be applied

${ }^{1}$ BMI: $\mathrm{kg} / \mathrm{m}^{2}$; DXA: \% body fat 
separately. For example, providing content in an interactive way can be combined with monitoring health behaviour and behaviour change.

Another important finding of this review was that in the studies included in the review, there was only a limited description of the strategies or efforts taken to improve exposure to the intervention. This knowledge is crucial, however, to get more insight into ways to improve exposure to Internet-delivered interventions and consequently, to increase behavioural change.

\section{Limitations}

The process of dissemination was only described to a limited extent in the included studies and most interventions were applied in a research setting and participants were recruited to participate in a study. Although the focus of this review was not on dissemination of Internet-delivered interventions, successful dissemination is required before participants can be exposed to the intervention content and use its components. Dissemination involves the distribution of the intervention among the target population, including bringing the intervention to the attention of the target population. Successful dissemination depends on the target population, the source and the intervention itself (Rogers, 2003). Incentives and advertisements that were used to increase attention mostly focused on convincing people to participate in a study instead of an intervention. In general, use of incentives is a strategy which is probably inapplicable once an Internet-delivered intervention is implemented in real-life, since this would increase costs enormously.

Sixty-seven percent of corresponding authors responded to our request to complete the extraction forms. A possible explanation why other authors did not respond could be that they did not want to provide the information we requested because it was unavailable or would create negative publicity regarding their intervention. Nevertheless, corresponding authors were very willing to share information regarding their intervention. This resulted, however, in very little new information. Therefore, it remains unclear whether information with regard to exposure methods, strategies, and outcomes was unavailable or not meant to be shared.

Finally, included studies were limited to original articles published in peer-reviewed English-language journals and strict inclusion and exclusion criteria were followed. In our zeal to be parsimonious and systematic in our review, we may have discarded other potentially valuable studies.

\section{Implications for future research and practice}

Although most studies did make explicit what theory was used to inform the intervention, these theories were primarily behaviour determinants or behaviour change theories. No exposure-specific theories were mentioned in the reviewed studies. Therefore, more attention should be paid to the development and application of theories regarding exposure, 
from which methods and strategies can be derived. Furthermore, in addition to a description of the educational content of an Internetdelivered intervention, future studies should also describe which strategies they have used specifically to attract attention to the intervention, to make using the entire intervention content attractive and to make a revisit attractive (when applicable), to gain more insight in potential effective strategies to improve exposure.

It was hard, due to the heterogeneity of exposure measures and inconsistent linkage of these exposure measures to strategies used in Internet-delivered interventions, to make a valid comparison between strategies used in these interventions and theories or empirical data on which they are based. It is recommended, therefore, to register and report multiple exposure measures (e.g. frequency of visiting, duration of visit and number of pages visited) (Chapter 6; Danaher, Boles, Akers, Gordon, \& Severson, 2006) and this may also provide more insight into intensity of exposure compared to the number of (unique) visitors (Chapter 7). Furthermore, more uniformity in reporting exposure measures would make it possible to compare or pool the results of various studies.

Most exposure measures can be tracked objectively, which is preferable above self-reported exposure measures that are dependent on participants' memory, interpretation, and social desirability. If exposure measures were linked to intervention outcome measures at the individual level, it would also be possible to study potentially mediating effects of exposure on these outcome measures (Chapter 7).

\section{Concluding remark}

The results of this systematic review revealed potential strategies which can be used in practice to facilitate exposure to Internet-delivered interventions, but also serve as handle for the formation of further research questions regarding effectiveness of these strategies.

\section{Acknowledgements}

We would like to thank Babs Franssen for her assistance during the first two phases of the review procedure. 


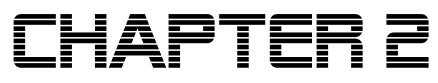

This chapter has been published as Crutzen, R., De Nooijer, J., Brouwer, W., Oenema, A., Brug, J., \& De Vries, N. K. (2008). Internet-delivered interventions aimed at adolescents: a Delphi study on dissemination and exposure. Health Education Research, 23, 427-439. 


\begin{abstract}
It appears that in practice exposure to Internet-delivered behaviour change interventions, encouraging a healthy lifestyle for adolescents with regard to health risk behaviours is quite low. There is, however, a lack of evidence-based insight into how to disseminate such interventions and how to reach optimal exposure. A more extensive exploration is therefore timely, since this knowledge is crucial to improve the public health impact of such interventions. By means of a three-round Delphi study factors associated with dissemination of and exposure (first visit, stay long enough and revisit) to Internet-delivered interventions aimed at adolescents had been identified, as well as the extent to which experts agree on the importance of these factors. Results showed that there was a high rate of consensus among experts from several disciplines with regard to the importance of factors like word of mouth recommendation, the interface of the intervention and utilisation of all features provided by the Internet. Experts do not agree, however, on a gold standard for successful dissemination. Overall, the results of this exploration serve as a handle for the formation of further research questions to be tested and answered in research among adolescents.
\end{abstract}




\section{Introduction}

From evidence of efficacy trials it appears that in practice exposure to Internet-delivered behaviour change interventions is quite low (De Nooijer et al., 2005), and in real situations exposure may be even lower (Evers et al., 2005). Explosive growth of the Internet has caused an increase in Internet-delivered interventions, aimed at promoting behaviours related to the primary prevention of chronic diseases and therefore encouraging a healthy lifestyle with regard to health risk behaviours (Bernhardt \& Hubley, 2001; De Nooijer \& De Vries, 2006; Pérez-Rodrigo et al., 2005). Previous research indicated that factors to improve dissemination of, and exposure to, such interventions, include high search-engine ranking (Griffiths \& Christensen, 2005), an appropriate domain name (URL) (Peterson, Aslani, \& Williams, 2003) and perceived credibility (Hong, 2006). There is, however, a lack of evidence-based insight into how to disseminate such interventions and how to reach optimal exposure, so a more extensive exploration, which provides an overview of factors associated with dissemination and exposure of Internet-delivered interventions, is timely. There were three reasons to focus on interventions aimed at adolescents. First, while many of these health risk behaviours (such as lack of physical activity, low consumption of fruit, cigarette-smoking, unprotected sex and excessive alcohol consumption) are acquired during adolescence, they track into adulthood, thereby affecting not only current health but also health in later life (Kelder et al., 1994). Second, the current generation of adolescents grew up with the Internet (Tapscott, 1998) and is more open towards new possibilities offered by this medium (Leung, 2003). They use the Internet differently compared with adults (Fox, 2006; Gross, 2004; Hansen et al., 2003) and their main online activities are instant messaging, gaming, downloading and visiting social-networking websites (Gross, 2004; Van den Eijnden \& Vermulst, 2006). The expectation is therefore that adolescents are susceptible to other factors associated with dissemination of and exposure to interventions. Third, this age group poses specific challenges to health promoters. In contrast to patients looking for treatment or medical information, adolescents without any chronic disease are not likely to be internally motivated to search for Internet-delivered behaviour change interventions (De Nooijer et al., 2005). Researchers in this study therefore expect other factors to be associated with dissemination of and exposure to Internet-delivered interventions aimed at promoting behaviours related to the primary prevention of chronic diseases.

Dissemination involves the distribution of the intervention among the target population, including bringing the intervention to the attention of the target population. Successful dissemination depends on the target population, the source and the intervention itself (Rogers, 2003). Exposure involves actual exposure of individuals to the intervention content, through use of the intervention, and is necessary because attention is a prerequisite to establish desired behaviour change 
(McGuire, 1985). The RE-AIM model is a very useful framework to look at dissemination and exposure. According to this model, the public health impact of an intervention can only be evaluated by the assessment of five dimensions: Reach, Efficacy, Adoption, Implementation and Maintenance (hence the acronym RE-AIM) (Glasgow, 2007; Glasgow, Vogt, \& Boles, 1999). So, besides the importance of evaluating efficacy of interventions (De Nooijer \& De Vries, 2006; Pérez-Rodrigo et al., 2005), these other four dimensions should also be addressed. The potential reach of Internet-delivered behaviour change interventions aimed at adolescents is enormous, since already 95\% of Dutch people between 12 and 25 had access to the Internet by 2006 (CBS, 2006). Internet penetration rates are also high in other countries in western Europe, North America and Australia (Internet World Stats, 2008a). The other two dimensions, adoption and maintenance, refer respectively to the proportion and representativeness of settings that adopt an intervention and the extent to which an intervention is sustained over time (Glasgow et al., 1999). In terms of Internet-delivered interventions, there are three different aspects with regard to exposure: (1) a first visit, (2) staying on the intervention long enough actually to use and process the information and (3) revisiting the intervention. The latter can be important, since there is a possible dose-response relationship between the number of visits and behaviour change outcomes (Lenert et al., 2003; Verheijden et al., 2007; Zebrack et al., 2005). With regard to staying long enough, it is hard to indicate an exact length of time, since this differs per intervention. It depends, for example, on the length of the questionnaire which precedes tailored feedback. Furthermore, there is also a difference between individuals. For example, some people are faster in processing information than others. In general, staying long enough is defined as the time which an individual needs to process the information provided at a specific intervention. In line with the RE-AIM model, these three different aspects of exposure relate to implementation: the extent to which an intervention is delivered as intended (Glasgow et al., 1999). Our focus in this study was on this dimension.

The aim of this study was (1) to identify factors that are associated with dissemination of and exposure (first visit, stay long enough and revisit) to Internet-delivered behaviour change interventions aimed at adolescents from the point of view of experts in different areas and (2) to identify the extent to which experts agree on the importance of these factors.

\section{Methods}

A three-round Delphi study was conducted through the Internet by the use of SurveyMonkey.com and within a three-month time-frame (September - December 2006). In a Delphi study a panel of experts was consulted over several rounds. All questionnaires of the three-round Delphi study were pre-tested among health promotion researchers and employees of health promotion institutions. 
The Delphi methodology was chosen for three reasons: First, because this method is useful to generate ideas where scientific knowledge is scarce. Second, the main characteristics of a Delphi study (anonymity, iteration and controlled feedback) allow participants to give and change (after having received feedback) their opinion freely (Linstone \& Turoff, 1975). This is highly relevant, since different disciplines are involved in carrying out Internet-delivered behaviour change interventions, e.g. health promotion research, e-marketing and communication, health promotion institutions and technical implementation. A heterogeneous sample of experts was therefore used in this Delphi panel to gain an insight into the opinion of their peers from different disciplines. Finally, a Delphi methodology can be helpful in situations where face-to-face discussions are impractical (Green \& Kreuter, 1999). For example, experts from different parts of the world (mainly Western Europe and North America) could be included, because this study could be conducted through the Internet and there were no barriers in distance. Furthermore, experts could complete each questionnaire at their own convenience (within a four or five-week period), which partly circumvents difficulties from non-matching schedules.

\section{First round}

\section{Procedures and participants}

For the first round, experts in the field of health promotion, e-marketing and communication and technical implementation were selected. In the field of health promotion, a distinction was made between experts working as researchers and those who had a more applied background. This difference is between those working at universities or other research institutes and those working in health promotion institutes. For the selection of relevant experts in the field of health promotion, experts who previously participated in qualitative interviews with regard to promotion of healthy behaviour through the Internet were screened (De Nooijer et al., 2005). Furthermore, experts from editorial boards of leading journals in the field of health promotion and the Internet were selected. To select relevant experts from other disciplines, the researchers in this study mainly used their international network in the field of health promotion research. They were asked to mention experts in health promotion institutes or ICT (Information and Communication Technology) companies, with whom they had previously cooperated. Experts in e-marketing and communication were not necessarily specialised in behaviour change interventions, but they had knowledge in other areas of e-marketing and communication which could also be appropriate for Internet-delivered behaviour change interventions. With regard to technical implementation, for example, web developers and designers were invited to take part. 
In an invitation letter, sent by e-mail in September 2006, with an explanation about the study goals and procedure, 62 experts were asked to participate in all three rounds of the Delphi study (Table 2.1). In this email, there was a link to the website where they could complete the first round questionnaire. Invitees received a reminder two weeks afterwards and had a five-week period to complete the first-round questionnaire. Thirty experts (48\% response rate) responded to the first-round questionnaire (Table 2.1).

Table 2.1 First round response

\begin{tabular}{lccc}
\hline Disciplines & Invitations & Response & \\
\cline { 2 - 4 } & $N$ & $N$ & $\%$ \\
\hline Health promotion research & 32 & 16 & 50 \\
E-marketing \& communication & 9 & 3 & 33 \\
Health promotion institutions & 11 & 7 & 64 \\
Technical implementation & 10 & 4 & 40 \\
\hline Total & 62 & 30 & 48 \\
\hline
\end{tabular}

\section{Questionnaire}

This first-round questionnaire consisted of four open-ended main questions. In line with the aim of this study, these questions were: (1) What are, according to your expertise, factors that determine whether an adolescent will visit an Internet-delivered behaviour change intervention for the first time? (2) What are, according to your expertise, factors that will determine whether an adolescent will stay on an Internet- delivered behaviour change intervention long enough to engage actively in and process the educational content provided in the intervention? (3) What are, according to your expertise, factors that will determine whether an adolescent will re-visit an Internet-delivered behaviour change intervention? (4) What are, according to your expertise, factors that are essential for successful dissemination of an Internet-delivered behaviour change intervention aimed at adolescents?

In the questionnaire instructions the interest in factors associated with dissemination of and exposure to Internet-delivered behaviour change interventions was explicitly defined (as in the introduction section of this chapter). Furthermore, it was stressed that the focus was on (1) interventions aimed at promoting behaviours related to the primary prevention of chronic diseases and therefore encouraging a healthy lifestyle with regard to health risk behaviours and (2) adolescents as a specific target group since they use the Internet differently compared with adults and the expectation was that they are susceptible to other factors associated with dissemination of and exposure to interventions. Finally, participants were asked to think of factors on several levels (e.g. user, intervention and source). 


\section{Data analysis}

The answers to each of the questions resulted in a list of potential factors associated with dissemination and exposure. Two researchers analysed this list of potential factors and merged factors that were semantically similar into one factor. After discussion about semantic similarity, both researchers fully agreed about all factors that were included in the second-round questionnaire (Tables 2.3-2.6). Two other researchers approved this questionnaire.

\section{Second round}

\section{Procedures and participants}

Experts who participated in the first round were also invited to participate in the last two rounds. Additional experts from all disciplines were selected for the last two rounds. Several databases (PubMed, PsycINFO and Medline) were searched for literature on Internetdelivered behaviour change interventions (scientific papers published between 2000 and 2006). Corresponding authors of journal articles were screened for relevant publications in the field of Internet-delivered behaviour change interventions. The same procedure was carried out with abstract books from relevant conferences (conferences of the Society for the Internet in Medicine (MEDNET), International Society of Behavioral Medicine (ISBM), national conferences). Furthermore, abstract books from conferences not purely focused on improving public health through the Internet (International Society for Behavioral Nutrition and Physical Activity (ISBNPA), European Health Psychology Society (EHPS)) were screened. An invitation letter, sent by e-mail in October 2006, with an explanation about the study goals and procedure asked 233 experts to participate in the last two rounds of the Delphi study (Table 2.2). Invitees received two reminders and had a four- week period to complete the second-round questionnaire. In total, 93 experts (40\% response rate) responded to the second-round questionnaire (Table 2.2).

\section{Questionnaire}

The factors that were mentioned by the experts in the first round formed the basis of the questionnaire for the second round. This second-round questionnaire consisted of 82 structured items (Tables 2.3-2.6) and experts were asked to indicate to what extent they thought each factor was important on a seven-point Likert scale ranging from 1 (not important at all) to 7 (extremely important).

\section{Data analysis}

Median scores (Mdn) and interquartile deviations (IQDs) were used to summarise the extent to which participants agreed with the importance of the factor under consideration (Jones \& Hunter, 1995). The median 
score can be defined as the score that falls exactly in the middle of a group of scores, the $50^{\text {th }}$ percentile. In this way it is possible to determine the agreement on the importance of a factor. The IQD is the absolute value of the difference between the $25^{\text {th }}$ and $75^{\text {th }}$ percentiles of the responses of the experts to an item, with smaller values indicating a higher degree of consensus among the experts. On a seven-point Likert scale, an IQD $\leq 1$ can be considered as good consensus and means that more than $50 \%$ of all opinions fall within one point on the scale (Linstone \& Turoff, 1975). A distinction between importance and consensus among experts was made, since it is possible that there is consensus among experts (IQD $\leq 1)$ that the factor under consideration is not important (low median). The cut-off point for importance of potential factors was a median score $\geq 6$. In combination with an IQD $\leq 1$, this represents factors that are rated as 'very important' (Mdn $=6)$ or 'extremely important' $(\mathrm{Mdn}=7)$ by more than $50 \%$ of the experts.

\section{Third round}

\section{Procedures and participants}

All the experts who completed the second-round questionnaire were invited for the third and final round. Exceptions were two experts who could not be identified since they did not provide their name and/or email address and three experts who explicitly stated in advance that they were not able to participate in the third round owing to time constraints. An invitation letter, sent by e-mail in November 2006, asked 88 experts to participate in the third round (Table 2.2) and procedures were comparable to the second round. Fifty-nine experts ( $67 \%$ of secondround participants, $25 \%$ response rate) completed the third-round questionnaire (Table 2.2).

Table 2.2 Second and third round response

\begin{tabular}{|c|c|c|c|c|c|c|}
\hline \multirow[t]{2}{*}{ Disciplines } & 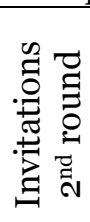 & 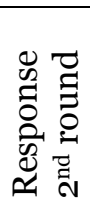 & \multicolumn{4}{|c|}{ 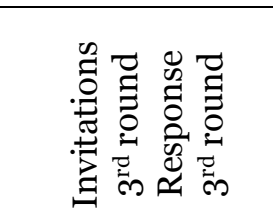 } \\
\hline & $N$ & $N$ & $\%$ & $N$ & $N$ & $\%$ \\
\hline Health promotion research & 155 & 65 & 42 & 62 & 41 & 66 \\
\hline E-marketing \& communication & 24 & 6 & 25 & 6 & 4 & " \\
\hline Health promotion institutions & 20 & 10 & 50 & 10 & 8 & 80 \\
\hline $\begin{array}{l}\text { Technical implementation } \\
\text { Unidentifiable }^{1}\end{array}$ & 34 & 10 & 29 & 10 & 6 & 60 \\
\hline $\begin{array}{l}\text { Unider } \\
\text { Total }\end{array}$ & 233 & $\begin{array}{c}2 \\
93\end{array}$ & 40 & 88 & & 67 \\
\hline
\end{tabular}

${ }^{1}$ These participants did not provide their name and/or e-mail address, nor was the use of cookies by their Internet browser enabled. Cookies provide a means for 
a web server to induce a client to store information about itself which can subsequently be called up by the web server when required.

\section{Questionnaire}

A questionnaire, with feedback on the second-round group results (median and IQD) for each item, was presented to third-round participants. In accordance with the Delphi methodology, experts were asked to re-rate their answers for items on which no consensus was obtained in the second round (IQD > 1). Items on which consensus was obtained were excluded, resulting in a third-round questionnaire of 63 items.

\section{Data analysis}

Group median ratings and IQDs were again analysed. All statistical analyses were conducted by means of SPSS 13.0.

\section{Results}

The items of the second-round questionnaire represented the factors that were identified during the first round. Items were split up with regard to (1) a first time visit (Table 2.3, 26 items), (2) whether a person will stay long enough to engage actively in and process the educational content provided (Table 2.4, 34 items), (3) revisiting (Table 2.5, 15 items) and (4) successful dissemination (Table 2.6, 7 items).

Consensus. In the second round, consensus was obtained on 19 items (IQD $\leq 1$ ). After experts re-rated their answers (during the third round) based on the feedback of the second-round group results, consensus was obtained on another 56 items. All together, consensus was obtained on 75 items (91\%).

Importance. A total of thirty of these items had a median score $\geq$ 6. Three (out of 26) of these items were related to first visit (12\%) (e.g. a positive recommendation by word of mouth and an attractive interface at first sight), 19 (out of 34) to staying on an intervention (56\%) (e.g. interactive features and an easy-to-follow navigation structure) and 8 (out of 15 ) to revisiting an intervention (53\%) (e.g. commitment to revisit and new content on a regular basis). Although experts obtained consensus about factors that potentially determine dissemination of Internet-delivered interventions among adolescents, none of these factors had a median score $\geq 6$. Providing the Internet-delivered intervention in a controlled setting (e.g. school curriculum), instruction of executives, an appealing name, assuring a high search-engine ranking, embedding the Internet-delivered intervention in other (health) programs and co-operation with commercial partners were all factors with a median score of 5 on a 7-point Likert scale. 
Table 2.3 Results for items related to a first visit of an intervention

\begin{tabular}{l}
\hline Item $^{1}$ \\
\hline How important do you think each of the \\
following factors are in determining \\
whether an adolescent will make a first \\
visit to an Internet-delivered behaviour \\
change intervention?
\end{tabular}

A. Whether the potential visitor

1. has sufficient skills to use the Internet

2. has experience with using the Internet

3. has access to the Internet at a private location (e.g. home)

4. has positive expectations of behaviour change interventions delivered through the Internet 5 . is motivated to visit a behaviour change intervention provided through the Internet 6. wants to improve his/her behaviour in relation to the topic of the Internet intervention 7. is curious about what the Internet intervention has to offer

8. is willing to spend time on visiting an Internet intervention

9. has a positive attitude regarding the use of behaviour change interventions delivered through the Internet

10. receives an incentive for visiting the Internet intervention

11. is referred to the Internet intervention by a health professional (e.g. GP, physical therapist, dietician)

* 12. gets a positive recommendation about the Internet intervention by word of mouth (e.g. friends, family)

13. receives a reminder to visit the Internet intervention

* 14. perceives the Internet intervention as relevant for him/herself

15. knows that the Internet intervention is effective

16. perceives the source (the organisation that provides the intervention) of the Internet intervention as credible 17. perceives the source (the organisation that provides the intervention) of the Internet

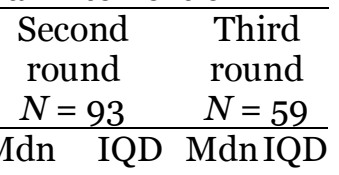




\begin{tabular}{|c|c|c|c|c|}
\hline Item $^{1}$ & & & & \\
\hline & Mdn & IQD & $\mathrm{Mdr}$ & IQD \\
\hline $\begin{array}{l}\text { intervention as reliable } \\
\text { B. Whether the Internet intervention }\end{array}$ & & & & \\
\hline 1. has an easy to remember domain name (URL) & 5 & 2 & 5 & 1 \\
\hline $\begin{array}{l}\text { 2. has a high search-engine ranking (e.g. } \\
\text { Google, Yahoo!, AltaVista) }\end{array}$ & 5 & 3 & 5 & 2 \\
\hline $\begin{array}{l}\text { 3. can be used with all types of Internet } \\
\text { connections, like dial-up, DSL, cable and } \\
\text { fibreglass }\end{array}$ & 5 & 3 & 5 & 2 \\
\hline $\begin{array}{l}\text { 4. can be used instantly without downloading } \\
\text { special software by the potential visitor (e.g. } \\
\text { plug-ins) }\end{array}$ & 5 & 2 & 5 & 1 \\
\hline${ }^{*}$ 5. has an attractive interface at first sight & 6 & 2 & 6 & $o$ \\
\hline $\begin{array}{l}\text { 6. has a navigation structure that appears to be } \\
\text { easy to use at first sight }\end{array}$ & 5 & 2 & 5 & O \\
\hline $\begin{array}{l}\text { 7. is created by experts in health behaviour } \\
\text { change }\end{array}$ & 3 & 2 & 3 & 1 \\
\hline 8. is endorsed by health professionals & 3.5 & 2.25 & 4 & 1 \\
\hline 9. is based on scientific kno & 3.5 & 3 & 4 & 1 \\
\hline
\end{tabular}

Table 2.4 Results for items related to staying on an intervention

\begin{tabular}{|c|c|c|c|c|}
\hline Item $^{1}$ & & & & \\
\hline & Mdn & IQD & $\mathrm{Mdr}$ & IQD \\
\hline $\begin{array}{l}\text { How important do you think each of the } \\
\text { following factors are in determining } \\
\text { whether an adolescent will stay on an } \\
\text { Internet-delivered behaviour change } \\
\text { intervention long enough to actively } \\
\text { engage in and process the educational } \\
\text { content provided in the intervention? } \\
\text { A. Whether the visitor }\end{array}$ & & & & \\
\hline $\begin{array}{l}\text { *1. can associate him/herself with the look and } \\
\text { feel of the Internet intervention }\end{array}$ & 6 & 1 & - & \\
\hline $\begin{array}{l}\text { 2. knows in advance how long it will take to go } \\
\text { through the whole intervention }\end{array}$ & 5 & 2 & 5 & 1 \\
\hline $\begin{array}{l}\text { 3. has to provide sensitive information to } \\
\text { register (e.g. home address) }\end{array}$ & 4 & 2 & 4 & 1 \\
\hline
\end{tabular}




\begin{tabular}{|c|c|c|c|c|}
\hline \multirow[t]{2}{*}{ Item $^{1}$} & \multicolumn{2}{|c|}{$\begin{array}{l}\text { Second } \\
\text { round } \\
N=93\end{array}$} & \multicolumn{2}{|c|}{$\begin{array}{l}\text { Third } \\
\text { round } \\
N=59\end{array}$} \\
\hline & Mdn & IQD & & IQD \\
\hline $\begin{array}{l}\text { 4. wants to improve his/her behaviour in } \\
\text { relation to the topic of the Internet intervention }\end{array}$ & 5 & 2 & 5 & 0 \\
\hline $\begin{array}{l}\text { *. perceives the topic and content of the entire } \\
\text { Internet intervention as being personally } \\
\text { relevant }\end{array}$ & 6 & 2 & 6 & $o$ \\
\hline $\begin{array}{l}\text { *6. experiences the use of the Internet } \\
\text { intervention as rewarding }\end{array}$ & 6 & 1 & - & - \\
\hline $\begin{array}{l}\text { 7. experiences the use of the Internet } \\
\text { intervention as challenging }\end{array}$ & 5 & 2 & 5 & 1 \\
\hline $\begin{array}{l}\text { * 8. experiences the use of the Internet } \\
\text { intervention as enjoyable }\end{array}$ & 6 & 2 & 6 & $O$ \\
\hline $\begin{array}{l}\text { *. likes receiving (tailored) feedback on the } \\
\text { answers he/she provided on questions } \\
\text { B. Whether the source of the Internet } \\
\text { intervention (the organisation that } \\
\text { provides the intervention) }\end{array}$ & 6 & 2 & 6 & 1 \\
\hline $\begin{array}{l}\text { 1. is identifiable as credible by the visitor (e.g. } \\
\text { through a logo, link to the website of the source } \\
\text { or a disclaimer, etc.) }\end{array}$ & 4 & 2 & 4 & 1 \\
\hline $\begin{array}{l}\text { 2. is identifiable as reliable by the visitor (e.g. } \\
\text { through a logo, link to website of the source or a } \\
\text { disclaimer, etc.) } \\
\text { C. Whether the Internet intervention }\end{array}$ & 4 & 2 & 4 & 1 \\
\hline $\begin{array}{l}\text { 1. provides the option of a trial before starting } \\
\text { for real }\end{array}$ & 3 & 3 & 3 & 1 \\
\hline $\begin{array}{l}\text { *2. uses visual materials (e.g. graphs, videos, } \\
\text { pictures) }\end{array}$ & 6 & 2 & 6 & $o$ \\
\hline $\begin{array}{l}\text { *. provides interactive features (e.g. tests, } \\
\text { forums, games, etc.) }\end{array}$ & 6 & 1 & - & - \\
\hline $\begin{array}{l}\text { 4. displays personal progress through the } \\
\text { program (e.g. progress bar, page numbers) }\end{array}$ & 5 & 1.75 & 5 & 1 \\
\hline $\begin{array}{l}\text { *. provides the opportunity for a visitor to } \\
\text { stop at any moment and to proceed at a later } \\
\text { time }\end{array}$ & $5 \cdot 5$ & 2 & 6 & 1 \\
\hline $\begin{array}{l}\text { 6. uses a virtual guide to guide a visitor through } \\
\text { the Internet intervention }\end{array}$ & 4 & 2 & 4 & 1 \\
\hline${ }^{*} 7$. is att & 6 & 2 & 6 & $o$ \\
\hline $\begin{array}{l}\text { 8. has a brief registration procedure (e.g. the } \\
\text { registration of login name and password) }\end{array}$ & 5 & 3 & 5 & 1 \\
\hline $\mathrm{n}$ that is clear to the visitor & 5 & 2 & 5 & 1 \\
\hline $\begin{array}{l}\text { 10. provides testimonials of successes of } \\
\text { previous visitors }\end{array}$ & 4 & 2.75 & 4 & 1 \\
\hline 11. provides information that appears reliable & 5 & 1.75 & & \\
\hline
\end{tabular}




\begin{tabular}{|c|c|c|c|c|}
\hline Item $^{1}$ & & & & \\
\hline & Mdn & IQD & $\mathrm{Mdn}$ & IQD \\
\hline the visitor & & & & \\
\hline $\begin{array}{l}\text { *12. provides information that is easy to } \\
\text { understand for the visitor }\end{array}$ & 6 & 1 & - & - \\
\hline $\begin{array}{l}\text { * 13. provides information that is perceived to } \\
\text { be useful for the visitor to help him/her in } \\
\text { changing behaviour }\end{array}$ & 6 & 1 & - & - \\
\hline $\begin{array}{l}\text { *14. has a tone of voice that is appealing to the } \\
\text { visitor }\end{array}$ & 6 & 2 & 6 & $o$ \\
\hline *15. has an easy to follow navigation structure & 6 & 1 & - & - \\
\hline $\begin{array}{l}\text { *16. provides brief textual information (i.e. } \\
\text { does not involve a lot of reading) }\end{array}$ & 6 & 2 & 6 & $o$ \\
\hline $\begin{array}{l}\text { *17. uses a short questionnaire for providing } \\
\text { tailored feedback }\end{array}$ & 6 & 1 & - & - \\
\hline $\begin{array}{l}\text { *18. does not take much time to complete } \\
\text { entirely }\end{array}$ & 6 & 1 & - & - \\
\hline * 19. provides tailored feedback & 6 & 1 & - & - \\
\hline $\begin{array}{l}\text { *20. provides tailored feedback which is } \\
\text { perceived as relevant to the visitor }\end{array}$ & 6 & 2 & 6 & 1 \\
\hline $\begin{array}{l}\text { 21. provides tailored feedback in sequence of } \\
\text { brief questionnaires and brief feedback sections }\end{array}$ & 5 & 2 & 5 & 1 \\
\hline $\begin{array}{l}\text { 22. provides behaviour change information that } \\
\text { seems achievable to the visitor }\end{array}$ & 6 & 2 & 6 & 2 \\
\hline * 23. can be used free of charge & 7 & 1 & - & - \\
\hline
\end{tabular}

${ }^{1}$ All items of the questionnaires are included. Dashes indicate that consensus was obtained on the item in the second round and was excluded from the third round questionnaire. Items on which consensus was obtained and which had a median score $\geq 6$ are printed in italics and are preceded by an asterisk.

Table 2.5 Results for items related to revisiting an intervention

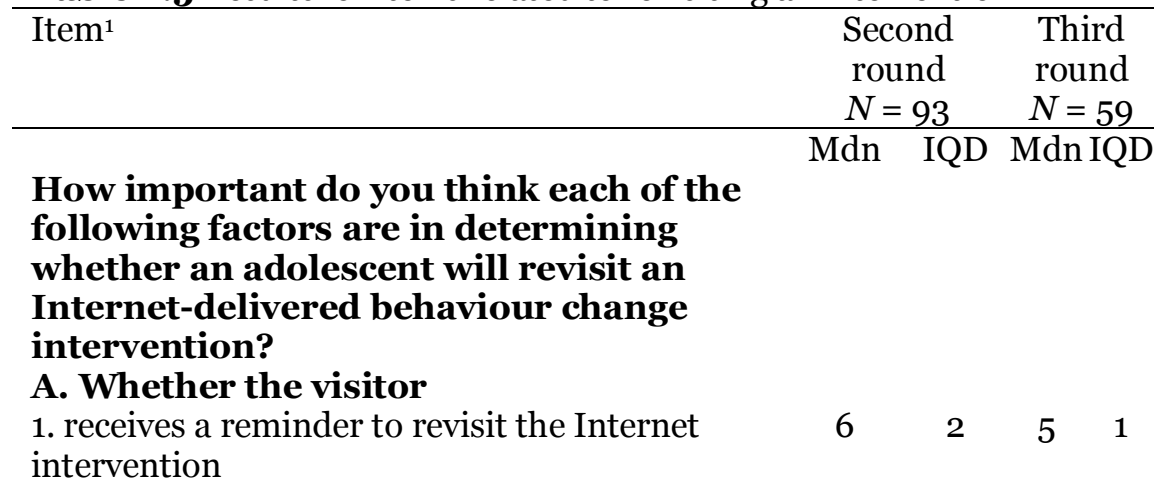




\begin{tabular}{|c|c|c|c|c|}
\hline Item $^{1}$ & & & & \\
\hline & Mdn & IQD & $\mathrm{Mdn}$ & $\frac{U}{\mathrm{IQD}}$ \\
\hline $\begin{array}{l}\text { * } 2 \text {. is committed to revisiting the Internet } \\
\text { intervention }\end{array}$ & 6 & 1 & - & - \\
\hline $\begin{array}{l}{ }^{*} 3 . \text { wants to improve his/her behaviour in } \\
\text { relation to the topic of the Internet intervention }\end{array}$ & 6 & 1 & - & - \\
\hline $\begin{array}{l}\text { * 4. has a positive experience with the previous } \\
\text { visit to the Internet intervention }\end{array}$ & 6 & 1 & - & - \\
\hline $\begin{array}{l}\text { 5. has a chance to receive an incentive by } \\
\text { revisiting the Internet intervention }\end{array}$ & 5 & 2 & 5 & 1 \\
\hline B. Whether the Internet intervention & 6 & ? & 6 & $O$ \\
\hline $\begin{array}{l}\text { * } 2 \text { provides the possibility for a visitor to } \\
\text { monitor his/her progress in changing a } \\
\text { behaviour }\end{array}$ & 6 & 1 & - & - \\
\hline $\begin{array}{l}\text { * } 3 . \text { includes the option for the visitor to } \\
\text { communicate with others (e.g. chat rooms, } \\
\text { blogs, forums) }\end{array}$ & 6 & 2 & 6 & 1 \\
\hline $\begin{array}{l}\text { 4. makes clear what the visitor can expect } \\
\text { during a revisit (e.g. by a preview) }\end{array}$ & 5 & 2 & 5 & o \\
\hline $\begin{array}{l}\text { 5. provides the possibility to post questions for } \\
\text { professionals (e.g. dietician, GP, physical } \\
\text { therapist) }\end{array}$ & 4 & 1 & - & - \\
\hline $\begin{array}{l}\text { 6. uses a modular approach in which a new visit } \\
\text { provides access to the next module }\end{array}$ & 5 & 2 & 5 & 1 \\
\hline $\begin{array}{l}\text { 7. has previously been experienced as easy to } \\
\text { use by the visitor }\end{array}$ & 5 & 1 & - & - \\
\hline $\begin{array}{l}\text { * } 8 \text {. has previously been experienced as } \\
\text { rewarding by the visitor }\end{array}$ & 6 & 1 & - & - \\
\hline $\begin{array}{l}\text { 9. has previously been experienced as } \\
\text { challenging by the visitor }\end{array}$ & 5 & 2.5 & 5 & 1 \\
\hline $\begin{array}{l}\text { *1o. has previously been experienced as } \\
\text { enjoyable by the visitor }\end{array}$ & 6 & 2 & 6 & $o$ \\
\hline
\end{tabular}


Table 2.6 Results for items related to dissemination of an intervention

\begin{tabular}{|c|c|c|c|c|}
\hline \multirow[b]{2}{*}{$\begin{array}{l}\text { How important do you think each of the } \\
\text { following strategies are in achieving } \\
\text { successful dissemination of Internet } \\
\text { interventions for adolescents? }\end{array}$} & \multicolumn{2}{|c|}{$\begin{array}{l}\text { Second } \\
\text { round } \\
N=93\end{array}$} & \multicolumn{2}{|c|}{$\begin{array}{l}\text { Third } \\
\text { round } \\
N=59 \\
\end{array}$} \\
\hline & Mdn & IQD & & \\
\hline $\begin{array}{l}\text { 1. Provide the Internet intervention in a } \\
\text { controlled setting, e.g. school curriculum }\end{array}$ & 5 & 3 & 5 & 1 \\
\hline $\begin{array}{l}\text { 2. Instruction of executives (e.g. workshops for } \\
\text { teachers or nurses) before using it in a } \\
\text { controlled setting }\end{array}$ & 5 & 2 & 5 & 1 \\
\hline $\begin{array}{l}\text { 3. Embed the Internet intervention in the social } \\
\text { context (e.g. at school, at a sports club) }\end{array}$ & 5 & 2.75 & 5 & 2 \\
\hline $\begin{array}{l}\text { 4. Give the Internet intervention an appealing } \\
\text { name }\end{array}$ & 5 & 2 & 5 & 1 \\
\hline $\begin{array}{l}\text { 5. Assure a high search-engine ranking of the } \\
\text { Internet intervention (in e.g. Google, Yahoo!, } \\
\text { AltaVista) }\end{array}$ & 5 & 2.25 & 5 & 1 \\
\hline $\begin{array}{l}\text { 6. Embed the Internet intervention in other } \\
\text { (health) programs }\end{array}$ & 5 & 3 & 5 & 1 \\
\hline $\begin{array}{l}\text { 7. Co-operate with commercial partners (e.g. } \\
\text { supermarkets, related products, soaps) for } \\
\text { promotion of the Internet intervention }\end{array}$ & 5 & 3 & 5 & 1 \\
\hline
\end{tabular}

${ }^{1}$ All items of the questionnaires are included.

\section{Discussion}

To date there is a lack of evidence-based insight into dissemination of and exposure to interventions delivered through the Internet and encouraging a healthy lifestyle for adolescents. This Delphi study, with experts from several disciplines, provided an overview of factors that potentially determine dissemination of and exposure to Internetdelivered interventions aimed at promoting healthy lifestyles in adolescents and the extent to which experts agree on these factors. These factors relate to the dimension of implementation in the RE-AIM model. Notably, most of the factors of which experts agreed on the importance were related to staying on and revisiting the intervention. The results of this exploration are based on the opinions of experts and can now be used for the formation of further questions to be tested and answered in research among adolescents. As a first step, focus group interviews with adolescents are to be conducted and will be reported elsewhere (Chapter 3). A next step would be to conduct observational, experimental and longitudinal studies to test if and how these factors improve dissemination and exposure. 
According to the experts included in our Delphi panel, a positive recommendation by word of mouth (WOM) is an important trigger for adolescents to visit an Internet-delivered intervention for the first time. Information received through WOM is considered more credible than information from, for example, the mass media (Bickart \& Schindler, 2001) since it is both tailored and independent (Silverman, 2001). Furthermore, an attractive interface at first sight is a key issue on the first visit. At first sight should be taken literally, since previous research has shown that people are very quick ( $50 \mathrm{~ms}$ ) in forming an opinion about web page visual appeal (Lindgaard, Fernandes, Dudek, \& Browñ, 2006). Besides these two factors, perception of the Internet-delivered intervention as relevant was the only other factor with regard to a firsttime visit that had a median score above the cut-off score. A good place to start would be to identify health-related topics that are of interest to adolescents and on which they might look for information, for example, weight loss instead of fruit consumption or increasing physical activity.

With regard to staying on the intervention, experts indicated a few factors that should be taken into account in the design of Internetdelivered interventions. One of these is that adolescents can associate themselves with the look and feel of the intervention. For example, the intervention should come across as discreet (Flicker et al., 2004) to increase perceived trustworthiness (Sillence, Briggs, Harris, \& Fishwick, 2006). Another factor mentioned by the experts is the importance of the use of visual materials (e.g. graphs, videos, pictures) and interactive features (e.g. tests, forums, games, etc.). In other words, Internetdelivered interventions should utilise all features provided by the Internet (Noar, Clark, Cole, \& Lustria, 2006; Rhee, Wyatt, \& Wenzel, 2006). Interventions should also provide the opportunity for a visitor to stop at any moment and to resume at a later time. A last point related to the design of the intervention is an easy navigation structure.

Time was mentioned as an important factor. An intervention should not take much time to complete entirely, provide brief textual information (i.e. does not involve a lot of reading) and include a short questionnaire to provide tailored feedback. Additionally, it should be possible to use the intervention free of charge (Barner, Mason, \& Murray, 1999).

According to the experts, it is important that adolescents, at the end of their first visit, are committed to revisit the intervention (if revisiting the intervention is required to establish desired behaviour change). If the intervention requests adolescents to indicate a time when they want to revisit, an implementation intention could be formed. This is a powerful self-regulatory strategy that promotes the initiation of goaldirected behaviours (Gollwitzer, 1999) and increases the likelihood that adolescents will revisit the intervention (Gärling \& Fujii, 2002). Apart from a commitment to revisit the intervention, experts indicated that interventions should provide new content on a regular basis and the chance for adolescents to monitor their progress in changing behaviour. 
All factors with regard to dissemination had a median score of 5 on a 7-point Likert scale. It can therefore be concluded that experts do not agree on a gold standard for successful dissemination of an Internetdelivered intervention.

Besides factors with regard to Internet-delivered interventions, experts also confirmed the importance of factors that are generally applicable to behaviour change interventions. The intervention should provide tailored feedback (Brug, Glanz, Van Assema, Kok, \& Van Breukelen, 1998; Kreuter \& Strecher, 1996), it should be easy to understand (Wilson, Brown, \& Stephens-Ferris, 2006) and perceived as personally relevant (Petty \& Cacioppo, 1986). Furthermore, the intervention and its use should be perceived as rewarding, enjoyable and attractive.

\section{Implications}

Encouragement of word of mouth recommendations could be facilitated by the provision of 'tell-a-friend'-services at such interventions, the online equivalent of word of mouth marketing (also 'virtual word of mouth' (Buttle, 1998)). Virtual word of mouth facilitates communication by removing barriers created by spatial distance and time (Rogers \& Hart, 2002). While early research on computer-mediated communication characterised this as impersonal, more current research has illuminated that communication via the Internet can be just as personal as face-to-face communication (Norman \& Russell, 2006). Further research should therefore concern the effectiveness of 'tell-afriend'-services to encourage word of mouth recommendations.

With regard to the design of an Internet-delivered intervention there are three important issues. First of all, an attractive interface at first sight, since people are very quick in judging the interface (Lindgaard et al., 2006). Second, further research should be conducted among adolescents to generate more detailed ideas about how to establish an intervention with a look and feel with which adolescents can associate themselves (Morgan \& Kreuger, 1998; Van Assema, Mesters, \& Kok, 1992). Third, using formative evaluations, designers should examine if and how adolescents understand the navigation structure of given interventions (Borzekowski \& Rickert, 2001). Besides focus group interviews, other approaches like in-depth interviews and card-sort methods are useful to improve web design with regard to these issues (Eysenbach \& Köhler, 2002; Koyani, Bailey, \& Nall, 2006).

Another point of interest is the utilisation of all features provided by the Internet and how this should be operationalised. Although previous research advocates an option for adolescents to communicate with each other (Ybarra, Mitchell, Wolak, \& Finkelhor, 2006), a more thorough investigation is needed. Although online communication can create a more equal communication field because of the anonymity associated with it (Christopherson, 2007), there are also issues with regard to security and confidentiality (Rochlen, Zack, \& Speyer, 2004). A 
possible solution would be to monitor these activities but it is not yet clear exactly how this changes the communication process (Smahel \& Subrahmanyam, 2007). Future research should focus on possible solutions and their effect on the communication process online.

Since experts do not agree on a gold standard with regard to dissemination, further research is also needed to understand how to maximise the public health impact of Internet-delivered interventions through successful dissemination of those interventions.

\section{Limitations}

This Delphi study examined a very broad topic. Through subdivision of this topic into several subtopics, however, (dissemination, first visit, stay long enough and revisit), several factors related to each subtopic are identified, as well as the extent to which experts agree on the importance of these factors. Despite the fact that the Delphi method itself leads to convergence, researchers in this study expected that more innovative ideas would be generated during the first round. Nevertheless, the results of this Delphi study are in line with many preconceived notions with regard to Internet-delivered interventions. Another way to generate more ideas would be to ask second-round participants to identify new factors but this is not in line with the Delphi methodology which is the base of this study (Linstone \& Turoff, 1975).

Although response rates were non-optimal, they are not exceptional when unsolicited questionnaires are used (Swanborn, 1987). Saturation, however, in the answers given to the open-ended questions of the first round indicates that - according to expert opinion - a broader spectrum of factors associated with dissemination of and exposure to Internet-delivered behaviour change interventions is identified, which was the aim of the present study. Furthermore, despite the heterogeneous sample of experts, a high rate of consensus (91\%) was found in comparison with other Delphi studies (De Vet, Brug, De Nooijer, Dijkstra, \& De Vries, 2005; Hahn, Toumey, Rayens, \& McCoy, 1999). This implies that experts from different disciplines strongly agree on factors that are associated with dissemination of and exposure to Internet-delivered interventions.

\section{Conclusion}

Although this exploration by means of a Delphi study is only a first step, factors that potentially determine dissemination of and exposure to Internet-delivered interventions aimed at promoting healthy lifestyles in adolescents have been identified. This knowledge is crucial to improve the public health impact of such interventions. The results of this exploration therefore serve as a handle for the formation of further research questions to be tested and answered in research among adolescents. 


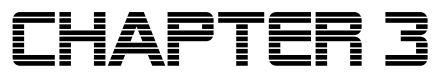

This chapter has been published as Crutzen, R., De Nooijer, J., Brouwer, W., Oenema, A., Brug, J., \& De Vries, N. K. (2008). Qualitative assessment of adolescents' views about improving exposure to Internetdelivered interventions. Health Education, 108, 105-116. 


\begin{abstract}
Purpose - To gain first insight into factors that might be associated with exposure to Internet-delivered interventions.

Design/methodology/approach - Semi-structured focus group interviews were conducted with five groups of Dutch adolescents $(N=$ 54), aged 12-17 years. Several aspects of exposure, (1) a first visit, (2) staying long enough actually to use and process the information and (3) revisiting the intervention, were explored.

Findings - Several factors that are likely to improve exposure to Internet-delivered interventions were identified, such as the use of word of mouth marketing, comparison of own behaviour with friends and the use of reminders.

Research limitations/implications - Focus group interviews are only a first step in the generation of ideas and opinions. A next step would be to conduct observational, experimental and longitudinal studies to test if and how these factors improve exposure to Internet-delivered interventions.

Practical implications - This chapter is a useful source for those developing Internet-delivered interventions who want to improve exposure rates to their interventions.

Originality/value - The results of this exploration serve as an important first step to gain more insight into factors that improve exposure to Internet-delivered interventions.
\end{abstract}




\section{Introduction}

The explosive growth of the Internet has caused an increase in Internetdelivered interventions, aimed at promoting behaviours related to the primary prevention of chronic diseases and thereby encouraging a healthy lifestyle with regard to health risk behaviours such as lack of physical activity, low consumption of fruit, cigarette-smoking, unprotected sex and excessive alcohol consumption (Bernhardt \& Hubley, 2001; De Nooijer \& De Vries, 2006; Pérez-Rodrigo et al., 2005). From evidence of efficacy trials it appears that exposure rates to such interventions are quite low (De Nooijer et al., 2005) and in real life exposure rates may be even lower (Evers et al., 2005). Although it has been proven that Internet-delivered interventions can be effective in changing behaviour (Jago et al., 2006; Mangunkusumo, Brug, De Koning, Van der Lei, \& Raat, 2007), there is a lack of evidence-based insight about how to reach optimal exposure rates for such interventions (De Nooijer et al., 2005). Exposure involves actual exposure of individuals to the intervention content, through use of the intervention, and is necessary since attention is a prerequisite to establish desired behaviour change (McGuire, 1985).

In terms of Internet-delivered interventions, there is a distinction between three different aspects of exposure: (1) a first visit, (2) staying on the intervention long enough actually to use and process the information and (3) revisiting the intervention. The latter can be important, since there is a possible dose-response relationship between the number of visits and behaviour change outcomes (Lenert et al., 2003; Verheijden et al., 2007; Zebrack et al., 2005).

There are two reasons to focus on adolescents. First, many health risk behaviours are acquired during adolescence and track into adulthood, thereby affecting health in later life (Kelder et al., 1994). Second, this age group also poses specific challenges to health promoters. In contrast to patients looking for treatment or medical information, adolescents without any chronic disease are not likely to be internally motivated to visit Internet-delivered behaviour change interventions and to stay long enough to engage actively in and process the educational content provided in the intervention (De Nooijer et al., 2005).

The potential reach of Internet-delivered behaviour-change interventions aimed at adolescents is enormous, since 95\% of Dutch people between age 12 and 25 had access to the Internet by 2006 (CBS, 2006). Internet penetration rates are also high in other countries in western Europe, North America and Australia (Internet World Stats, 2008a). According to the RE-AIM model, the public health impact of an intervention is a function of four other factors besides reach: efficacy, adoption, implementation and maintenance. The different aspects of exposure relate to implementation, the extent to which an intervention is delivered as intended (Glasgow et al., 1999). The aim of the present study was to gain first insight into factors which might be associated with 
exposure to Internet-delivered interventions. Explorative research questions were therefore:

- When do adolescents visit an Internet-delivered behaviour change intervention for the first time?

- How can adolescents be kept long enough on such an intervention to engage actively in and process the educational content provided in the intervention?

- How can adolescents be motivated to revisit an Internetdelivered behaviour change intervention?

The answers to these research questions are used to suggest practical implications for improvement of exposure rates to Internet-delivered behaviour change interventions.

\section{Methods}

\section{Design}

Focus group interviews were used to answer our research questions. A focus group interview is a qualitative research method whose results provide information about the ideas and opinions of the target group on a particular subject. Focus groups are guided discussions, in which the interviewer serves essentially as a moderator who guides the conversation gently towards each topic until it appears to have become unproductive. Additionally, it allows participants to raise important issues and nuances that researchers do not foresee. Focus group interviews are a useful initial method, especially if little is known about the subject to be studied. Unlike quantitative methods, they offer an opportunity to do explorative research and at the same time discuss specific topics in greater detail. Another reason to use focus group interviews is the expectation that the interaction between the participants would yield additional information (Morgan \& Kreuger, 1998; Van Assema et al., 1992).

\section{Participants and procedures}

Five focus group interviews were conducted in three schools in different parts of the Netherlands. One of these schools was located in an urban area, while two were located in a suburban area. Two schools were contacted through personal contacts with teachers in these schools and one school was randomly recruited by a local community health service (GGD). A total of 54 adolescents (age range from 12-17 years) participated in the focus group interviews and group sizes varied from 10-12. Adolescents were randomly recruited by their teacher and we asked them to distribute the groups equally with regard to sex if possible. Four groups consisted of adolescents who attended the same educational level (two low - preparatory secondary vocational education, two high senior general secondary education or university preparatory education) and one group was mixed. All groups consisted of adolescents from the same year. 
Participants were told in advance that the focus group interviews were about their opinion on several topics with regard to the Internet and healthy lifestyle. It was stressed that there were no good or bad opinions or answers to the questions and they were also stimulated to express if and why they agreed or disagreed with other participants. They were also told that the interviews would be tape-recorded, but only for research purposes. It was explicitly stated that no other people (e.g. teachers, parents) would have access to these recordings. Participants signed an informed consent form, which stated that the interviews would be taperecorded and their participation was voluntary. Film vouchers were used as an incentive for all participants.

\section{Interviews}

The interviews were chaired by the first author and an assistant who supported the chairperson in guiding the process of the group interview. An interview scheme was drawn up in advance to guide the interviews and stimulate response and interaction (Table 3.1). The interview sessions were semi-structured, meaning that the natural flow of the conversation was followed, and checked to see whether all key questions were discussed. The natural flow of the conversation attempted to stimulate adolescents to express their opinions freely.

Table 3.1 Interview scheme

\begin{tabular}{|c|c|}
\hline Main topic & Key questions ${ }^{1}$ \\
\hline $\begin{array}{l}\text { First time visit to an } \\
\text { Internet-delivered behaviour } \\
\text { change intervention. }\end{array}$ & $\begin{array}{l}\text { How do you search for healthy } \\
\text { lifestyle information on the Internet? } \\
\text { Which method do you use to arrive at } \\
\text { the website of a lifestyle } \\
\text { intervention? } \\
\text { Which way do you prefer? And why? } \\
\text { What would you do to attract visitors } \\
\text { to a lifestyle intervention? }\end{array}$ \\
\hline $\begin{array}{l}\text { Stay long enough on an } \\
\text { Internet-delivered behaviour } \\
\text { change intervention to } \\
\text { engage actively in and } \\
\text { process the educational } \\
\text { content provided in the } \\
\text { intervention. }\end{array}$ & $\begin{array}{l}\text { - Why do you stay at the website of a } \\
\text { lifestyle intervention? } \\
\text { - Why do you leave a lifestyle } \\
\text { intervention? } \\
\text { - What would you do to keep visitors } \\
\text { at a lifestyle intervention? }\end{array}$ \\
\hline $\begin{array}{l}\text { Revisit an Internet-delivered } \\
\text { behaviour change } \\
\text { intervention. }\end{array}$ & $\begin{array}{l}\text { - Why do you come back to a lifestyle } \\
\text { intervention? } \\
\text { - Why do you not come back to a } \\
\text { lifestyle intervention? } \\
\text { - What would you do to motivate } \\
\text { visitors to revisit a lifestyle }\end{array}$ \\
\hline
\end{tabular}


intervention?

${ }^{1}$ These questions do not explicitly state "Internet-delivered" every time. At the beginning of each interview, however, we mentioned that our focus was on Internet-delivered interventions only.

Data analysis

The audiotapes of the interviews were transcribed and then analysed by means of the qualitative data analysis package QSR Nvivo 2.0

(http://www.qsrinternational.com/). A thematic approach was used, meaning that the research questions were used to define a classification into main topics (first visit, stay long enough, revisit) and sub-topics (factors related to these main topics). Two researchers analysed the transcripts of each interview, selected relevant sections, assigned them to the right topics and discussed their analysis to improve the reliability of their interpretation. Inconsistencies were resolved through discussion. The key results of the interviews, those most outstanding and most discussed, are described below.

\section{Results}

Use of the Internet in general

Adolescents in all groups stated that they used the Internet mainly for instant messaging, gaming, downloading and visiting social-networking websites and that they did not use the Internet very often for schoolrelated purposes. Older adolescents and those who attended at a higher education level preferred social-networking websites with a focus on interaction between members to get to know each other (popular Dutch example: www.sugababes.nl), while the younger and lower-educated adolescents preferred websites with a game component (e.g. www.habbo.com).

First time visit

When adolescents were asked how they searched for healthy lifestyle information on the Internet, most of them answered that they did not look spontaneously for such information. Some, however, mentioned that they did search for healthy lifestyle information if they were told to do so by their teacher (e.g. for a homework assignment) or when recommended (e.g. after a visit to a dietician). Nevertheless, the use of the Internet was, according to most adolescents, not sufficiently stressed in their curriculum. The answer to the question how they searched for such information was clear: they did not mention the word search engine, but only the word Google (they even made a verb out of it). It was also important that the intervention had a short name and corresponding URL (Universal Resource Locater, an address of an Internet resource): "Not a long name, with twenty of those slashes behind it. Just an easy one: www followed by the name. Keep it short. Not such a long one, with all those digits. In that case you want to type it and you already 
lose 3 minutes. And then it turns out you put one digit in the wrong place and you can start all over" [third-year pupil, low educational level, suburban school].

Adolescents in all groups stated that their social network exerted influence on the decision to visit an Internet-delivered intervention. They had a strong preference for receiving recommendations for interventions from their friends: "You get it from friends, who also get it from friends, from friends, from friends" [first-year pupil, mixed educational level, suburban school]. Not just friends in the old-fashioned sense (classmates or kids from the same neighbourhood), however, but also friends they knew purely online, e.g. through social-networking websites. Almost everybody preferred to receive a link during an instant messaging conversation, through e-mail or at social network websites, because in that case links are immediately clickable.

Another strategy mentioned by some adolescents to motivate them for a first time visit to an Internet-delivered intervention was through cross-media. Most mentioned was advertising on TV. For example, in one group they referred to a current campaign using celebrities: "Yes- $R$ [a Dutch rapper] is quite popular at the moment. If he is part of it, you immediately know that there is something for young people" [third-year pupil, low educational level, suburban school]. Besides advertising, they also mentioned more serious references to interventions, such as newspaper articles or news items on television as a reason for a first visit.

\section{Staying long enough}

Important factors influencing the decision to extend the visit to the intervention were that the information provided in the intervention should be in adolescents' mother tongue and easy to understand: "No difficult words for which you need a dictionary" [fourth-year pupil, low educational level, suburban school]. Furthermore, this information should be presented in a serious way: straight to the point and not trying to be popular (e.g. by use of slang). To keep adolescents long enough on a website to engage in and process the educational material provided in the intervention, this content should not be solely textual information. Adolescents in all groups stated that they wanted a combination of textual information with a variety of other elements like pictures, movies, and games, which should be content-related. They wanted to be active (e.g. playing games) and encounter ways to communicate (e.g. forum, chat). Furthermore, most of them wanted direct access to all these elements: "When you click on something you need to get there immediately without doing ten other things first" [fourth-year pupil, high educational level, urban school].

Many adolescents appreciated tailored advice, although they mentioned that the questionnaire used to generate this advice should not take long to complete. Another feature which some of the adolescents recommended was the chance to ask questions directly of an expert (e.g. 
a nutritionist). If they had to register to use such elements, most of them were only willing to do so if the intervention offered unique elements. To prevent adolescents leaving the intervention, the home page should clearly state why they should register and which elements are accessible after registration: "You should not do this [registration procedure] at the beginning of the site. You should do this somewhere in the middle, if one wants to use something extra" [fourth-year pupil, low educational level, suburban school]. Many adolescents were not willing to provide personal details (e.g. home address) during the registration procedure, but did not mind completing a questionnaire about health risk behaviours. Again, this questionnaire should not take long to complete.

One group proposed the idea of an avatar (an Internet user's representation of him/ herself, whether in the form of a threedimensional model used in computer games (Lessig, 1999) or a twodimensional icon used on Internet forums and other communities (Fink, 1999)): "That you could keep a personal logbook and, for example, next to it is a little figure and if you mention that you ate four portions of French fries that day, this figure will get fat. That you actually get a second you at the Internet" [fourth-year pupil, low educational level, suburban school]. Elaborating on this idea, participants mentioned that this avatar could also be used as a playful element. For example, through the reaction of your avatar on your behaviour, you will learn to avoid health risk behaviours. Others appreciated this idea when it was suggested to them and added that this would be a good reason to revisit an intervention.

\section{Revisit}

A prerequisite for revisiting an Internet-delivered intervention was an enjoyable previous experience, as mentioned by adolescents in all groups. According to some adolescents, a reminder would be appropriate to attract them again to an intervention. There was, however, a debate as to whether reminders should be sent through e-mail or SMS (Short Message Service). Some adolescents indicated that a text message was more personal, but were worried about privacy aspects: "If you get a text message they also got your number and this is not always nice" [firstyear pupil, high educational level, suburban school]. Another issue with regard to reminders through SMS was that adolescents are not always online at the moment they receive the reminder. The layout was the most important issue for an e-mail-reminder: "But if it [the reminder] has short paragraphs and a nice typeface, then I'll read it" [first-year pupil, high educational level, suburban school].

Most of the adolescents indicated that the intervention should be updated regularly, for example, once a week. Not only information should be updated, but also new elements should be added to the interventions, for example, games and quizzes: "And then you'll come back to the homepage and check whether there are some more interesting things" [first-year pupil, high educational level, suburban 
school]. Old elements should, however, stay available since they also attract adolescents who appreciate these elements. According to some adolescents, the intervention should also provide an opportunity to give feedback on these renewals.

Finally, information about their own behaviour would attract most adolescents to revisit an Internet-delivered intervention. The opportunity to monitor their behaviour over time is a good example of this. Some adolescents also mentioned comparing their own behaviour with that of others as a reason to revisit an intervention: "It would be useful if your score [with regard to physical activity] is low in comparison with other kids, because then you know that you need to exercise more" [first-year pupil, high educational level, suburban school].

\section{Trustworthiness}

Trustworthiness of information found on the Internet was frequently mentioned by adolescents themselves and does not relate to all aspects of exposure. Adolescents were suspicious about information they received through the Internet. Once they read information, some of them doublechecked this at other places on the Internet. Despite this suspicion, most of them did not actively search for the source of information. They were not suspicious, however, if friends referred them to an intervention: "They won't tell bad things to me and that I have to go there" [fourthyear pupil, high educational level, urban school].

\section{Discussion}

The present study reports the results of focus group interviews aimed at gaining first insight into factors which might be associated with exposure to Internet-delivered interventions. These results will be discussed and suggestions for practical implications to improve exposure will be given.

\section{Implications for practice and research}

First time visit. First of all, most adolescents stated that they do not spontaneously search for healthy lifestyle information. A reason for this could be that most of the interventions are presented as being about rather boring topics (according to adolescents), for example, fruit consumption. A good place to start would be to identify health-related topics that are of interest to adolescents and which they might look for information on, for example, weight loss instead of fruit consumption. This would also provide guidance on the sort of terms to include in names and URLs of interventions. Furthermore, adolescents in all groups stated that the Internet is not often used for educational purposes. If it were, this could enhance the opportunities for health promotion. A first possibility, therefore, to improve exposure to Internet-delivered interventions could be to pay more attention to the use of the Internet in the curriculum of Dutch secondary schools. This lack of attention to the use of the Internet in school curricula is a concern in other countries as 
well (Erstad, 2006; Gray, Klein, Noyce, Sesselberg, \& Cantrill, 2005b). It also appeared that adolescents appreciate interventions that are recommended by their friends. Although the concept of friendship in the e-communication era is no longer restricted to persons in the physical environment of adolescents (Markow, 2006), the mutual influence between friends in the new definition still exists. Adolescents feel they belong to their group of friends and they affect each other's opinions (Berndt, 1996; Thornburg, 1981), so recommendations by friends could increase the likelihood of visits to Internet-delivered interventions. This could be facilitated by offering "tell-a-friend"-services at such interventions, the online equivalent of word of mouth marketing (Maibach, Van Duyn, \& Bloodgood, 2006). Information received through word of mouth (WOM) is considered more credible than information from, for example, the mass media (Bickart \& Schindler, 2001) since it is both tailored and independent (Silverman, 2001). Online WOM is more influential owing to its speed and one-to-many reach (Phelps, Lewis, Mobilio, Perry, \& Raman, 2004). The measurement of online WOM and the related consequences are still difficult (Sun, Youn, Wu, \& Kuntaraporn, 2006) and this should be taken into account in future research.

Staying long enough. Many adolescents appreciated comparing their own behaviour with that of friends, which was also found in another study (De Nooijer et al., 2008). Previous research has shown, however, that comparison with "the average adolescent" is perceived as vague, whereas the comparison of their own behaviour with that of close friends is a strong predictor of actual behaviour (Yanovitzky, Stewart, \& Lederman, 2006). Adolescents can project different parts of their personalities to others online (Gillispie \& Gackenbach, 2007). The opportunity for adolescents to compare their own behaviour with friends could therefore be provided by Internet-delivered interventions to keep adolescents longer on the intervention. Another idea which was proposed to improve exposure to Interne-delivered behaviour change interventions was the use of an avatar. The concept of avatars originates from the gaming industry but is receiving increased attention in scientific research as well. Although research with regard to avatars in the field of health promotion is scarce (Lee et al., 2004), there is a growing body of research on related topics like persuasion (Guadagno, Blascovich, Bailenson, \& McCall, 2007) and social influence (Bailenson, Beall, Blascovich, Loomis, \& Turk, 2005). This research shows that avatars are a useful instrument to stimulate attitude change, possibly through their interactivity (Gillispie \& Gackenbach, 2007). In research on virtual communities, like Second Life, avatars are also getting more attention (Yee, Bailenson, Urbanek, Chang, \& Merget, 2007). Future research should explore the opportunities for the use of avatars in Internet-delivered behaviour change interventions, since most adolescents indicated that they appreciated the concept and it would improve exposure rates. Besides the presence of several elements as described in this chapter, it is again also 
important to explore which health-related topics are of interest to adolescents. There are two issues to explore: (1) which health issues will hold adolescents' interest, followed by (2) which elements will keep them engaged. Although this research gives more insight into the latter, future research should focus also on the first issue.

Revisit. More knowledge on this issue is also crucial with regard to revisiting an intervention, since adolescents will not revisit an intervention about a topic which does not hold their interest. If they are interested, a revisit could be achieved through the use of reminders. Adolescents were, however, divided about the media channel that should be used to send reminders. Since $91 \%$ of Dutch adolescents between 12 and 17 have an e-mail address and 95\% own a cell-phone (CBS, 2002), both channels seem appropriate. But, of course, using one does not exclude using the other as well. More insight into the preferences of adolescents is therefore needed, with regard also to privacy aspects, timing and layout of reminders.

Non-Internet-specific issues. Notably, many adolescents mentioned non-Internet-specific issues. These issues are generally applicable to behaviour change interventions and also apply to Internetdelivered interventions, for example, the use of an appropriate literacy level (Bartholomew et al., 2006) and tailored advice (Brug et al., 1998; Neuhauser \& Kreps, 2003). Although these are non-Internet-specific issues, they may be more important for Internet interventions. For example, the Internet has the reach of a mass medium (e.g. comparable to TV), but it also provides the opportunity to tailor information (e.g. comparable to a letter). Furthermore, some adolescents stressed that the source of the intervention should be perceived as credible, since this also has an impact on the intention to revisit an Internet-delivered intervention (Hong, 2006). Trustworthiness is of more importance on the Internet since there is no traditional gatekeeper at the input side of the information as there is with other media like radio or television (Bruns, 2005). It has, however, recently been demonstrated that differences in attribution to a source did not have a significant effect on the evaluation of the quality of information (Bates, Romina, Ahmed, \& Hopson, 2006) and are therefore less relevant as a factor to improve exposure rates.

\section{Limitations of the present study}

Focus group interviews are only a first step to generate ideas and opinions and are not meant to gather quantitative data from a representative sample. The aim of the present study was to obtain this information from a broad perspective, and not from a representative sample. In order to obtain viewpoints from diverse strata, the participants in our focus group interviews differed in educational level, sex and region. Nevertheless, we found hardly any differences between participants from the different subgroups. 
Since groups consisted of adolescents from the same year, they were acquaintances. This is not necessarily a disadvantage, since they have gone through experiences together and may well be prepared to discuss precisely the things that are of interest (Morgan \& Kreuger, 1998). Furthermore, peer pressure is not so much of an influence on the topics discussed, in contrast to topics such as alcohol consumption (Yanovitzky et al., 2006).

Finally, it is not clear to what extent these results lay the foundation of practical implications for the design of Internet-delivered interventions. Future research is needed to test the factors revealed during this exploration.

Concluding remarks

The results of this exploration serve as an important first step to get more insight into factors that improve exposure to such interventions. Factors like, for example, the use of WOM-marketing, avatars and reminders need to be thoroughly investigated. A next step would therefore be to conduct observational, experimental and longitudinal studies to test if and how these factors improve exposure to Internet-delivered interventions.

\section{Acknowledgements}

We would like to thank Evelien Reinaerts and Janaica Grispen for their assistance during the group interviews. 


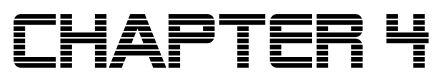

This chapter has been submitted for publication as Crutzen, R., De Nooijer, J., Brouwer, W., Oenema, A., Brug, J., \& De Vries, N. K. A conceptual framework for understanding and improving adolescents' exposure to Internet-delivered interventions. 


\begin{abstract}
Although exposure is crucial to improve the public health impact of Internet-delivered interventions, it appears that in practice exposure to such interventions is low. Therefore, a conceptual framework, which incorporates elements of user experience of websites, is applied to Internet-delivered health behaviour change interventions aimed at adolescents and results from previous explorative research are incorporated. This framework, described from the point of view of an intervention's development team, can be used in practice to optimise user experience and therewith improving exposure rates to Internetdelivered interventions and increasing the number of revisiting users.
\end{abstract}




\section{Introduction}

The huge increase in possibilities of and access to the Internet has initiated an expansion of Internet-delivered health behaviour change interventions, for example aiming to promote healthful physical activity, consumption of fruits and vegetables, smoking cessation, safe sex practices and restrictive alcohol consumption (Bernhardt \& Hubley, 2001; De Nooijer \& De Vries, 2006; Pérez-Rodrigo et al., 2005). Evidence from efficacy trials indicates that exposure rates to such interventions are quite low (De Nooijer et al., 2005) and in real life exposure rates may be even lower (Evers et al., 2005). In this chapter we will introduce a conceptual framework for understanding and improving adolescents' exposure to Internet-delivered interventions.

Exposure, or paying attention to the intervention content as well as active use and elaboration of the intervention components, is necessary because attention is a prerequisite to establish desired behaviour change (McGuire, 1985). In terms of Internet-delivered interventions, three different aspects of exposure can be distinguished: (1) accessing the intervention website, i.e. a first visit, (2) staying on the intervention website long enough to use and process the information and (3) revisiting the intervention website. The latter only applies to interventions which are developed to be visited multiple times since there is a possible dose-response relationship between the number of visits and behaviour change outcomes of these interventions (Lenert et al., 2003; Verheijden et al., 2007; Zebrack et al., 2005). With regard to staying long enough, it is hard to indicate a desirable length of time, since this differs per intervention. Furthermore, there may also be a difference in time needed between individuals, depending on their capability to process information. Therefore, staying long enough is defined as the time which an individual needs to process the information provided at a specific intervention website.

We focus on interventions aimed at adolescents because many health risk behaviours are acquired during adolescence and track into adulthood, thereby affecting not only current health but also health in later life (Kelder et al., 1994). In contrast to patients looking for treatment or medical information, adolescents without any chronic disease are not likely to be internally motivated to search for behaviour change interventions in the domain of health promotion (De Nooijer et al., 2005). Furthermore, the current generation of adolescents grew up with the Internet (Tapscott, 1998) and is more open towards new possibilities offered by this medium (Leung, 2003). They use the Internet differently compared to adults (Fox, 2006; Gross, 2004; Hansen et al., 2003). Their main online activities are instant messaging, gaming, downloading and visiting social-networking websites (Gross, 2004; Van den Eijnden \& Vermulst, 2006) while adults use the Internet mainly for e-mail and information seeking (Jackson et al., 2005). Therefore, factors associated with exposure probably differ between adolescents and adults. 


\begin{abstract}
Aim
The aim of this chapter was to propose a useful tool, for the development process of Internet-delivered interventions, which aims to improve exposure rates and increase the number of revisiting users. A conceptual framework related to website design in general, as described by Garrett (2002a), is applied to Internet-delivered health behaviour change interventions aimed at adolescents and previously explored factors will be contextualised (Chapters 2 and 3). A closer look at these factors reveals that they can all be related to the concept of user experience. According to our definition, user experience includes the total time span of a visit to an Internet-delivered intervention and refers to how a person acts and what a person thinks and feels during and after a visit. User experience relates to all three aspects of exposure since a positive user experience during and after the first visit is a prerequisite to revisit an Internet-delivered intervention and for staying long enough to complete the intervention.
\end{abstract}

\title{
Garrett's concept of user experience
}

Garrett (2002a) distinguishes five planes (surface, skeleton, structure, scope, and strategy (Figure 4.1)) to conceptualise user experience. On the surface, the user perceives the visual design which relates to the visual presentation of interface elements (e.g. typeface, images, navigational components). This does not only relate to what is perceived as aesthetically pleasing, but also how effective the design supports decisions made at the other planes. The skeleton primarily concerns the arrangement of interface elements (e.g. placing important elements, such as navigation menu and search bar, consistently) and is a concrete expression of the more abstract structure of a website which defines how the intervention will function (e.g. options involved in performing and completing tasks). In other words, structure defines how various features and functions of the intervention fit together (e.g. visual materials, interactive features). The structure gives shape to the scope which covers what these features and functions are. The scope is fundamentally determined by the strategy of a website and incorporates not only what the intervention wants to establish (e.g. behaviour change), but also what the user needs are. 

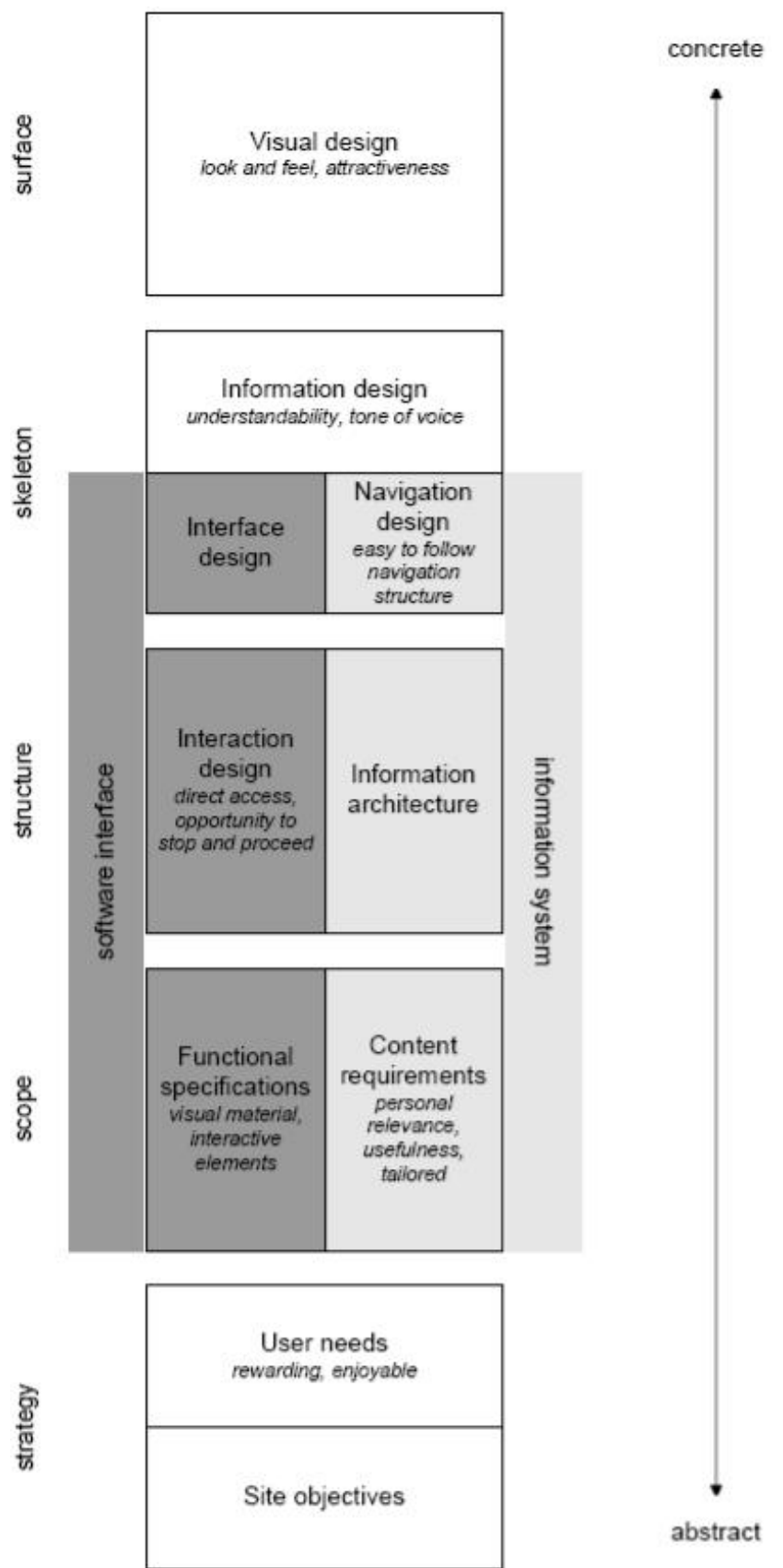

Figure 4.1 The elements of user experience (Garrett, 2002a) and their related factors (in italics) that resulted from previous explorative research (Chapters 2 and 3). 
The issues one has to deal with during intervention development are positioned on a continuum varying from very concrete (surface - top) to very abstract (strategy - bottom). The user is first confronted with the surface of an Internet-delivered intervention. However, from the point of view of intervention development, the starting point is the lowest, more abstract, plane. Plane by plane, from the bottom to the top, the decisions of an intervention development team become more concrete. Decisions on a lower plane have an influence on the choices available on higher planes. Dependencies run in both directions, however, with decisions made on higher planes sometimes forcing a re-evaluation of decisions on lower planes. Therefore, during intervention development, work on a higher plane can start, but never finish, before work on a lower plane has finished (Garrett, 2002a).

\section{Elements of user experience}

Each plane consists of elements which Garrett (2002a) denominates as the elements of user experience (Figure 4.1). Some of these elements are related to an Internet-delivered intervention as an information system (Figure 4.1; light gray). This does not only concern gathering information, but also the ability to interact with an information system. This ability to interact with an information system is an important reason why Internet-delivered interventions are attractive to deliver tailored information (De Vries \& Brug, 1999; Eng, Maxfield, Patrick, Deering, Ratzan, \& Gustafson, 1998). On the other hand, interaction with an information system also requires a software interface which enables this interaction. Therefore, other elements are related to the development of an Internet-delivered intervention's software interface (Figure 4.1; dark grey).

Our point of view is that of an intervention's development team and, therefore, the starting point will be the lowest plane.

\section{Strategy}

Site objectives: Since the focus is on Internet-delivered behaviour change interventions, "behaviour change" seems to be the easy answer when asked to explicate the site objective. However, a good objective should be formulated 'SMART' (Specific, Measurable, Attainable, Realistic and Timely) and thus include statements on what will change specifically in a specified population, how much it will change, and by what period of time. This could be specified in terms of behaviour or its determinants (Bartholomew et al., 2006). For example, a twenty percent increase of adolescents' (12-17 years) knowledge about healthy alternatives for unhealthy food within 3 months after release of the website. The amount of expected change and the time frame must be empirically justifiable (Bartholomew et al., 2006). Furthermore, it is important to keep the feasibility of the site objective in mind. The Internet can be a suitable delivery mode for an objective which relates to increasing knowledge. However, nutrition behaviour, for example, is influenced by 
intrapersonal (i.e. food preferences), social (i.e. family eating habits) and cultural factors (i.e. culture is often expressed through food), as well as factors in the physical environment (i.e. availability of healthy food) (Reinaerts, De Nooijer, \& De Vries, 2008).

User needs: User needs at the strategy plane do not refer to needs with regard to health or health behaviours, but to needs with regard to experiencing the use of an Internet-delivered intervention. Two needs which resulted from previous explorative research are experiencing the use as (1) rewarding and (2) enjoyable (Chapters 2 and 3). During focus group interviews, adolescents frequently mentioned "It [using the intervention] just has to be fun"; but they could not clarify this in more detail for Internet-delivered interventions in general. Those needs should be related to the site objectives which will be illustrated when we apply the framework later on.

\section{Scope}

What exactly will be developed has to be defined on the scope plane. An intervention's functionality relates to its software interface, while its content relates to an intervention as an information system. However, in gathering requirements for both an intervention's functionality as well as its content, user involvement is highly important (Garrett, 2002a).

Functional specifications: If you ask users what they require, they mention all kind of features which can possibly be provided on an Internet-delivered intervention (Chapter 3; Rhee et al., 2006); both visual materials (e.g. graphs, videos, pictures) as well as interactive features (e.g. tests, forums, games, etc.). However, during development the format of a piece of content should be in line with its purpose (Garrett, 2002a) and the intervention itself should not be a conglomeration of all possible features. A feature should be proven effective and not be available at an intervention for the sake of being available.

Content requirements: Although the purpose of an Internetdelivered intervention's content should be in line with its objectives (as defined on the strategy plane), it also need to be personally relevant, useful, and tailored (Chapters 2 and 3). For example, previous research indicated that the content should be tailored to a user's intention to change behaviour, to improve exposure to an Internet-delivered intervention (Chapter 6). Furthermore, theoretical methods that can influence change in determinants should be identified as well as conditions under which a given method is most likely to be effective (Bartholomew et al., 2006).

When gathering requirements for an intervention's functionality and content, these requirements should be in line with the strategy defined on the lower plane. Sometimes it is necessary to revise your strategy if your requirements fall outside the scope. If that is the case, however, it probably indicates that the development team jumped into gathering requirements too soon (Garrett, 2002a). 


\section{Structure}

Interaction design: Interaction design concerns the options involved in performing and completing tasks (Garrett, 2002a). Although this is a very broad research field (Rimmer, 2004), two factors with regard to interaction design resulted from previous explorative research: the user needs to have (1) direct access to the intervention and (2) the opportunity to stop at any moment and to proceed at a later time without information from earlier steps being lost. In practice, however, it is not always possible to realise this, since some interventions require visitors to log on or to finish a module before it is possible to stop. Furthermore, it should somehow be registered at which point in the intervention the user has stopped. If there is no log on procedure, this must be done through the use of IP addresses ${ }^{2}$ or cookies 3 . Since a personal computer (PC) can have a dynamic IP address and the same IP address can be linked to several computers, this method is not recommended. Cookies, on the other hand, are stored on a user's computer, but the use of them can be switched off and a revisiting user will not be recognised when using another computer. Furthermore, both methods are only able to trace computers which can be used by multiple users.

Information architecture: Information architecture deals with the options involved in conveying information to a user. It is concerned with creating schemes that allow users to move through intervention content efficiently and effectively. Although this also holds for more static media with a linear structure, e.g. print (Kools, Ruiter, Van de Wiel, \& Kok, 2007), it is even more important for an interactive medium with a non-linear structure (e.g. the Internet), since there are more possibilities to move through content delivered through such a medium. The information architecture should not be precisely tuned and fitted to the existing content of an intervention, but needs to be flexible enough to accommodate changes or additions (Garrett, 2002a). The most effective way to represent the structure is through the use of an architecture diagram in which conceptual relationships are documented. More information about how to create such a diagram - called visual vocabulary - can be found elsewhere, but in general it should be small and self-contained (Garrett, 2002b).

\section{Skeleton}

The skeleton plane consists of three elements which are closely bound together.

Interface design: If it involves providing users with the ability to do things, it is interface design. Interface design is all about the

\footnotetext{
2 The numeric address of a computer connected to the Internet.

3 Cookies provide a means for a web server to induce a client to store information about itself which can subsequently be called up by the web server when required.
} 
arrangement of interface elements to enable visitors to interact with the intervention (Garrett, 2002a). Notably, no factors with regard to the interface design resulted from previous explorative research, despite the ongoing debate in the literature about its paradigms, principles and methods (Lin, Zhang, Koubek, \& Mourant, 2006). However, some basic guidelines (Koyani et al., 2006) need to be kept in mind (e.g. placing important elements, such as a menu, consistently (Bernard, 2001)).

Navigation design: If it involves providing users with the ability to go places, it is navigation design. The navigation design of any website must accomplish three simultaneous goals. It should (1) provide users with a means for getting from one point to another on the website, and communicate the relationship between (2) the elements it contains and (3) its content and the page the user is currently viewing (Garrett, 2002a). Attempts might be made to have an easy to follow navigation structure (Chapter 2), which implies that it is supposed to be part of usability testing during development of an intervention (Stoddard, Augustson, \& Mabry, 2006). This could prevent problems such as adolescents who do not click on links since their lay-out is not in line with the default hyperlink lay-out (blue, underlined) (De Nooijer et al., 2008).

Information design: If it involves communicating ideas to the user, it is information design. Neither interface design nor navigation design can be fully successful without good information design to support them (Garrett, 2002a). Two main criteria, resulting from previous explorative research, are that information is (1) understandable and its (2) tone of voice appropriate for adolescents (Chapters 2 and 3).

\section{Surface}

On the surface plane you have to determine how the arrangement of the skeleton plane should be presented visually (Garrett, 2002a). Previous research has shown that people are very quick $(50 \mathrm{~ms})$ in forming an opinion about webpage visual appeal (Lindgaard et al., 2006). Eyetracking can be a useful method to decide which elements of an intervention attract attention (Pan, Hembrooke, Gay, Granka, Feusner, \& Newman, 2004). According to Garrett (2002a), however, such sophisticated methods are not always necessary. Simply asking users which elements attract attention will maybe never capture all the nuances that eye-tracking equipment can provide and is depending on memory and consciousness, but it is perfectly suitable to get a first impression about which elements do attract attention.

\footnotetext{
Applying the framework within the field of health promotion Several tasks are involved in the development process to optimise user experience. Conform Bartholomew et al. (2006), we make a distinction between theory-based methods and practical strategies and the intervention itself.
} 


\begin{abstract}
Strategy
On the strategy plane, the development team of the Internet-delivered intervention needs to define site objectives and identify user needs. Research tools like surveys, interviews or focus groups are most suitable for gathering user needs (Garrett, 2002a). We use the site objective "a twenty percent increase of adolescents' (12-17 years) knowledge about healthy alternatives for unhealthy food within 3 months after release of the website" as an example to illustrate further tasks of the development team. Although this is an example on the individual level and it does not include intrapersonal, social or cultural factors, it is convenient to illustrate the use of the conceptual framework during the development process.
\end{abstract}

\title{
Scope \& structure: Theory-based methods and practical strategies
}

First, functional specifications and content requirements need to be specified, for example through focus group interviews (Dijk, De Nooijer, Heinrich, \& De Vries, 2007a). Together with user needs, they might be linked to each other and to the site objectives. In our example, the intervention's objective is to increase knowledge. If users want to increase knowledge in an enjoyable way, the development team need to focus on the entertainment aspect. However, if users want to find information as quickly as possible this should be the main focus of the development team. These needs should be translated into functional specifications (including appropriate methods). If users want to increase knowledge in an enjoyable way, a game (using active learning) could be an appropriate tool. However, if users want to find information as quickly as possible, a FAQ (Frequently Asked Questions) seems more appropriate. Content requirements are even more directly linked to site objectives. In our example, the focus is on increasing knowledge. Although this may seem evident, the intervention content should then also focus on knowledge and not on other determinants which are not defined in the site objectives. The second task is to define the structure of the intervention, resulting in a visual vocabulary. Extended information about constructing such a visual vocabulary can be found elsewhere (Garrett, 2002b).

\section{Skeleton \& surface: Intervention}

The first task is to design and test the information. An important aspect to keep in mind while designing the information is the literacy level of the intervention's target group. Since many people with limited reading skills do not seek help with reading tasks (Bartholomew et al., 2006), information should be adapted to the target group. Useful instruments are available to determine the target group's literacy level with regard to skills (Baker, Williams, Parker, Gazmararian, \& Nurss, 1999) or ability to interpret information (Smerecnik \& Mesters, 2007). Subsequently, it needs to be tested among the target group whether the information is 
correctly adapted. The second task is probably the moment where health promoters should hand over their activities to people who are more competent in interface and navigation design and have more technical and design experience. We recommend involving the technical and design staff in the intervention's development team right from the start to facilitate cooperation with health promoters. The technical and design staff create a prototype which, conversely, should still be compared to the original health promotion goals. This prototype lays the foundation of the last task: fine-tuning the intervention. Even if all the previous tasks are executed in an optimal way, this final task is still important to lift the intervention to a higher level. On the surface plane, it is all about detail: a slightly darker background, larger typeface, more narrow buttons and so on. Towards the end of the development process, the focus is more and more on the aesthetic sense of user experience.

\section{Discussion}

The conceptual framework described above is a useful tool during the development process to aim for a positive user experience during the fist visit and therewith improving exposure rates and increasing the number of revisiting users. Although there are other sources available on how to develop a good website (Beaird, 2007; Lawrence \& Tavakol, 2006; Quick, 2007), these are more practical step-by-step guides and are not based on a theoretical framework such as Garrett's.

The division into neat boxes and planes is a convenient way to think about user experience (Garrett, 2002a). However, those elements interact with each other, which indicates the complexity of user experience. To improve user experience, all these elements should be addressed and the focus should not be on merely a single element. Therefore, it is also hard to change one of these elements once the intervention is finished. This shows, once again, that one needs to think about user experience before and during the development process of an Internet-delivered intervention.

Garrett's work has been applied to Internet-delivered behaviour change interventions aimed at adolescents and related to factors that resulted from previous explorative research and potentially determine exposure. Probably, other factors can be relevant for other target groups (e.g. children, adults). The conceptual framework in itself, however, is useful for all Internet-delivered interventions.

\section{Future research}

Previous explorative research (Chapters 2 and 3) was an important first step to identify factors that might improve exposure to Internet-delivered interventions. Future research, however, could (1) test if and how these factors improve exposure and (2) possibly identify even more factors. The conceptual framework presented in this chapter can therefore be extended. Furthermore, the framework must be seen as a tool during the development process of Internet-delivered interventions. Utilising this 
framework could provide insight into its effectiveness in terms of increased exposure rates, since these are crucial to improve the public health impact of Internet-delivered interventions.

\section{Acknowledgements}

We would like to thank Kathelijne Bessems, Vincent Cox, Jessica Gubbels, Evelien

Heinrich, Hilde van Keulen, Stef Kremers, and Bilbo Schickenberg for their comments on a previous version of this chapter. 


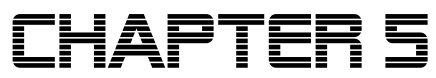

This chapter has been published as Crutzen, R., De Nooijer, J., Brouwer, W., Oenema, A., Brug, J., \& De Vries, N. K. (e-pub ahead of print). Effectiveness of online word of mouth on exposure to an Internetdelivered intervention. Psychology \& Health. 


\begin{abstract}
The use of online word of mouth (WOM) seems a promising strategy to motivate young people to visit Internet-delivered interventions. An Internet-delivered intervention aimed at changing implicit attitudes related to alcohol was used in two experiments to test effectiveness of email invitations on a first visit to the intervention. The results of the first experiment $(N=196)$ showed that an invitation by e-mail from a friend was more effective to attract young adults (aged 18 to 24 years) to the intervention website than an invitation from an institution. A 2x2 design was used in the second experiment $(N=236)$ to test manipulations of argument strength and the use of peripheral cues in invitations. Results showed that weak arguments were more effective to attract young adults to the intervention website when an incentive was withheld. These results need to be taken into account when using online WOM as a strategy to improve exposure to Internet-delivered interventions.
\end{abstract}




\section{Introduction}

In the last decade, the number of Internet-delivered health behaviour interventions aiming to contribute to primary prevention of chronic disease has increased rapidly (Bernhardt \& Hubley, 2001; De Nooijer \& De Vries, 2006; Pérez-Rodrigo et al., 2005). Due to high Internet penetration rates in many countries (CBS, 2006; Internet World Stats, 2008a), the Internet is thought to have great potential as a communication channel that can combine a high reach with tailored or targeted health promotion (Brug et al., 2005). However, evidence from trials indicates that true exposure to such interventions may be low (Buller, Buller, \& Kane, 2005; De Nooijer et al., 2005) and outside the relatively controlled research setting exposure rates may be even lower (Evers et al., 2005). Therefore, specific strategies need to be developed to improve exposure to evidence-based Internet-delivered health behaviour intervention websites. Explorative research identified information received through word of mouth (WOM) as one of the most successful approaches for motivating young people to visit Internet-delivered interventions (Chapters 2 and 3). Originally, WOM stems from the field of marketing and has been widely acknowledged as an effective marketing tool that can influence human behaviour (Katz \& Lazarfeld, 1955). The explosive growth of the Internet has fed the idea that this medium could be utilised for WOM purposes (Stauss, 2000; Subramani \& Rajagopalan, 2003). This idea has also been addressed in empirical studies regarding consumer behaviour (Cheung, Lee, \& Rabjohn, 2008; Senecal \& Nantel, 2004). To date, however, there is a lack of evidence about the effectiveness of online WOM in health promotion, and how such online WOM should be designed to improve exposure to Internetdelivered interventions. The aim of this study was to investigate the effects of online WOM on exposure to an Internet-delivered intervention aimed at young adults.

In terms of Internet-delivered interventions, three different aspects of exposure can be distinguished: (1) accessing the intervention website, i.e. a first visit, (2) staying on the intervention website long enough to use and process the information and (3) revisiting the intervention website. The latter only applies to interventions that are developed to be visited multiple times since there is a possible doseresponse relationship between the number of visits and behaviour change outcomes of these interventions (Lenert et al., 2003; Verheijden et al., 2007; Zebrack et al., 2005). In this study, we focused on a first visit to the intervention website, since this is a necessary step to intervention use and information processing. Young adults are not likely to be internally motivated to visit an Internet-delivered intervention aimed at reducing risk behaviours related to chronic diseases (De Nooijer et al., 2005). According to the elaboration likelihood model (ELM), people with on average low involvement with the health behaviour topic can more likely be persuaded with peripheral cues than with strong arguments 
(Petty \& Cacioppo, 1986; Petty, Cacioppo, \& Schumann, 1983). This should be taken into account when designing online WOM.

An Internet-delivered intervention aimed at changing implicit attitudes related to alcohol (http://www.impliciet.eu) was used as an experimental playground to investigate the effects of online WOM on exposure. Positive implicit alcohol associations predict alcohol consumption more strongly than explicit attitudes toward drinking alcohol (Houben \& Wiers, 2007). Promoting less alcohol consumption is especially relevant among young adults, since $34.1 \%$ of males and $9.4 \%$ of females until 24 years old are problem drinkers according to the definition of Van Dijck and Knibbe (2005) and high alcohol consumption is strongly associated with chronic diseases (Macdonald, 1999).

\section{Experiment I: Effect of invitation's source}

The most important reason why online WOM can be effective in facilitating exposure to an Internet-delivered intervention is that information received through WOM is considered more credible than information from, for example, anonymous persons or institutions (Bickart \& Schindler, 2001), since information from friends is perceived as more independent (Silverman, 2001). Petty and Cacioppo (1986) denominated this credibility as a message source factor, a peripheral cue. Our research question focused on whether receiving an invitation by email to participate in an Internet-delivered intervention from a friend was more effective than receiving an invitation from an institution (in this case Maastricht University). Based on previous explorative research (Chapters 2 and 3; Brouwer, Oenema, Crutzen, De Nooijer, De Vries, \& Brug, 2008), it was hypothesised that an invitation from a friend is more effective to attract young people to an Internet-delivered intervention aimed at changing implicit attitudes related to alcohol.

\section{Methods}

\section{Procedure and participants}

To test this hypothesis, undergraduate students were approached at university computer rooms to assist in this experiment. They were asked to provide two e-mail addresses of friends between 18 and 24 years of age. To one randomly selected friend they sent a personal invitational email (FI), the other friend received an e-mail from an institution (II). These invitations stated that the addressee could earn $€ 15$ by participating in an enjoyable Internet-delivered intervention about alcohol. The URL to the intervention's homepage was also provided. The only difference between the two invitations was that in the FI students could choose their own salutation and closing, so the invitation would come across as a regular e-mail to their friend. The II had a personalised salutation ("Dear X") and default closing ("Kind regards, Impliciet.eu Universiteit Maastricht"). The students participated on a voluntary basis, received no compensation and were immediately debriefed. University 
Ethical Committee approval had been obtained and the research was carried out in accordance with universal ethical principles.

\section{Measures}

Participants [receivers of the e-mail] had to take three steps, from invitation to start of the intervention, which were tracked by referral IDs (which were integrated in the URL). These steps were: (1) click on the URL in the invitation and visit the homepage, (2) click through to the information page (containing general information) and (3) log on to the intervention. The students [senders] were asked to report participants' sex on paper to have this information from all participants regardless of whether they logged on to the intervention.

\section{Analyses}

Logistic regression analyses were conducted with SPSS 13.o. An alpha of .05 was used for statistical significance. Dependent variables were whether or not participants had taken each of the three steps (visit the homepage, click through to the information page, and log on to the intervention) from invitation to start of the intervention. Since women are more likely to use the Internet for searching health-related information (Bleakley, Merzel, VanDevanter, \& Messeri, 2004; Gray, Klein, Noyce, Sesselberg, \& Cantrill, 2005a), gender was taken into account to correct for possible gender effects. Invitation (dummy coded, $\mathrm{II}=0, \mathrm{FI}=1)$, gender $(\mathrm{O}=$ male, $1=$ female $)$ and their interaction were used as predictors in the initial model of each dependent variable. The interaction term was left out of the final model when it was not significant.

\section{Results}

In total, 196 participants (56\% males, no difference between groups: $\chi^{2}=$ $.007, p=.935$ ) received an invitation. There was no significant interaction between invitation type and gender in any of the initial models. Therefore, none of the final models included an interaction term and main effects are reported (Table 5.1).

Participants in the FI condition were more likely to visit the homepage and the information page. There was no effect of invitation with regard to logging on to the intervention. No effect of gender was found in the first two steps from invitation to start of the intervention. However, more females logged on to the intervention (the third step). 


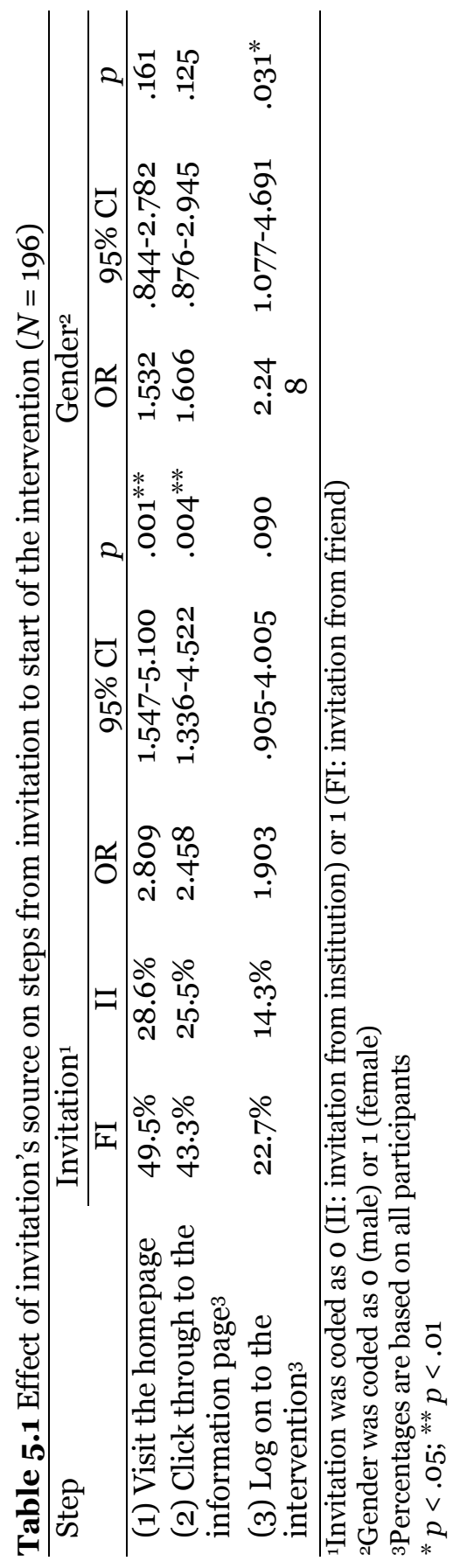




\section{Experiment II: Effect of invitation's content}

The results of the first experiment showed that an invitation by e-mail from a friend was more effective than an invitation from an institution to attract young adults to the intervention website. In the second (followup) experiment, message source (friend) was fixed and the next step was that we manipulated the content of the invitation (argument strength and the use of a peripheral cue). Our research question focused on the relation between the invitation's content and its effect on attracting young people to an Internet-delivered intervention. In line with the ELM, we manipulated argument strength (reason to visit) and the use of a peripheral cue (incentive). If an invitation contains a peripheral cue, it might be more effective to attract a low-involved public (Petty \& Cacioppo, 1986; Petty et al., 1983). Since previous research indicated a positive effect of incentives on logging on (Thompson et al., 2008) and exposure in general (An et al., 2006; Escoffery et al., 2004), incentives were used as a peripheral cue. It was hypothesised that incentives had more effect on attracting a low-involved public (i.e. young adults) to an Internet-delivered intervention aimed at changing implicit attitudes related to alcohol than argument strength.

\section{Methods}

\section{Procedure and participants}

To test this hypothesis, undergraduate students were approached to assist in this experiment after participating in another (unrelated) experiment. Students were asked to send four e-mail invitations to separate, preferably male, friends between 18 and 24 years of age. Students were encouraged to approach male friends because men are more likely to be problem drinkers (Van Dijck \& Knibbe, 2005). Students were not obliged to send invitations to male friends only, to avoid e-mail invitations to random people in their address book, instead of only to those who were considered as friends. Students could again choose their own salutation and closing, so the invitation would come across as a regular e-mail they would send to their friend. The four e-mail addresses were randomly assigned to the four types of invitation. Afterwards, students were debriefed and received a voucher worth $€ 5$.

\section{Design}

A 2x2-design was used to test two factors; argument strength (weak/strong) and incentive (mentioned/withheld). Arguments mentioned in the invitation to visit the intervention were either that participants would receive personalised feedback through an interactive website (strong) or that they would receive more information about the aim of the study through a nice website (weak). These arguments contain information about (1) the kind of information ("about the aim of the study" vs. "personalised feedback") and (2) the way of delivery ("through a nice website" vs. "through an interactive website") and were based on 
previously conducted explorative research in which experts agreed on the importance of these factors (Chapter 2; Brouwer et al., 2008). A pre-test (using seven-point Likert scales) among sixteen members of the target group revealed that there were significant differences on both aspects; the kind of information $\left(\mathrm{M}_{\text {diff }}=2.50, t(15)=4.33, p=.001\right)$ and the way of delivery $\left(\mathrm{M}_{\text {diff }}=2.13, t(15)=6.04, p<.001\right)$. That participants would receive an incentive was either mentioned (in accordance with the first experiment; $€ 15$ to participate) or withheld in the invitation to test the effect of incentives as a peripheral cue. This manipulation only exerted influence on the invitation; all participants received an incentive of $€ 15$ if they decided to participate in the intervention.

\section{Measures}

Whether or not participants [receivers] had taken the steps from invitation to start of the intervention, was tracked by referral IDs. Since the information page was integrated with the login page, only two steps needed to be taken in this experiment: (1) click on the URL in the invitation and visit the homepage and (2) log on to the intervention. If participants logged on, they were asked to self-report on alcohol use (based on the timeline follow-back method (Sobell \& Sobell, 1990)) and alcohol-related problems (using the AUDIT (Saunders, Aasland, Babor, De la Fuente, \& Grant, 1993)). As in Houben and Wiers (2006), participants were also asked to self-report (using seven-point Likert scales) both positive (eight items, Cronbach's $\alpha=.95$ ) and negative (seven items, $\alpha=.92$ ) alcohol-related expectancies (e.g. "After drinking alcohol, I feel...") and their attitude (e.g. "I consider drinking alcohol...”); which was composed of both an affective (two items: unpleasantpleasant, boring-fun; $\alpha=.95$ ) and a cognitive (two items: bad-good, stupid-smart; $\alpha=.87$ ) component. Alcohol use and alcohol-related problems, expectancies and attitudes were used to test whether there was a difference between participants in each condition. The students [senders] were asked again to report participants' sex.

\footnotetext{
Analyses

Logistic regression analyses were conducted with an alpha of .05 for statistical significance. There were two dependent variables; whether or not participants conducted each of the two steps (visit the homepage, log on to the intervention) from invitation to start of the intervention. Argument strength ( $\mathrm{O}=$ weak, $1=$ strong), incentive ( $\mathrm{O}=$ withheld, $1=$ mentioned $)$, gender ( $\mathrm{O}=$ male, $1=$ female $)$ and all possible interactions between these variables were used as predictors in the initial model of each dependent variable. A backward procedure was used to create final parsimonious models. Main effects of argument strength and incentive were always included in the final models, since we were interested in effectiveness of those two factors on the dependent variables.
} 
To test whether participants in each condition differed in alcohol use and alcohol-related problems, expectancies and attitudes, 2 (argument strength) x 2 (incentive) multivariate analysis of variance was used (MANOVA).

\section{Results}

In total, 236 participants (23.5\% females) received an invitation. Females were equally distributed over conditions $\left(\chi^{2}=.241, p=.971\right)$ and none of the final models included an interaction or main effect regarding gender.

There was a significant interaction between argument strength and incentive (Figure 5.1) with regard to clicking on the URL in the invitation and visiting the homepage of the intervention. Post-hoc contrast analyses of simple effects showed that when receiving an incentive was withheld, weak arguments were more effective (OR $=.540$, $95 \% \mathrm{CI}=.322-.906, p=.020$ ). No effects were found for the second step, logging on to the intervention (Table 5.2).

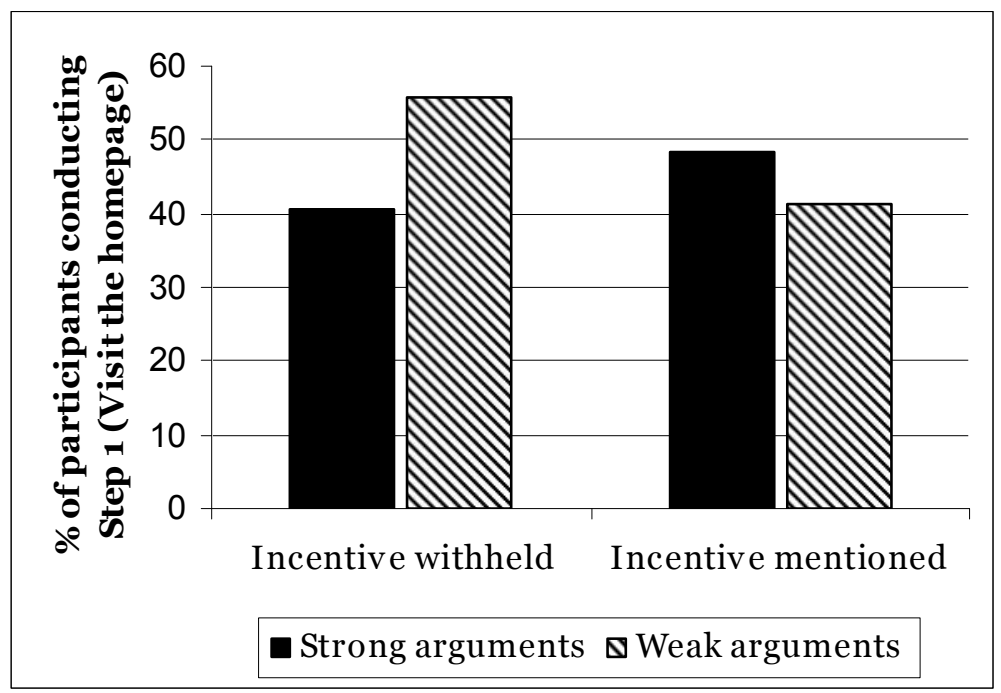

Figure 5.1 Interaction between argument strength and incentive 


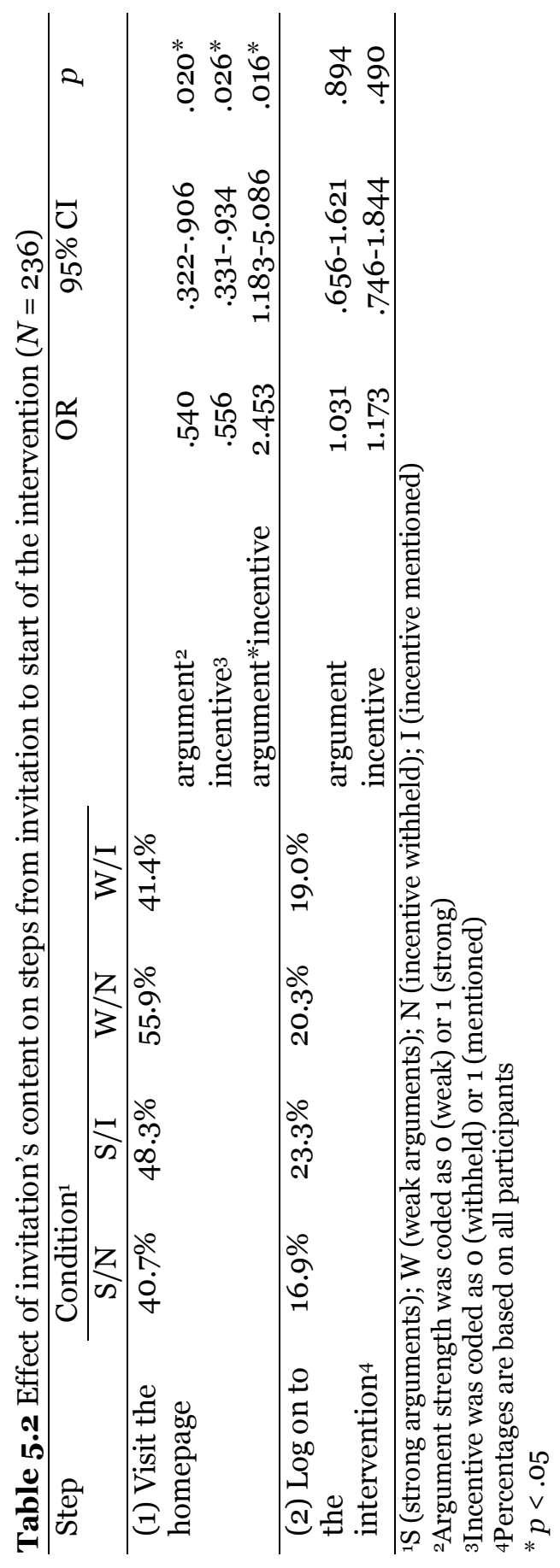


Results of MANOVA showed no relation between argument strength or incentive on the one hand, and alcohol use or alcohol-related problems, expectancies or attitudes on the other hand. The only exception was an effect of argument strength on the cognitive component of attitude $(F(1,46)=7.376, p=.009)$. Participants who were attracted by an invitation containing strong arguments had a more positive attitude towards alcohol than participants attracted by an invitation containing weak arguments ( $\mathrm{M}=4.2$ vs. 2.9 on a 7-point Likert scale).

\section{Discussion}

This study focused on the effectiveness of online word of mouth promotion to attract young adults to an Internet-delivered intervention. Our results first indicated that an invitation from a friend was more effective than an invitation from an institution to attract young adults to an Internet-delivered intervention aimed at changing implicit attitudes related to alcohol. Secondly, weak arguments were more effective when there was no rather than there was an incentive mentioned.

The effectiveness of friend invitations indicates that peer influence is expected to remain, despite the concept of friendship in the e-communication era being no longer restricted to persons in the physical environment (Markow, 2006). A friendship invitation, however, had no significant impact on actually logging on to the intervention. The invitations' impact could have been diminished because they were formulated as a request to participate instead of a recommendation. Moreover, we did not manipulate the intervention itself, but only the invitation. This could also diminish the effect of our manipulations in both experiments on logging on to the intervention, since there was no difference between conditions once participants were attracted to the intervention. The results of the second experiment showed an interaction between argument strength and incentive regarding the first step, visiting the homepage, which was not fully in line with our initial hypothesis. Strong arguments being less effective when an incentive was withheld could be explained by expected effort that was required by consenting to the invitation. Strong arguments stated that participants would "receive personalised feedback through an interactive website". Therefore, participants could have thought that this would require much effort. This could have lead to strong arguments being less effective when an incentive was withheld. Moreover, a friend (source) stating that "you will receive more information ... through a nice website" (weak argument) can serve as a peripheral cue that is more effective to attract a low-involved target group (Petty \& Cacioppo, 1986; Petty et al., 1983). A possible explanation for the lack of effect of argument strength when an incentive was mentioned, on the other hand, could be that the incentive served as a motivator. In this case, this motivator had a larger effect on attracting a low-involved target group than a friend using weak arguments. Although we expected otherwise, this is not in contradiction 
with the ELM, which states that a variable can serve as a peripheral cue and a motivator (Petty \& Cacioppo, 1986).

\section{Limitations}

Only one intervention focusing on one specific health risk behaviour and target group was used in this study. It is not obvious to generalise our results to interventions addressing other health risk behaviours, since previous research indicated that determinants of exposure differ per health risk behaviour (Chapter 6). Furthermore, the current generation of young adults grew up with the Internet and use it differently than adults (Fox \& Madden, 2005; Leung, 2003). Their main online activities are instant messaging, gaming, downloading and visiting socialnetworking websites (Gross, 2004; Van den Eijnden \& Vermulst, 2006). Hence, results cannot be generalised to older age groups with different online activities.

Undeliverable messages may have influenced the results of the experiments. Since invitations were sent in a randomised way, however, we do not expect this to be the case. Moreover, none of the e-mail messages sent by ourselves in the first experiment were undeliverable. Since all other e-mail messages were sent by students themselves, it was not possible for us - after the experiment - to track whether messages were undeliverable (i.e. due to server time outs or other errors). Nevertheless, e-mail providers (i.e. Hotmail, Gmail) offer huge capacities these days and there were no immediate bounces ${ }^{4}$ in our experiments.

Lastly, the information page was integrated with the login page in the second experiment. Therefore, it is not justified to compare absolute figures of the first and second experiment, but our main interest was to look at the effect of our manipulations.

\section{Recommendations}

E-mail invitations from friends could be effective to attract young adults to websites of Internet-delivered interventions and this could be encouraged by offering tell-a-friend services at such interventions (Maibach et al., 2006). E-mail invitations sent through such services could arouse curiosity for Internet-delivered interventions. These services, however, should be carefully implemented to avoid the idea that they can be used as a vehicle to spam other people.

Although e-mail invitations from friends could be effective to attract young adults to Internet-delivered interventions, only one in five participants actually logged on to the intervention in our in experiments. Even though we were interested in the effect of our manipulations, this observation confirms that exposure to Internet-delivered interventions is non-optimal and more research into how to reach optimal exposure is timely (De Nooijer et al., 2005; Evers et al., 2005). Previous explorative

4 E-mails that immediately return after sending and which are classified as undeliverable, i.e. due to full mail boxes or non-existing e-mail addresses. 
research gave more insight into factors (e.g. direct access, attractiveness of the interface at first sight) that could be manipulated in future experimental research to test the effectiveness of these factors on facilitating exposure (Chapters 2 and 3; Brouwer et al., 2008). Although the focus of this study was on a first visit to the intervention website, future research should also address the other aspects of exposure (staying and revisiting).

Regarding the content of e-mail invitations, our recommendations for future research are not only to mention or withhold incentives, but also to alter incentive schedules (Alexander et al., 2008). An issue regarding the use of incentives, however, is whether this is feasible once an intervention will be implemented on a large scale. Furthermore, we recommend not only to pre-test argument strength, but also the consequences for participants (e.g. required effort) of the arguments that are used. Therefore, the results of these experiments need to be taken into account when designing invitations to attract young adults to an Internet-delivered intervention.

\section{Conclusion}

E-mail invitations from friends were more effective to attract young adults to the homepage of an Internet-delivered intervention's website than e-mail invitations from anonymous persons of institutions. Furthermore, using weak arguments in e-mail invitations sent by friends was more effective to attract young adults to the intervention website when an incentive was withheld. This needs to be taken into account when using online WOM as a strategy to improve exposure to Internetdelivered interventions.

\section{Acknowledgements}

We would like to thank Katrijn Houben and Reinout Wiers for the use of their intervention as our experimental playground, Michiel Vestjens for his technical assistance and Claire Jeukens, Jonathan van 't Riet, Chris Smerecnik and Michelle Stoel for their help in conducting the experiments. The intervention itself was supported by STW (grant 07353) via NWO Applied Cognition Grant accredited to Reinout Wiers. 


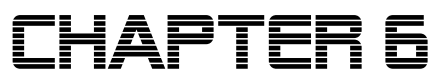

This chapter has been published as Crutzen, R., De Nooijer, J., Candel, M. J. J. M., \& De Vries, N. K. (2008). Adolescents who intend to change multiple health behaviours choose greater exposure to an Internetdelivered intervention. Journal of Health Psychology, 13, 906-911. 


\begin{abstract}
Despite a growth of Internet-delivered interventions, exposure rates to such interventions are still low. In total, 35,104 adolescents participated in the E-MOVO project: an Internet-delivered lifestyle intervention aimed at multiple health behaviours. By means of multilevel analyses, we demonstrated the relationship between intention to change behaviour and adolescents' exposure to E-MOVO's functionalities. There was a clustering of intention to change risk taking behaviours in an unhealthy way and energy balance-related behaviours in a health way. This should be taken into account with the design of Internet-delivered interventions.
\end{abstract}




\section{Introduction}

Despite an explosive growth of Internet applications in health promotion practice (Bernhardt \& Hubley, 2001) it appears that exposure rates to Internet-delivered behaviour change interventions are low (Evers et al., 2005). Nevertheless, there is little scientific knowledge about how to improve these rates. Exposure can be distinguished in three different aspects: (1) a first visit, (2) staying on the intervention long enough to use and process the information and (3) revisiting the intervention (the latter is optional). In this chapter, we studied the intention to change behaviour in relation to exposure to an Internet-delivered lifestyle intervention. In the context of this intervention, we focused on the second aspect of exposure: stay on the intervention and make use of its functionalities. We especially took intention to change behaviour into account, since this is the most important predictor of behaviour itself (Godin \& Kok, 1996).

Since many health risk behaviours are acquired during adolescence and track into adulthood (Kelder et al., 1994), Dutch Community Health Services (CHS's) have a legal obligation to monitor adolescents' health in order to set priorities for health promotion activities (Meijer, 1991). The E-MOVO (Dutch acronym that stands for Electronic Monitoring and Health Promotion) project provides insight into adolescents' health and is a large-scale collaboration between seven CHS's (in the eastern part of the Netherlands) and Maastricht University to develop and implement an electronic monitoring instrument with the opportunity to provide tailored feedback at the individual level (De Nooijer \& De Vries, 2006).

Within the E-MOVO project, monitoring is done via the Internet. The combination of an Internet-delivered monitoring instrument with the opportunity to provide tailored feedback at the individual level makes E-MOVO unique. In this way, one can reach adolescents who otherwise would not seek healthy lifestyle information and tailor this information. Within E-MOVO this is done via a so called E-MOVO score which adolescents get after they have completed the monitoring questionnaire. This score is tailored on lifestyle behaviours and consists of feedback on current behaviour and a colour code to visualise whether their reported behaviour was in line (green), roughly in line (orange), or not in line (red) with the Dutch health recommendations (e.g. eat at least two pieces of fruit a day). With this E-MOVO score, two links to subject specific websites per lifestyle behaviour were offered to obtain more information. With regard to fruit consumption and smoking there was an additional link to obtain tailored advice.

The main research question of this study focused on the relationship between adolescents' intention to change their behaviour and their use of E-MOVO's functionalities. The use of E-MOVO's functionalities was divided into reading the E-MOVO score, clicking on links to obtain more information, and clicking on links to obtain tailored advice. We also took several demographic variables into account (age, 
sex, level of education) as they do influence the use of e-health functionalities in general (Gray et al., 2005a; Rice, 2006).

\section{Methods}

Procedures and participants

All high schools in the region of the collaborating CHS's were approached to participate in this project. Since the CHS's have had previous contact with schools through their regular monitoring activities, response rates were high, varying from $73-93 \%$ ( $44 \%$ in one region due to a merge of CHS's). During one class period (approximately 45 minutes) participants filled out the monitoring questionnaire, in the course of compulsory school activities and on separate computers. Due to the legal obligation of Dutch CHS's to monitor the health of adolescents, no parental consent was needed. However, the project is registered at the Dutch Data Protection Authority, which supervises the fair and lawful use and security of personal data. Participants had to log on afterwards to obtain their individually tailored feedback due to the fact that participants were only available for one class period.

Two months after participants filled out the monitoring questionnaire, they were invited by e-mail to fill out a second questionnaire on a voluntary basis during their spare time. The main purpose of this questionnaire was to evaluate the E-MOVO project (De Nooijer et al., 2008), but also to assess whether or not participants had read their E-MOVO score.

\section{Measures}

Adolescents were asked to report their age, sex and level of education. Adolescents were divided into younger (second year students, approximately 14-15 years old) and older students (fourth year students, approximately 16-17 years old). Educational level was categorised into a low (preparatory secondary vocational education) and a high (senior general secondary education or university preparatory education) level.

Questionnaire items were constructed on the basis of several existing (some validated) instruments, which were previously used by CHS's (De Nooijer \& De Vries, 2006). Intention to change behaviour was measured using five-point Likert scales ranging from certainly not (-2) to certainly yes (+2) (e.g. "Do you intent to eat more fruit in the near future?”). We measured physical activity in minutes, fruit consumption in portions, whether or not participants smoke, drink alcohol (consumption in standard glasses), and use condoms (five-point Likert scale, ranging from never to always).

Furthermore, it was registered whether or not participants logged on to the website. Per lifestyle behaviour it had been registered on how many links participants clicked to obtain more information or tailored advice (if applicable). In the second questionnaire, participants reported 
for each lifestyle behaviour whether or not they read their E-MOVO score.

\section{Analyses}

Since data was nested (students within classes within schools), we used multilevel analyses to study the relationship between (intention to change) behaviour and adolescents' use of E-MOVO's functionalities. Variables included were demographic variables, behaviour measures, and intention to change behaviour. We used top-down testing, with a level of significance of .05, resulting in a model per lifestyle behaviour with only significant variables left.

\section{Results}

In total, 35,104 participants completed the initial questionnaire. Participants who attended classes covering different educational levels were excluded from further analyses. In total, 33,644 participants (95.8\%) from 144 schools were included in analyses. Of these participants, $50.8 \%$ were girls and $44.6 \%$ attended higher educational level. Relatively more girls attended higher educational level $\left(\chi^{2}=\right.$ $12.338, p<.001)$. More than half of the participants $(55.7 \%)$ logged on to the website. Older adolescents were more inclined to $\log$ on $(\beta=0.242, p$ $<$.0001), as were girls $(\beta=-0.372, p<.0001)$ and adolescents who attended a higher educational level $(\beta=0.273, p<.0001)$. Of those participants who provided their e-mail address $(N=25,195), 650$ completed the second questionnaire (a response of 2.6\%). Compared to those who did not complete the second questionnaire, these participants included more girls $\left(\chi^{2}=63.730, p<.001\right)$ and were more likely to attend a higher educational level $\left(\chi^{2}=84.032 \mathrm{~s}, p<.001\right)$. They were less physically active $(\mathrm{t}=6.932, p<.001)$ and more likely to be a non-smoker $\left(\chi^{2}=30.641, p<.001\right)$. They also drank less $(\mathrm{t}=5.483, p<.001)$. With regard to their intention to change behaviour, they only had a higher intention to use condoms $(\mathrm{t}=5.409, p<.001)$.

Second questionnaire. Adolescents with a high intention to be more physically active were more inclined to read their E-MOVO score on physical activity (Table 6.1). Adolescents who attended a lower educational level were more inclined to read their score on fruit consumption. With regard to smoking, non-smoking boys were more inclined to read their score on smoking. Adolescents who did smoke, but also had a low intention to stop smoking, were also more inclined to read their score on smoking. Adolescents with high alcohol consumption were more inclined to read their score on alcohol consumption. With regard to condom use, there were no significant results.

Observational data. After reading their E-MOVO score, 1,535 adolescents (4.6\%) clicked on at least one link to obtain more information or a tailored advice. Girls were more inclined to click on links to obtain more information about physical activity and fruit 
consumption. Adolescents who did not smoke, but had a high intention to start smoking, were more inclined to click on links to obtain more information about smoking. Also, adolescents with high alcohol consumption and a high intention to drink more alcohol were more likely to click on a link to obtain more information. No significant results were found with regard to condom use. Girls, adolescents who attended a higher educational level, and those with a high intention to eat more fruit, were more inclined to click on a link to obtain tailored advice on fruit consumption. For both (smokers and non-smokers), girls and adolescents who attended a higher educational level were more inclined to click on a link to obtain tailored advice on smoking. We found the same results for non-smokers with a high intention to start smoking and smokers with a low intention to stop smoking. 
Table 6.1 Determinants of adolescents' use of functionalities

Reading the E-MOVO score ${ }^{1}$

\begin{tabular}{|c|c|c|c|}
\hline & & $\beta$ & $p$ \\
\hline physical activity & intention & 0.365 & .0022 \\
\hline $\begin{array}{l}\text { fruit consumption } \\
\text { smoking }\end{array}$ & education $^{2}$ & -0.584 & .0318 \\
\hline (smokers) & intention & -0.545 & .0116 \\
\hline (non-smokers) & $\operatorname{sex}^{3}$ & 0.511 & .0270 \\
\hline alcohol consumptior & behaviour & 0.543 & .0261 \\
\hline
\end{tabular}

Clicking on links to obtain more information

\begin{tabular}{|c|c|c|c|}
\hline \multirow{6}{*}{$\begin{array}{l}\text { physical activity } \\
\text { fruit consumption } \\
\text { smoking } \\
\text { (non-smokers) } \\
\text { alcohol consumption }\end{array}$} & & \multicolumn{2}{|l|}{$\beta$} \\
\hline & & -0.015 & $<.0001$ \\
\hline & sex & -0.015 & $<.0001$ \\
\hline & intention & 0.004 & $<.0001$ \\
\hline & behaviour & 0.006 & .0027 \\
\hline & intention & 0.004 & .0455 \\
\hline \multicolumn{4}{|c|}{ Clicking on links to obtain tailored advice } \\
\hline \multirow{4}{*}{ fruit consumption } & & $\beta$ & $p$ \\
\hline & & -0.927 & $<.0001$ \\
\hline & education & 0.876 & $<.0001$ \\
\hline & intention & 0.185 & .0032 \\
\hline \multicolumn{4}{|l|}{ smoking } \\
\hline (smokers) & sex & -0.619 & .0003 \\
\hline \multirow{5}{*}{ (non-smokers) } & education & 0.390 & .0154 \\
\hline & intention & -0.156 & .0133 \\
\hline & $\operatorname{sex}$ & -0.633 & $<.0001$ \\
\hline & education & 0.478 & .0001 \\
\hline & intention & 0.287 & .0091 \\
\hline
\end{tabular}

${ }^{1}$ Measured by the second questionnaire; all other dependent variables are observational data from all participants

${ }^{2}$ Educational level was coded as o (preparatory secondary vocational education) or 1 (senior general secondary education or university preparatory education) 3Sex was coded as o (girls) or 1 (boys) 


\section{Discussion}

Adolescents with a high intention to start smoking and to drink more alcohol were more inclined to use E-MOVO's functionalities. Information and tailored advice that adolescents get should focus on changing this intention into an intention to change behaviour in a healthy way. With regard to physical activity and fruit consumption we found that those who had a higher intention to be more physical active and to eat more fruit, were more inclined to use E-MOVO's functionalities. Since these adolescents already have a high intention to change behaviour in a healthy way, information and tailored advice they get should focus on reinforcing the transition from intention to behaviour. Other research has shown that risk taking behaviours (start smoking, drink more alcohol) (De Vries et al., 2008) and energy balance-related behaviours (more physical activity, higher fruit consumption) (Kremers, De Bruijn, Schaalma, \& Brug, 2004) are clustered. These findings can be extended to exposure to Internet-delivered interventions aimed at changing these behaviours. However, we did not find these results with regard to smoking cessation and condom use. Those can be seen as risk avoidance behaviours, just like energy balance-related behaviours. In contrast to energy balance-related behaviours, there is an absolute norm with regard to smoking (no smoking, not even one puff) and using condoms (every time when sexual intercourse takes place) and therefore the consequences of conducting these behaviours according to the Dutch health recommendations are more resolute.

Although we have obtained more insight, this is only based on one intervention which, nevertheless, focuses on multiple health risk behaviours. Intention to change behaviour was not significant in all multilevel models, but, if present, we found a consistent pattern of effects. However, this pattern can also be caused by the fact that people can achieve a goal (e.g. being healthy) by means of a variety of behaviours which are more or less salient to each individual (Scheier \& Carver, 2003). Therefore, experimental studies are needed to investigate this possible explanation in more detail.

The percentage of participants that logged on to the website was high, especially taking into account that adolescents frequently fail to realise their need for health education (Paperny, Aono, Lehman, Hammar, \& Risser, 1990). However, there was still a big gap between the percentage of participants that logged on to the website and the percentage of participants that clicked on at least one link to obtain more information or tailored advice. Reasons indicated by adolescents (De Nooijer et al., 2008) were that they simply did not want to obtain more information and because they did not notice the links since their lay-out was not in line with the default hyperlink lay-out (blue, underlined). Another explanation is that users do not prefer Internet-delivered interventions that continually send users "off-site" (Kerr, Murray, Stevenson, Gore, \& Nazareth, 2006). 
Due to technical flaws, the results of whether or not participants read their E-MOVO score per theme were only based on self-report. To get more insight into exposure to Internet-delivered interventions, a crucial step in data-gathering is to register as many user activities as possible. Also the fact that participants had to fill out the second questionnaire two months after they filled out the monitoring questionnaire may have biased the results. Furthermore, there was a low response rate for the second questionnaire. Besides time delay, this could also be due to the fact that participants had to fill out the second questionnaire in their spare time and it was not part of obligatory school activities. No second prompt was used, to prevent an even longer time delay between use of E-MOVO and the second questionnaire.

\section{Conclusion}

There is a clustering of risk taking and energy balance-related behaviours with regard to the relationship between intention to change multiple behaviours and adolescents' exposure to E-MOVO's functionalities which should be taken into account with the design of Internet-delivered interventions.

\section{Acknowledgements}

E-MOVO was supported by a grant from the OGZ Fund. 


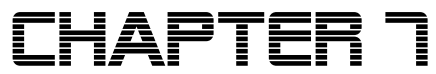

This chapter has been submitted for publication as Crutzen, R., De Nooijer, J., Van Dorst, A. G., Crone, M. R., Brouwer, W., Oenema, A., Brug, J., \& De Vries, N.K.

Utilizing exposure measures of Internet interventions: a commendable example on smoking behavior. 


\begin{abstract}
There is a considerable increase in Internet-delivered interventions related to smoking behaviour, especially interventions aimed at adolescents. Despite exposure being a prerequisite to establish desired behaviour change, exposure rates to Internet-delivered interventions are generally quite low. Therefore, it remains important to assess exposure. Several exposure measures (e.g. frequency, duration, activity) are available, but there is no gold standard. Our aim was to explore the potential of tracking multiple exposure measures and linking them to variables at the individual level (e.g. socio-demographic and behavioural measures). It appeared that these exposure measures provided insight into different patterns of exposure for subgroups based on educational level. Hence, more insight into exposure can be gained by linking exposure measures to variables at the individual level. This also offers the opportunity to study potentially mediating effects of exposure on interventions' outcome measures. Furthermore, exposure measures can be useful during process evaluation to provide insight into where participants either leave the intervention website or have come to a standstill. This information can be used to adapt interventions and therewith increase exposure rates and probability of behaviour change.
\end{abstract}




\section{Introduction}

The explosive growth of the Internet caused a considerable increase in Internet-delivered behaviour change interventions (Bernhardt \& Hubley, 2001). These interventions can be especially suitable for the current generation of adolescents since they grew up with online information (Tapscott, 1998) and are more open towards new possibilities offered by this medium (Leung, 2003). Since smoking prevalence amongst adolescents remains high in many countries, including the Netherlands (STIVORO, 2007), smoking cessation interventions for this target group are still needed, and the Internet may be suitable for this purpose (Dijk et al., 2007a; Patten et al., 2006). Exposure rates to Internet-delivered interventions, however, are generally quite low (De Nooijer et al., 2005; Evers et al., 2005). Exposure of individuals to the intervention content, through use of the intervention, is necessary since attention is a prerequisite to establish desired behaviour change (McGuire, 1985). Therefore, it remains important to assess exposure to Internet-delivered interventions. There are several measures to assess exposure to Internetdelivered interventions, such as frequency and duration of visits, but there is no gold standard. Each exposure measure relates to a different aspect of exposure (Danaher et al., 2006). One can visit an intervention very frequent, for example, but only for a short period of time. Duration of visits, on the other hand, does not necessarily give a clear picture of participants' online activity. All such exposure measures can be tracked objectively and are, in contrast to self-reported exposure measures, independent of participants' memory, interpretation, or social desirability. It might be even more valuable if exposure measures can be linked to variables at the individual level (Chapter 1). The aim of this chapter is to explore the potential of tracking multiple exposure measures and linking them to variables at the individual level, using an Internet-delivered intervention aimed at smoking behaviour as an example.

\section{Methods}

\section{Intervention}

Data was obtained from an existing Internet-delivered intervention aimed at smoking behaviour among adolescents (www.actieffniet.nl). This intervention concentrates on peer support, which is a main predictor of smoking behaviour (Dijk, Reubsaet, De Nooijer, \& De Vries, $2007 \mathrm{~b}$ ), and is targeted at both smokers and non-smokers. The Internet, due to its interactive character, seems highly appropriate to promote peer support (Cunningham, Van Mierlo, \& Fournier, 2008; Robinson, Patrick, Eng, \& Gustafson, 1998).

Participants were recruited through posters in schools, youth associations, and busses. If they participated, they had to fill out an intitial questionnaire. Subsequently, they were asked to conduct six smoking-related activities online during three months (November 1, 
2007 - February 1, 2008) and assess the results of other participants' activities to create a supportive atmosphere to restrain from smoking: (1) create a webpage about themselves and smoking, (2) create a logo, (3) think up a first prize (worth $€ 500$; decided by a jury), (4) think up a recipe for a snack when not smoking, (5) do a knowledge quiz, and (6) think up a stop or non-initiation tip. Participants were explained in advance that they had to conduct a total of six activities and these activities were made available sequentially during a predefined time period.

\section{Measures}

Four exposure measures were tracked by means of unique IDs per participant: (1) whether particpants visited the website [first visit], (2) how often [frequency] and (3) how long [duration] they visited the website (in minutes), and (4) how many webpages they visited within the website [activity]. Participants were asked to report their age, sex, level of education and current smoking behaviour. Educational level was categorised into low ((preparatory) secondary vocational education) and high (senior general secondary education or university preparatory education) level. Smoking behaviour was dichotomised as smoking (either regular or experimental) or non-smoking (never smokers or quitters) (Kremers, De Vries, Mudde, \& Candel, 2004).

\section{Analyses}

Regression analyses were conducted by means of SPSS 13.0 with first visit, frequency, duration, and activity as dependent variables and age, sex, level of education and current smoking behaviour as independent variables. Backward procedure was used to create final models which are parsimonious, which is a common practice in explorative research.

\section{Results}

Twenty-four participants completed the initial questionnaire. Their mean age was $16.6(\mathrm{SD}=1.7), 62.5 \%$ were girls, $45.8 \%$ attended higher educational level, and $50 \%$ smoked. Of these participants, fourteen payed a visit to the intervention's website. On average, they visited the website 3.6 times during the course of the intervention. The average total time of visitation was 31 minutes (range 1 - 153) and an average of 90 webpages (range 1 -528) within the website were visited during this period of time. Participants who attend lower educational level were more likely to visit the website ( $81 \%$ vs. $38 \%$ ) compared to participants who attend higher educational level. Those who attend higher educational level, however, visited the website more frequently (7.0 vs. 1.8 times) and for a longer time ( 73 vs. 8 minutes), and visited more webpages (207 vs. 25) within the website compared to participants who attend lower educational level (Table 7.1). 


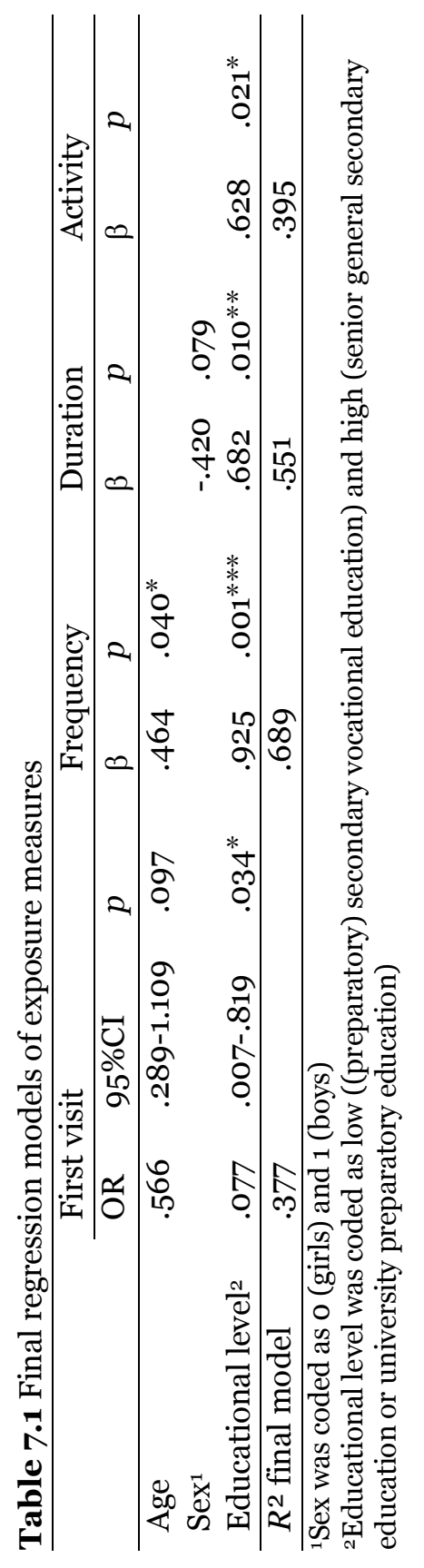




\section{Discussion}

An Internet-delivered intervention aimed at smoking behaviour was used as an example to explore the potential of tracking multiple exposure measures and linking them to variables at the individual level. At first sight it seems promising that especially participants who attend lower educational level visit an Internet-delivered intervention aimed at adolescents, since this subgroup is more likely to smoke (STIVORO, 2008). When looking at more detailed exposure measures, however, it becomes evident that those participants who attend higher education level visit the intervention more often, longer and more actively and are therefore more likely to establish a desired behaviour change. In this example, one could wrongfully conclude that participants from a specific subgroup (lower educational level) have higher exposure rates (based on the dichotomous measure of visiting). Detailed exposure measures, however, showed the opposite. This illustrates the value of tracking multiple exposure measures.

To fruitfully utilise exposure measures it has to be possible to link them to variables at the individual level, to be able to compare subgroups that differ on socio-demographic, psycho-social, or behavioural measures. Moreover, exposure measures on the individual level can also be linked to outcome measures of an intervention. By doing so, it is possible to study potentially mediating effects of objectively tracked exposure on interventions' outcome measures. The latter, however, is no common practice to date (Chapter 1). For example, recent studies (An et al., 2006; Chen \& Yeh, 2006; Escoffery et al., 2004) reported a limited number of exposure measures and did not relate them to the intervention's outcome measures, making it impossible to study potentially mediating effects of exposure.

Only one intervention has been described in this chapter. The procedure of tracking exposure measures, however, is applicable to every Internet-delivered intervention. Although we described an Internetdelivered intervention with a relatively small sample size, this was only used as an example to illustrate the potential value of tracking exposure measures. It was not our aim at the first place to set up a large quantitative study.

\section{Practice implications}

There are no known technical barriers to track exposure measures of Internet-delivered interventions. It is important, however, to realise this from the start of an intervention development process and to involve technical staff during this initial phase (Chapter 4). Furthermore, dependent on the laws in certain countries or states, it may be necessary to take additional steps. In a recent Dutch project, for example, it was necessary to register the project at the Dutch Data Protection Authority, which supervises the fair and lawful use and security of personal data (Chapter 6). If these legal issues are covered, we recommend to track as many exposure measures as possible since there is no gold standard 
(Chapters 1 and 6). Each exposure measure has its own characteristics. Duration of visits, for example, is no indicator of participants' online activity, since one does not know to how much information participants are possibly exposed. Therefore, number of visited web pages would be more appropriate to assess online activity. Another advantage of having multiple exposure measures available is their usefulness during process evaluation of Internet-delivered interventions. They provide detailed insight into where participants either leave the intervention website or have come to a standstill. This information can be used to adapt interventions and therewith increase exposure rates and probability of behaviour change.

\section{Conclusion}

The potential value of tracking multiple exposure measures becomes evident when looking at more detailed exposure measures linked to variables at the individual level. This offers the possibility to compare subgroups that differ on socio-demographic, psycho-social, or behavioural measures and to study potential mediating effects of exposure on interventions' outcome measures.

\section{Acknowledgements}

We would like to thank Jochen Mikolajczak for his comments on a previous version of this chapter. 


\section{ㄷENERRAL DISCUSSIIIN}

A part of this chapter has been published as Crutzen, R., De Nooijer, J., \& De Vries, N. K. (2008). How to reach a target group with Internetdelivered interventions? The European Health Psychologist, 10. 
The aim of the present dissertation was to understand dissemination of and exposure to Internet-delivered behaviour change interventions aimed at adolescents. Opportunities to improve dissemination and exposure could result from such understanding. The first part of this dissertation described explorative research and consisted of three studies, covering the literature, experts and potential users of Internetdelivered interventions, which made data triangulation possible. Results of these studies were contextualised in a proposed conceptual framework for understanding and improving adolescents' exposure to Internetdelivered interventions. The second part of this dissertation described applied research and consisted of three studies, focusing on the effect of online word of mouth (WOM) on exposure, the influence of intention to change multiple health risk behaviours on exposure and the potential of tracking multiple exposure measures. The main results of the presented studies are discussed and integrated in this general discussion. First, possible ways to facilitate dissemination and exposure will be discussed. Second, effectiveness of strategies related to exposure will be discussed. Subsequently, considerations that emerged while conducting the presented studies and implications for practice and future research will be discussed.

It should be noticed that the focus while conducting these studies was not on the content of Internet-delivered interventions, but purely on dissemination of and exposure to such interventions. The distinction between dissemination and exposure is not as straightforward as it may seem, since the first aspect of exposure (accessing the intervention website) also relates to dissemination. Dissemination involves the distribution of the intervention among the target population, including bringing the intervention to the attention of the target population. This implies that successful dissemination increases the likelihood that members of the target group access the intervention website. In other words, successful dissemination could result in exposure to the intervention. Subsequently, people need to stay on the intervention website and need to be exposed to the content of the intervention to increase the likelihood that desired behaviour change will be established. The latter is in line with McGuire's idea that attention is an essential first phase to establish the impact of persuasive communications (McGuire, 1985).

\section{Main results}

\section{How to facilitate dissemination and exposure?}

The systematic review resulted in an overview of methods and strategies which have been used to facilitate exposure to current Internet-delivered interventions and reported in studies evaluating these interventions. To get a more complete overview, both experts and potential users were consulted to identify factors which were possibly related to dissemination and exposure. The results of these studies are triangulated and will be 
discussed in the following paragraphs. The results regarding dissemination will be discussed first, since successful dissemination is required before participants can be exposed to the intervention content and use its components. Subsequently, results regarding exposure (accessing, staying and revisiting the intervention website) will be discussed.

\section{Dissemination}

After triangulation, embedding an Internet-delivered intervention in a social context (e.g. linking it to school activities) could be defined as a feasible and appropriate way to disseminate such an intervention. This is comparable with offline (non-Internet-delivered) interventions, where adolescents also indicate that interventions can effectively be provided during class hours (Martens, Wind, Van Assema, \& Brug, 2002). The feasibility, appropriateness and effectiveness of such a social context could be explained by the infrastructure being available and intermediaries (e.g. teachers) being accustomed to such settings (e.g. providing education during class hours) (Reinaerts, De Nooijer, \& De Vries, 2007). Social context is not limited to schools, but also sports clubs (Kokko, Kannas, \& Villberg, 2006), youth centres (Pettifor et al., 2005) or hospitals (Tercyak, Britto, Hanna, Hollen, \& Hudson, 2008) could be used for embedding the intervention. Embedding the intervention in a social context, however, does not guarantee exposure outside the context, because motivation to continue using the intervention independently is often lacking (Bruning Brown, Winzelberg, Abascal, \& Taylor, 2004; Buller et al., 2008; De Nooijer et al., 2008). A possible explanation for this lack of motivation could be that an association with, for example, school activities has a negative influence on exposure outside the context of school (Chapter 6). A second dissemination strategy, indicated by adolescents and experts, was cross-medial promotion (e.g. advertising on TV). This strategy is not limited to online promotion and is less dependent on a social context. Previous research indicated the effectiveness of such a strategy to reach a low-involved target group (Reisch \& Bietz, 2007; Story \& French, 2004).

Unfortunately, the process of dissemination was only described to a limited extent in studies in the systematic review in Chapter 1. An explanation for this limited description could be that most studies were conducted in a research setting and participants were recruited to participate in a study, which made a comparison with the process of dissemination during real-life implementation difficult. Moreover, triangulation of the results only limitedly contributed to a better understanding regarding successful dissemination of an Internetdelivered intervention. 
Accessing the intervention website (i.e. a first visit) Invitations to participate were frequently used in current Internetdelivered interventions included in the systematic review, to trigger a first visit and therewith exposure to the intervention. According to adolescents themselves, such invitations need to be disseminated by WOM, since their social network strongly exerts influence on their decisions. Invitations received through WOM could be an important trigger to visit (and therewith being exposed to) an Internet-delivered intervention. WOM originally stems from the field of marketing (Katz \& Lazarfeld, 1955) and has been used to influence consumer behaviour (Cheung et al., 2008; Senecal \& Nantel, 2004). Although the "product" (e.g. being healthy or some aspect thereof) in health promotion is perceived as less salient for adolescents, health is also related to behaviour. Therefore, strategies derived from marketing - aimed at changing behaviour - could be useful to promote this (e.g. by WOM). Experts agreed on the importance of WOM as a possible strategy to promote a first visit, but were not specific about the source of WOM. Adolescents stressed that the source of recommendations for interventions should be friends. Friendships are not necessarily restricted to the physical environment of adolescents, but could also exist purely online (Markow, 2006). Information from friends is perceived as independent (Silverman, 2001) and this increases the perceived trustworthiness of the information (Chapter 3) and therewith the likelihood that this information contributes to influencing behaviour. The influence of friends, known as peer influence, has been proven effective in studies regarding consumer (Dotson \& Hyatt, 2005) and health behaviour (Maxwell, 2002). Therefore, effectiveness of the use of the WOM strategy was tested in an experimental setting (Chapter 5) and results will be discussed later on.

Another important factor mentioned by both experts and adolescents is an attractive interface at first sight, since people are very quick in forming an opinion about web page visual appeal. Previous research has shown that a decision can be made in $50 \mathrm{~ms}$, which supports the idea that judgements of visual appeal could represent a pure physiological response (Damaiso, 2000; Lindgaard et al., 2006). Moreover, visual appeal appeared to be closely related to other concepts such as design and use of colour (Lindgaard et al., 2006). This has been described in studies in the systematic review regarding current Internetdelivered interventions as addressing the first experience of the target group while accessing the intervention website.

\section{Staying on the intervention website}

Attractiveness of the interface is on the on the dividing line between accessing and staying on the intervention website. This is related to adolescents' need to associate with the look and feel of the intervention. Adolescents stated that they wanted a combination of textual information with a variety of other (content-related) elements like pictures, movies, 
and games, which constitute the look and feel of the intervention. They wanted to be active (e.g. playing games) and encounter ways to communicate. The latter is already provided by some of the current Internet-delivered interventions included in the systematic review, for example by Escoffery and colleagues (2004) and by Woodruff and colleagues (2007). This is also in line with experts mentioning the importance of the use of visual materials and interactive features and has generally been acknowledged as an advantage of the Internet (Eng, Gustafson, Henderson, Jimison, \& Patrick, 1999; Robinson et al., 1998; Street \& Rimal, 1997).

Although experts stated that Internet-delivered interventions should utilise all features provided by the Internet, this is mitigated in Chapter 4. There we conclude that the format of content should be in line with its purpose and the intervention itself should not be a conglomeration of all possible features. In other words, although it may be technically possible to offer, for example, a discussion board, one should not offer this for the sake of offering it. Why should one offer a discussion board if there is no reason for participants to communicate with each other? Results of Chapter 1 indeed showed that some features provided by Internet-delivered interventions were seldom utilised. The format of content being in line with its purpose does not mean that the peripheral route (Petty \& Cacioppo, 1986) cannot be employed to deliver information. Offering a game in an Internet-delivered intervention, for example, can be used to attract attention (via the peripheral route; by simple cues), but playing the game can be very involving and therefore lead to more intensive information processing (via the central route; by extensive elaboration of relevant arguments). It should be taken into account, however, that adolescents prefer information related to their health to be serious, to enhance credibility of the information (Dijk et al., 2007a).

\section{Revisiting the intervention website}

It is important that adolescents are committed to revisit an intervention. This commitment could possibly be established by the formation of implementation intentions (Gollwitzer, 1999). Implementation intentions are if-then plans that specify what behaviour one will perform and in what situation one will perform it. For example, if I finish my homework on Wednesday, then I will visit [the intervention website]. Previous research indicated that the formation of implementation intentions did affect website visiting positively, even when participants encounter an unexpected barrier (e.g. an error message) (Martijn, Alberts, Sheeran, Peters, Mikolajczak, \& De Vries, 2008). Reminders were already used in current Internet-delivered interventions included in the systematic review to promote revisiting the intervention, but could be used to strengthen the effect of implementation intentions.

Apart from a commitment to revisit the intervention, the provision of new content on a regular basis and the chance for 
adolescents to monitor their progress in changing behaviour was mentioned by experts and adolescents. This monitoring is not limited to behaviour itself, but also to its consequences, e.g. financial (Saitz et al., 2007), or in relation to assignments (Suminski \& Petosa, 2006) or use of components (Williamson et al., 2006). Furthermore, monitoring could be used to create higher levels of immersion and, therewith, increase intrinsic motivation of participants to change or maintain behaviour (IJsselsteijn, De Kort, Westerink, De Jager, \& Bonants, 2006).

The results described above gave first insight into opportunities to facilitate dissemination and exposure. Opportunities one need to put into effect are embedding an Internet-delivered intervention in a social context, the use of WOM and features provided by the Internet, and creating commitment to an intervention.

After triangulation, the results were lined up to create a clearer picture. This revealed that the results can mostly be related to the concept of user experience, which is associated with all three aspects of exposure since a positive user experience during and after the visit is a prerequisite to revisit an Internet-delivered intervention and for staying long enough to complete the intervention. Subsequently, the results were linked to an existing framework to conceptualise user experience (Chapter 4). Five interrelated planes are distinguished in this framework, varying from very concrete (surface - top) to very abstract (strategy bottom). Each plane consists of elements which are denominated as the elements of user experience. This conceptual framework can serve as a useful tool during the development process of Internet-delivered interventions. It may be used for the guidance of strategies to establish a positive user experience and, therewith, increase exposure to Internetdelivered interventions. The complexity of user experience, however, is indicated by the interaction between elements within this framework. It is hard to change one of these elements once intervention development is finished and, therefore, one needs to think about user experience before and during the development process of an Internet-delivered intervention. Anticipating on user experience is an essential element of planned intervention development which could be enhanced by including members of the target group in a linkage group (Bartholomew et al., 2006). Nevertheless, an important next step would be to firstly conduct experimental (i.e. Chapter 5), observational (i.e. Chapter 6) and longitudinal studies to test the effectiveness of strategies to improve dissemination and exposure.

\section{Effectiveness of improving exposure}

Results of the systematic review regarding current Internet-delivered interventions showed that discussion boards were only moderately used for peer support. Professional support (e.g. ask-the-expert), although often provided, was only limitedly used. This moderate or even limited use is surprising, since these factors were indicated by both experts and 
adolescents as possibly associated with improvement of exposure to Internet-delivered interventions. Furthermore, it appeared that, for those interventions that made a distinction between interactive and noninteractive content, providing content in an interactive way was associated with higher exposure rates. The combination of tailored communication, the use of reminders to visit or revisit or invitations to participate, and the use of incentives appeared to be effective in facilitating exposure to current Internet-delivered interventions included in the systematic review. The effectiveness of invitations to participate through online WOM was also tested in two experimental studies (Chapter 5). Manipulation of the source of an invitation to visit an Internet-delivered intervention revealed that an invitation from a friend was more effective than an invitation from an institution to effectuate a first visit to an Internet-delivered intervention aimed at changing implicit attitudes related to alcohol. This is in line with the results of the explorative research described above. Manipulation of the invitation's content revealed that weak arguments were more effective when there was no rather than there was an incentive mentioned. Weak arguments can serve as a peripheral cue that is more effective to attract a lowinvolved target group when a motivator (incentive) to critically apprehend the message's content is not present in the invitation. Although this explanation is in line with the elaboration likelihood model (ELM) (Petty \& Cacioppo, 1986), the possibility of a double role for certain variables (peripheral cue and motivator) is also a limitation of the ELM. The possibility that the same variable can explain two different effects makes falsification of the ELM impossible, because the same variable can effectuate processing via the peripheral route and the central route and this distinction is the core of the ELM.

A prerequisite to test effectiveness of strategies which aim to improve exposure, both in experimental studies and during real-life implementation, is the measurement of exposure. Results of the systematic review showed that to date reported exposure measures are very heterogeneous. Registering and reporting detailed exposure measures (at least frequency of visiting, duration of visiting and number of pages visited) is recommendable, since they provide more insight into intensity of exposure compared to the number of (unique) visitors and each exposure measure relates to a different aspect of exposure (Danaher et al., 2006). An Internet-delivered intervention aimed at smoking behaviour was used as an example to explore the potential of tracking multiple exposure measures and linking them to variables at the individual level (Chapter 7). It appeared that those participants who attend lower educational level schools (a subgroup that is more likely to smoke) were more likely to visit the intervention. A possible explanation could be that these schools were explicitly addressed in the recruitment of participants (Van Dorst \& Crone, 2006). When looking at more detailed exposure measures, however, it became evident that those participants who attend higher education level schools visited the 
intervention more often, longer and more actively and were therefore more likely to display a desired behaviour change. If exposure measures were linked to the intervention's outcome measures at the individual level, it would also be possible to study potentially mediating effects of exposure on these outcome measures. The latter, however, was no common practice in current Internet-delivered interventions included in the systematic review (Chapter 1).

\section{Considerations}

The studies described in this dissertation were among the first in the developing field of e-health which focused on dissemination of and exposure to Internet-delivered interventions. The results serve as a departure point for future research regarding dissemination and exposure and the development of new Internet-delivered interventions. In the following paragraphs, more general issues that emerged while conducting these studies will be discussed. Subsequently, implications for practice and future research which can be derived from these issues will be described.

\section{If the mountain will not come to Mahomet, should Mahomet go to the mountain?}

Although the process of dissemination of current Internet-delivered interventions included in the systematic review was only described to a limited extent, knowledge regarding this issue remains crucial since dissemination is required before participants can be exposed to the intervention content and use it components. Embedding an intervention in a social context (e.g. linking it to school activities) appeared to be a feasible solution, but it remains questionable whether this is suitable for (1) all available Internet-delivered interventions in view of their number and (2) interventions aimed at adolescents who are hard to reach (e.g. school drop-outs) but who are a highly relevant target group for health behaviour change. Apart from this, one could even question to what extent adolescents realise that behaviour change interventions are available and delivered through the Internet. Even if adolescents are willing to change behaviour, they will not search online if they are unaware of the existence of Internet-delivered interventions. In line with the precaution adoption process model (Weinstein \& Sandman, 1992), one could assume that adolescents need to be aware of the existence of Internet-delivered intervention and realise that they have personal relevance, before they take action and actually visit such interventions. If adolescents are unaware of the existence of Internet-delivered interventions, one should question whether a possible solution would be to raise awareness by disseminating these interventions at online places which are already popular among adolescents. As defined in the (rephrased) proverb in this paragraph's title, the question to be answered is: "If the mountain will not come to Mahomet, should Mahomet go to the mountain?" 
An example of such a popular online place (in which health education is delivered besides entertainment) is Second Life, which is part of the Web 2.0 movement and its future. Second Life is a unique social experience, allowing people to meet and interact with each other and in groups, using a comprehensive and well integrated range of asynchronous and real-time communication tools (Kamel Boulos, Hetherington, \& Wheeler, 2007). It is a virtual world which is characterised by the simultaneous presence of multiple users who inhabit and interact via avatars within the same simulated space (Gorini, Gaggioli, Vigna, \& Riva, 2008). Second Life could be a suitable place to disseminate health promotion interventions. For example, in the Nutrition Game proposed by Ohio University, players can learn about the impact that fast food has on health. This is achieved by allowing players to experiment with different eating styles in simulated fast-food restaurants to learn about the short- and long-term health impacts of their choices (Kamel Boulos et al., 2007). These simulated fast-food restaurants are present in a virtual world (Second Life) which is already popular among and accessed by adolescents, thereby streamlining the process of dissemination5. According to Gorini et al. (2008), the key factor of a hybrid experience merging the physical and virtual world (i.e. Second Life) is the interreality experience which is achieved through: (1) an extended sense of presence: visitors do not receive abstract information, but live meaningful experiences; (2) an extended sense of community (social presence); and (3) real-time feedback between the physical and virtual world (e.g. the avatar's reaction on a person's behaviour).

Another example of a popular online place is YouTube. Health promotion has embraced both mass media and interpersonal communication, but the field has not fully recognised the growing benefit of hybrid communication forms like YouTube which appeal to adolescents. The mainstream use of the Internet means that YouTube videos are open to nonstop, widespread observation and could be used to enhance intervention adoption (Lillie, 2008), e.g. as a gateway to another website. This gateway principle is, for example, also applied in an Internet-based HIV-prevention intervention who uses virtual pursers on a popular e-dating website to invite users to the intervention website (Kok, Harterink, Vriens, De Zwart, \& Hospers, 2006). The intervention (about dating and sexual behaviour) was brought to the attention of chatters (at an e-dating website for men who have sex with men) by these virtual chatters, before and after they logged on.

It is important to realise that Internet-delivered interventions could be disseminated through popular online places, but adolescents may be less interested in health behaviour change when visiting popular online places compared to more "serious" online places (e.g. Kennisnet,

5 A more detailed description can be found at

http://vital.cs.ohiou.edu/vitalwiki/index.php/Nutrition_Game. 
the Dutch website supporting primary and secondary education), since they visit these places for other reasons (i.e. distraction) than behaviour change. It should be taken into account, therefore, that adolescents recruited through popular online places are possibly low-involved (Petty et al., 1983) and should first be motivated to change behaviour.

Moreover, they may have less attention for the intervention's content. In spite of this, collaborations with (commercial) partners regarding the use of popular online place for health promotion purposes may have a positive effect on dissemination of Internet-delivered interventions. Such collaborations, however, should not interfere with the way in which one would like an intervention to come across.

Finally, it needs to be stressed that dissemination of Internetdelivered interventions is not restricted to online promotion. As mentioned above, cross-medial promotion (e.g. using advertising on TV) appeared to be an effective strategy to reach a low-involved target group (Reisch \& Bietz, 2007; Story \& French, 2004).

Implications for practice: Internet-delivered interventions could be disseminated through collaborations with partners regarding the use of popular online places to reach highly relevant target groups for health behaviour change. A good example is the collaboration with the chat room operator of a popular e-dating website to promote the previously mentioned intervention about dating and sexual behaviour (Kok et al., 2006). Other possibilities to deploy in the near future are collaborations with social networking websites (e.g. Hyves, Facebook, MySpace) which are popular among and repeatedly visited by adolescents (Lenhart \& Madden, 2007). The latter characteristic connects with the idea of monitoring progress in behaviour change which was also derived from triangulation of results of previously explorative research (Chapter 1-3). Fruitful collaborations could be established by including these partners in a linkage group at the beginning of the development process of the intervention (Bartholomew et al., 2006) and actively using them for consultation purposes (Kok et al., 2006).

Implications for future research: General optimism for possibilities to contact hard to reach groups through the Internet has by now been mitigated by disappointing experiences. Although some positive examples of recruitment through popular online places are quoted, it needs to be investigated whether this is effective to successfully disseminate Internet-delivered interventions. The next paragraph will be devoted to determining successfulness of dissemination. An important issue to keep in mind, however, is that motivation to change health behaviour among adolescents recruited through popular online places may be low because adolescents primarily visit these places for other reasons (e.g. distraction). Therefore, future research needs to look at other differences regarding socio-demographic, psycho-social, or behavioural measures of adolescents recruited through different online 
places. It could be that one could reach a hard to get, but highly important target group for health promotion (e.g. those who lack motivation to change) through popular online places. In that case, one should first focus on enhancing motivation to change. Motivational interviewing (MI) could be a possible way to achieve this (besides tailored advice). Motivational interviewing is "a client-centred, directive method for enhancing intrinsic motivation to change by exploring and resolving ambivalence" (Miller \& Rollnick, 2002) and has been proven to be an effective method for behaviour change (Brug, Spikmans, Aartsen, Breedveld, Bes, \& Fereira, 2007; Carels et al., 2007; Resnicow et al., 2001). Recently, MI has been successfully applied in an online context (Woodruff et al., 2007). This stresses the idea that future research need to look at the effectiveness of MI, especially when applied in Internetdelivered interventions.

\section{When is dissemination successful?}

Before determining if an Internet-delivered intervention has been disseminated successfully, one should first determine when an intervention is successfully disseminated. This is not as straightforward as it may seem. Absolute figures may cause unrealistic optimism, since thousands of visitors are not uncommon for websites in general. Relative figures, on the other hand, may cause unrealistic pessimism, since they may be very low if one relates number of visitors to Internet penetration rates. To estimate the reach of a recruitment approach and the generalisability of results, it is important to report the target group, the number exposed to recruitment, the number who respond, the number eligible, and the number who actually participate (Graham, Bock, Cobb, Niaura, \& Abrams, 2006). Furthermore, one should determine a final target in advance. There is, however, no "default" cut off point for such a target to determine successfulness of dissemination, since this may differ per intervention (e.g. an intervention aimed at reducing alcohol use among high school students versus party drug use among school dropouts). Issues such as the general accessibility of the target group and the prevalence of health risk behaviours among the target group should be taken into account when determining a final target for successfulness of dissemination.

The determination if an Internet-delivered intervention has been disseminated successfully does not only depend on your final target, but also on the denominator you choose to estimate reach. In a study by Graham et al. (2006), for example, Internet users were recruited based on use of the terms quit(ting) smoking or stop(ping) smoking in a major search engine. When a user clicked on a link to the intervention in the results of a search engine query, an intercept page appeared inviting them to participate in the study of Graham and colleagues. If they accepted, three questions were asked to determine preliminary eligibility. Reach estimates vary depending on the denominator selected: $2.7 \%$ of all Internet users seeking cessation information; $6.9 \%$ of those who 
demonstrated preliminary interest in the study; $13.7 \%$ of those who were eligible to participate; $21.1 \%$ of those eligible and recruited; and $51.3 \%$ of those consented.

This also raises an interesting statistical issue, since it is difficult to identify the population to which samples refer when there is no clear sampling method (i.e. everybody can access your intervention). Questions need to be asked to determine eligibility to participate. It remains unclear, however, whether missing data regarding eligibility is due to visitors' perception of non-eligibility (e.g. parents visiting the intervention because they are interested in the subject or non-smokers accidentally hitting on a website aimed at smoking cessation) or actual drop-out of potential participants. Appropriate methods of analysis are needed to deal with the vast amount of missing data (Christensen, Griffiths, \& Korten, 2002) and to determine the recruited sample size from your target group.

The difficulties regarding measurement of online reach are not limited to the field of health promotion. The Interactive Advertising Bureau Europe (IAB Europe) and the European Interactive Advertising Association (EIAA) have announced to develop a measurement standard for website reach. In this project, denominated as Measurement of Interactive Audience Project (MIA Project), several online measurement methods will be evaluated (Marketing Online, 2007).

Implications for practice: It is recommended to report the target group of your intervention, the number exposed to recruitment, the number who responded, the number eligible, and the number who actually participated to determine whether dissemination has been successful. These numbers should be compared with a final target which should be determined in advance and which depends on the intervention (e.g. its subject and target group). Despite this dependence on the intervention itself, one may look at other Internet-delivered interventions to get an idea about the order of magnitude of a suitable final target.

Implications for future research: Analyses regarding data from Internetdelivered interventions are not as straightforward as they may seem, since data can be missing for several reasons (e.g. visitors which do not perceive the intervention as being relevant to them once they logged on or visitors whose needs are fulfilled halfway the intervention). Although it is probably too conservative to consider all missing data as drop-outs, this is recommended as long as appropriate methods of analysis are lacking. Furthermore, due to the openness of Internet as a medium, not all visitors of your intervention are necessary members of your target group (e.g. parents, people who are generally interested in the topic of your intervention). These "participants" should be excluded from data analysis. 


\section{How could strategies which aim to improve dissemination and exposure be tested on effectiveness?}

It is recommended (in Chapter 1) to conduct experimental research in more controlled settings to increase evidence-based insight into effectiveness of strategies regarding dissemination and exposure, before applying these strategies in practice. Advantage of such a controlled setting is the minimisation of possible confounding effects. Disadvantage of these experimental settings, however, is the isolated way in which strategies are tested on effectiveness, which is less comparable with reallife implementation. Even if strategies are immediately applied in practice, there are appropriate designs, such as a time series design (Chen et al., 2005; Murry, Stam, \& Lastovicka, 1993), to test effectiveness of these strategies. In such a design, strategies are first applied separately. Subsequently, combinations of several strategies are applied. Intervention use is monitored during the whole period to determine which strategy or combination between them is most effective. Although this design is more sensitive to confounding effects (e.g. changing environment), strategies are tested in a less isolated way and this could give more insight into effectiveness regarding dissemination and exposure in real life. If all methods described above are inapplicable due to limited resources, one could test the effectiveness of dissemination strategies by simply asking visitors where they came from and how they heard about the intervention (Gordon, Akers, Severson, Danaher, \& Boles, 2006). Although this method is based on self-report and therefore less objective, it is easily applicable and less time consuming. Yet, this method remains a last resort (when all else fails).

Dissemination and exposure do not only depend on the intervention itself, however, but also on its users. There is evidence that the acquisition of skills to use a website may influence its adoption (Paswan \& Ganesh, 2003). It has also been shown, however, that Internet self-efficacy is not a significant predictor of exposure (Steele, Mummery, \& Dwyer, 2007). The interaction between the Internetdelivered intervention and its user refers to the concept of usability which considers the following factors: (1) the ease of understanding the structure of a website, its functions, interface and the content that can be observed by the user; (2) simplicity of use of the website in its initial stages; (3) the speed with which users can find what they are looking for; (4) the perceived ease of navigation in terms of time required and action necessary in order to obtain the desired results; and (5) the ability of users to control what they are doing, and where they are, at any given moment (Casaló, Flavián, \& Guinalíu, 2008). If familiarity with a website increases, then perceived usability influences loyalty to the website (Casaló et al., 2008). This is in line with the principle of cognitive lock-in, accounting for users' preference of better-known websites (Murray \& Häubl, 2002). In terms of Internet-delivered interventions, this could be conducive to revisits of the intervention. Since usability depends on the interaction between the intervention and its user, this also effects testing 
of strategies on effectiveness regarding exposure in the sense that results cannot be generalised (even if users are from the same target group).

Implications for practice: Caution regarding the use of strategies to improve dissemination and exposure is recommended as long as evidence-based insight into effectiveness is scarce. Evidence-based insight into strategies which aim to improve dissemination and exposure, however, could also be gained by applying strategies in practice and investigating, for example, server registrations (objective) or visitors' self-reporting (subjective). Applying strategies in practice can be seen as natural experiments to test effectiveness of these strategies. Although this research method is more common in fields where laboratory experiments are more difficult, such as sociology and economics (Angrist \& Evans, 1998), there are also examples in the field of health promotion - e.g. with regard to the effect of a smoking ban (Sargent, Shepard, \& Glantz, 2004).

Implications for future research: To increase evidence-based insight into effectiveness of strategies regarding dissemination and exposure, future research should not be limited to experimental research in controlled settings, but also use alternatives such as a time series design. Such a time series design can also be used to test effectiveness of dissemination strategies for existing Internet-delivered interventions.

\section{Differences between behaviours}

An advantage of Internet-delivered interventions addressing multiple behaviours (De Nooijer \& De Vries, 2006; Kypri \& McAnally, 2005) is the possibility to look at differences between behaviours regarding exposure. In that case, exposure can be linked to variables related to these behaviours (e.g. determinants). Results from Chapter 6, for example, revealed differences between risk taking and energy balance-related behaviours. Implications for the design of Internet-delivered interventions have been discussed in Chapter 6, but this also raises the issue of classification of behaviours. Other disciplines, such as chemistry, biology and medicine, have gained by classifying respectively chemicals, plants and diseases. It remains unclear, however, how we decide whether methods and strategies regarding behaviour A are also applicable to behaviour B. This presupposes that we can decide whether A and B are the same type of behaviours and this in turn requires some form of classification of behaviours (Johnston \& Dixon, 2008). Given the importance of behaviour, remarkably little effort has been put into classification of behaviours. A recent review has focused on similarities between behaviour-specific determinants of four health behaviours: smoking, (binge) drinking, safe sex and healthy nutrition (Peters, Wiefferink, Hoekstra, Buijs, Ten Dam, \& Paulussen, 2008). To allow a comparison across different behaviours, the determinants were carefully categorised, where possible, to a higher non-behaviour-specific level. 
Although several determinants were found to be relevant for all four behaviours, 51 out of a total of 86 determinants could not be classified meaningfully to a higher level or have only been studied for one behaviour. This stresses the possible difficulty to generalise findings regarding (determinants of) dissemination of and exposure to Internetdelivered interventions from one health behaviour to others.

Implications for practice: Effectiveness of strategies regarding dissemination and exposure may not be transferable between Internetdelivered interventions focusing on different behaviours. Hence, effective strategies can be derived from Internet-delivered interventions focusing on different behaviours, but behaviour-specific evidence-based insight needs to be gained. In other words, if one develops an Internet-delivered intervention which aims to promote safe sex behaviours, one may look at Internet-delivered interventions related to smoking cessation to get ideas about certain strategies, but this does not guarantee the effectiveness of these strategies in the context of promoting safe sex behaviours.

Implications for future research: More effort needs to be put into classification of behaviours. So far, there are rough categories depending on the specific research field, e.g. addictive vs. non-addictive behaviours, risk taking vs. risk avoidance behaviours or preventive vs. detection behaviours. Although the distinction between, for example, prevention and detection behaviours can be useful in message framing (Rothman \& Salovey, 1997), it is inapplicable to the behaviours which are related to the primary prevention of physical chronic diseases (the focus of this dissertation). Until a more detailed classification of behaviours is available, effectiveness of strategies regarding dissemination and exposure need to be tested separately for each behaviour.

\section{General conclusion}

So far, embedding an Internet-delivered intervention in a social context appeared to be a feasible and appropriate way to disseminate it and the use of online word of mouth has been proven to be effective to attract visitors to an Internet-delivered intervention. Furthermore, the Internetdelivered intervention itself should be developed in such a way that it increases the likelihood that visitors stay and eventually revisit the intervention. Therefore, a conceptual framework has been proposed which can serve as a useful tool in the development process to optimise user experience and therewith possibly improve exposure rates. Although this dissertation started as a fairy tale, the reported findings also serve as a handle for ideas and opportunities to explore in future research and practice before this fairy tale can be concluded with 'happily ever after'. 


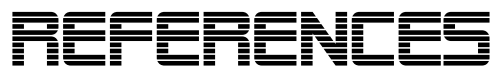

Alexander, G. W., Divine, G. W., Couper, M. P., McClure, J. B., Stopponi, M. A., Fortman, K. K., et al. (2008). Effect of incentives and mailing features on online health program enrollment. American Journal of Preventive Medicine, 34, 382-388.

An, L. C., Perry, C. L., Lein, E. B., Klatt, C., Farley, D. M., Bliss, R. L., et al. (2006). Strategies for increasing adherence to an online smoking cessation intervention for college students. Nicotine \& Tobacco Research, 8 (S1), S7-S12.

Angrist, J., \& Evans, W. (1998). Children and their parents' labor supply: evidence from exogenous variation in family size. American Economic Review, 88, 450-477.

Bailenson, J. N., Beall, A. C., Blascovich, J., Loomis, J., \& Turk, M. (2005). Transformed social interaction, augmented gaze, and social influence in immersive virtual environments. Human Communication Research, 31, 511-537.

Baker, D. W., Williams, M. V., Parker, R. M., Gazmararian, J. A., \& Nurss, J. (1999). Development of a brief test to measure functional health literacy. Patient Education and Counseling, 38, 33-41.

Barak, A., \& Fisher, W. A. (2003). Experience with an Internet-based, theoretically grounded educational resource for the promotion of sexual and reproductive health. Sexual and Relationship Therapy, 18, 293-308.

Barner, J. C., Mason, H. L., \& Murray, M. D. (1999). Assessment of asthma patients' willingness to pay for and give time to an asthma self-management program. Clinical Therapeutics 21, 878-894.

Bartholomew, L. K., Parcel, G. S., Kok, G., \& Gottlieb, N. H. (2006). Planning health promotion programs: an Intervention Mapping approach. San Francisco, California: Jossey-Bass.

Bates, B. R., Romina, S., Ahmed, R., \& Hopson, D. (2006). The effect of source credibility on consumers' perceptions of the quality of health information on the Internet. Medical Informatics and the Internet in Medicine, 31, 45-52.

Beaird, J. (2007). The Principles of Beautiful Web Design (1st ed.). Collingwood: SitePoint.

Bernard, M. (2001). Developing schemas for the location of common web objects. Retrieved September 13, 2007, from http://psychology.wichita.edu/surl/usabilitynews/3W/web_obj ect.htm.

Berndt, T. (1996). Transitions in friendship and friends' influence. In J. A. Graber, J. Brooks-Gunn \& A. C. Petersen (Eds.), Transitions 
through adolescence: interpersonal domains and context (pp. 57-84). Mahwah, NJ: Lawrence Erlbaum.

Bernhardt, J. M., \& Hubley, J. (2001). Health education and the Internet: the beginning of a revolution. Health Education Research, 16, 643-645.

Bickart, B., \& Schindler, R. M. (2001). Internet forum as influential sources of consumer information. Journal of Interactive Marketing, 1, 31-40.

Bleakley, A., Merzel, C. R., VanDevanter, N. L., \& Messeri, P. (2004). Computer access and Internet use among urban youths American Journal of Public Health, 94, 744-746.

Borzekowski, D. L. G., \& Rickert, V. I. (2001). Adolescents, the Internet, and health: issues of access and content. Applied Developmental Psychology, 22, 49-59.

Brouwer, W., Oenema, A., Crutzen, R., De Nooijer, J., De Vries, N. K., \& Brug, J. (2008). An exploration of factors related to dissemination of and exposure to Internet-delivered behavior change interventions aimed at adults: a Delphi study approach. Journal of Medical Internet Research, 1O, e10.

Brug, J., Glanz, K., Van Assema, P., Kok, G., \& Van Breukelen, G. J. P. (1998). The impact of computer-tailored feedback and iterative feedback on fat, fruit, and vegetable intake. Health Education \& Behavior, 25, 517-531.

Brug, J., Oenema, A., Kroeze, W., \& Raat, H. (2005). The internet and nutrition education: challenges and opportunities. European Journal of Clinical Nutrition, 59, S130-S139.

Brug, J., Spikmans, F., Aartsen, C., Breedveld, B., Bes, R., \& Fereira, I. (2007). Training dietitians in basic motivational interviewing skills results in changes in their counseling style and in lower saturated fat intakes in their patients. Journal of Nutrition Education \& Behavior, 39, 8-12.

Bruning Brown, J., Winzelberg, A. J., Abascal, L. B., \& Taylor, C. B. (2004). An evaluation of an Internet-delivered eating disorder prevention program for adolescents and their parents. Journal of Adolescent Health, 35, 290-296.

Bruns, A. (2005). Gatewatching. New York, NY: Peter Lang Publishing.

Buller, D. B., Borland, R., Woodall, W. G., Hall, J. R., Hines, J. M., Burris-Woodall, P., et al. (2008). Randomized trials of Consider This, a tailored, Internet-delivered smoking prevention program for adolescents. Health Education \& Behavior, 35, 260-281.

Buller, D. B., Buller, M. K., \& Kane, I. (2005). Web-based strategies to disseminate a sun safety curriculum to public elementary schools and state-licensed child-care facilities. Health Psychology, 24, $470-476$.

Buttle, F. A. (1998). Word of mouth: understanding and managing referral marketing. Journal of Strategic Marketing 6, 241-254. 
Carels, R. A., Darby, L., Cacciapaglia, H. M., Konrad, K., Coit, C., Harper, J., et al. (2007). Using motivational interviewing as a supplement to obesity treatment: a stepped-care approach. Health Psychology, 26, 369-374.

Casaló, L., Flavián, C., \& Guinalíu, M. (2008). The role of perceived usability, reputation, satisfaction and consumer familiarity on the website loyalty formation process. Computers in Human Behavior, 24, 325-345.

CBS. (2002). Gebruik ICT-hulpmiddelen, november 2001 [Use of ICTtools, November 2001]. Heerlen: Centraal Bureau voor de Statistiek [Statistics Netherlands].

CBS. (2006). Onderzoek ICT gebruik bij personen [Survey ICT use by persons]. Heerlen: Centraal Bureau voor de Statistiek [Statistics Netherlands].

Chalmers, A. F. (1999). What is this thing called science? Indianapolis: Hackett Publishing.

Chen, H.-H., \& Yeh, M.-L. (2006). Developing and evaluating a smoking cessation program combined with an Internet-assisted instruction program for adolescents with smoking. Patient Education and Counseling, 61, 411-418.

Chen, H.-H., Yeh, M.-L., \& Chao, Y.-H. (2006). Comparing effects of auricular acupressure with and without an Internet-assisted program on smoking cessation and self-efficacy of adolescents. The Journal of Alternative and Complementary Medicine, 12, 147-152.

Chen, J., Smith, B. J., Loveday, S., Bauman, A., Costello, M., Mackie, B., et al. (2005). Impact of a mass media campaign upon calls to the New South Wales Hep C helpline. Health Promotion Journal of Australia, 16, 11-14.

Cheung, C. M. K., Lee, M. K. O., \& Rabjohn, N. (2008). The impact of electronic word-of-mouth: the adoption of online opinions in online customer communities. Internet Research, 18, 229-247.

Chiauzzi, E., Green, T. C., Lord, S., Thum, C., \& Goldstein, M. (2005). My student body: a high-risk drinking prevention web site for college students. Journal of American College Health, 53, 263-274.

Christensen, H., Griffiths, K. M., \& Korten, A. (2002). Web-based cognitive behavior therapy: analysis of site usage and changes in depression and anxiety scores. Journal of Medical Internet Research, 4, e3.

Christopherson, K. M. (2007). The positive and negative implications of anonymity in Internet social interactions: "On the Internet, nobody knows you're a dog". Computers in Human Behavior, 23, 3038-3056.

Crutzen, R., Brouwer, W., Brug, J., De Vries, N. K., Oenema, A., \& De Nooijer, J. (2008). Gezondheidsbevorderende interventies via internet: onderzoek naar mogelijkheden voor effectievere verspreiding en blootstelling [Health promotion interventions 
through the Internet: research on possibilities for more effective dissemination and exposure]. Maastricht: Maastricht University.

Crutzen, R., De Nooijer, J., Brouwer, W., Oenema, A., Brug, J., \& De Vries, N. K. (2008a). Internet-delivered interventions aimed at adolescents: a Delphi study on dissemination and exposure. Health Education Research, 23, 427-439.

Crutzen, R., De Nooijer, J., Brouwer, W., Oenema, A., Brug, J., \& De Vries, N. K. (2008b). Qualitative assessment of adolescents' views about improving exposure to Internet-delivered interventions. Health Education, 108, 105-116.

Crutzen, R., De Nooijer, J., Brouwer, W., Oenema, A., Brug, J., \& De Vries, N. K. (e-pub ahead of print). Effectiveness of online word of mouth on exposure to an Internet-delivered intervention. Psychology \& Health.

Crutzen, R., De Nooijer, J., Brouwer, W., Oenema, A., Brug, J., \& De Vries, N. K. (submitted-a). A conceptual framework for understanding and improving adolescents' exposure to Internet-delivered interventions.

Crutzen, R., De Nooijer, J., Brouwer, W., Oenema, A., Brug, J., \& De Vries, N. K. (submitted-b). How to facilitate exposure to Internet-delivered health behavior change interventions aimed at adolescents or young adults? A systematic review on methods, strategies and outcomes.

Crutzen, R., De Nooijer, J., Candel, M. J. J. M., \& De Vries, N. K. (2008). Adolescents who intend to change multiple health behaviours choose greater exposure to an Internet-delivered intervention. Journal of Health Psychology, 13, 906-911.

Crutzen, R., De Nooijer, J., \& De Vries, N. K. (2008). How to reach a target group with Internet-delivered interventions? The European Health Psychologist, 10.

Crutzen, R., De Nooijer, J., Van Dorst, A. G., Crone, M. R., Brouwer, W., Oenema, A., et al. (submitted). Utilizing exposure measures of Internet interventions: a commendable example on smoking behavior.

Cunningham, J. A., Van Mierlo, T., \& Fournier, R. (2008). An online support group for problem drinkers: AlcoholHelpCenter.net. Patient Education and Counseling, 70, 193-198.

Damaiso, A. R. (2000). A second chance for emotion. In R. D. Lane \& L. Nadel (Eds.), Cognitive neuroscience of emotions (pp. 12-24). New York, NY: Taylor and Francis.

Danaher, B. G., Boles, S. M., Akers, L., Gordon, J. S., \& Severson, H. H. (2006). Defining participant exposure measures in web-based health behavior change programs. Journal of Medical Internet Research, 8, e15.

De Haan, J., Van 't Hof, C., \& Van Est, R. (2006). De digitale generatie [The digital generation]. In J. De Haan \& C. Van 't Hof (Eds.), Jaarboek ICT en samenleving: de digitale generatie [Yearbook 
ICT and society: the digital generation] (pp. 11-23). Amsterdam: Boom.

De Nooijer, J., \& De Vries, N. K. (2006). Monitoring health risk behavior of Dutch adolescents and the development of health promoting policies and activities: the E-MOVO project. Health Promotion International, 22, 5-10.

De Nooijer, J., Oenema, A., Kloek, G., Brug, J., De Vries, H., \& De Vries, N. K. (2005). Bevordering van gezond gedrag via internet: $n u$ en in de toekomst [Promotion of healthy behavior through the Internet: now and in the future]. Maastricht: Maastricht University.

De Nooijer, J., Veling, M. L., Ton, A., De Vries, H., \& De Vries, N. K. (2008). Electronic monitoring and health promotion: the evaluation of the E-MOVO website by adolescents. Health Education Research, 23, 382-391.

De Vet, E., Brug, J., De Nooijer, J., Dijkstra, A., \& De Vries, N. K. (2005). Determinants of forward stage transitions: a Delphi study. Health Education Research, 20, 195-205.

De Vries, H., \& Brug, J. (1999). Computer-tailored interventions motivating people to adopt health promoting behaviors: Introduction to a new approach. Patient Education and Counseling, 36, 99-105.

De Vries, H., Van 't Riet, J., Spigt, M., Metsemakers, J., Van den Akker, M., Vermunt, J. K., et al. (2008). Clusters of lifestyle behaviors: Results from the Dutch SMILE study. Preventive Medicine, 46, 203-208.

Dijk, F., De Nooijer, J., Heinrich, E., \& De Vries, H. (2007a). Adolescents' view on smoking, quitting and health education. Health Education, 107, 114-125.

Dijk, F., Reubsaet, A., De Nooijer, J., \& De Vries, H. (2007b). Smoking status and peer support as the main predictors of smoking cessation in adolescents from six European countries. Nicotine \& Tobacco Research, 9, S495-S504.

Dotson, M. J., \& Hyatt, E. M. (2005). Major influence factors in children's consumer socialization. Journal of Consumer Marketing, 22, 35-42.

Eng, T. R., Gustafson, D. H., Henderson, J., Jimison, H., \& Patrick, K. (1999). Introduction to evaluation of interactive health communication applications. American Journal of Preventive Medicine, 16, 10-15.

Eng, T. R., Maxfield, A., Patrick, K., Deering, M. J., Ratzan, S. C., \& Gustafson, D. H. (1998). Access to health information and support, a public highway or a private road? Journal of the American Medical Association, 280, 1371-1375.

Erstad, O. (2006). A new direction? Digital literacy, student participation and curriculum reform in Norway. Education and Information Technologies, 11, 415-429. 
Escoffery, C., McCormick, L., \& Bateman, K. (2004). Development and process evaluation of a web-based smoking cessation program for college smokers: innovative tool for education Patient Education and Counseling, 53, 217-225.

Evers, K. E., Cummins, C. O., Prochaska, J. O., \& Prochaska, J. M. (2005). Online health behavior and disease management programs: are we ready for them? Are they ready for us? Journal of Medical Internet Research, 7, e27.

Evers, W., \& Carol, B. (2007). An Internet-based assessment tool for food choices and physical activity behaviors. Journal of Nutrition Education and Behavior, 39, 105-106.

Eysenbach, G. (2005). The law of attrition. Journal of Medical Internet Research, 7, e11.

Eysenbach, G., \& Köhler, C. (2002). How do consumers search for and appraise health information on the world wide web? Qualitative study using focus groups, usability tests, and in-depth interviews. $B M J, 324,573-577$.

Fink, J. (1999). Cyberseduction: reality in the age of psychotechnology. Amherst, NY: Prometheus books.

Flicker, S., Goldberg, E., Read, S., Veinot, T., McClelland, A., Saulnier, P., et al. (2004). HIV-positive youth's perspectives on the Internet and eHealth. Journal of Medical Internet Research, 6, e32.

Fox, S. (2006). Online health search 2006. Washington: Pew Internet \& American Life Project.

Fox, S., \& Madden, M. (2005). Generations online. Washington: Pew Internet \& American Life Project.

Gärling, T., \& Fujii, S. (2002). Structural equation modeling of determinants of planning. Scandinavian Journal of Psychology, $43,1-8$.

Garrett, J. J. (2002a). The elements of user experience: user-centered design for the web. Berkeley, CA: New Riders press.

Garrett, J. J. (2002b). A visual vocabulary for describing information architecture and interaction design. Retrieved September 12, 2007, from www.jjg.net/ia/visvocab.

Gilbert, L. K., Temby, J. R. E., \& Rogers, S. E. (2005). Evaluating a teen STD prevention web site. Journal of Adolescent Health, 37, 236242.

Gillispie, J. F., \& Gackenbach, J. (2007). Cyber rules: what you really need to know about the Internet. New York, NY: W. W. Norton \& Company.

Glasgow, R. E. (2007). eHealth evaluation and dissemination research. American Journal of Preventive Medicine, 32, S119-S126.

Glasgow, R. E., Vogt, T. M., \& Boles, S. M. (1999). Evaluating the public health impact of health promotion interventions: the RE-AIM framework. American Journal of Public Health, 89, 1322-1327. 
Godin, G., \& Kok, G. (1996). The theory of planned behavior: a review of its applications to health-related behaviors. American Journal of Health Promotion, 11, 87-98.

Gollwitzer, P. M. (1999). Implementation intentions: Strong effects of simple plans. American Psychologist, 54, 493-503.

Gordon, J. S., Akers, L., Severson, H. H., Danaher, B. G., \& Boles, S. M. (2006). Successful participant recruitment strategies for an online smokeless tobacco cessation program. Nicotine \& Tobacco Research, 8, S35-S41.

Gorini, A., Gaggioli, A., Vigna, C., \& Riva, G. (2008). A Second Life for eHealth: prospects for the use of 3-D virtual worlds in clinical psychology. Journal of Medical Internet Research, 10 , e21.

Graham, A. L., Bock, B. C., Cobb, N. K., Niaura, R., \& Abrams, D. B. (2006). Characteristics of smokers reached and recruited to an internet smoking cessation trial: a case of denominators. Nicotine \& Tobacco Research, 8, S43-48.

Gray, N. J., Klein, J. D., Noyce, P. R., Sesselberg, T. S., \& Cantrill, J. A. (2005a). Health information-seeking behaviour in adolescence: the place of the internet. Social Science \& Medicine, 6o, 14671478.

Gray, N. J., Klein, J. D., Noyce, P. R., Sesselberg, T. S., \& Cantrill, J. A. (2005b). The Internet: a window on adolescent health literacy. Journal of Adolescent Health, 37, 243.e241-243.e247.

Green, L. W., \& Kreuter, M. W. (1999). Health promotion planning: an educational and environmental approach (3rd ed.). Mountain View, CA: Mayfield.

Griffiths, K. M., \& Christensen, H. (2005). Website quality indicators for consumers. Journal of Medical Internet Research, 7, e55.

Gross, E. F. (2004). Adolescent Internet use: What we expect, what teens report. Applied Developmental Psychology, 25, 633-649.

Guadagno, R. E., Blascovich, J., Bailenson, J. N., \& McCall, C. (2007). Virtual humans and persuasion: the effects of agency and behavioral realism. Media Psychology, 10, 1-22.

Hahn, E. J., Toumey, C. P., Rayens, M. K., \& McCoy, C. A. (1999). Kentucky legislators' views on tobacco policy. American Journal of Preventive Medicine, 16, 81-88.

Hansen, D. L., Derry, H. A., Resnick, P. J., \& Richardson, C. R. (2003). Adolescents searching for health information on the Internet: an observational study. Journal of Medical Internet Research, 5, e25.

Hawkins, R. P., Kreuter, M. W., Resnicow, K., Fishbein, M., \& Dijkstra, A. (2008). Understanding tailoring in communicating about health. Health Education Research, 23, 454-466.

Higgins, J. P. T., \& Green, S. (2006). Cochrane handbook for systematic reviews of interventions 4.2.6 [updated September 2006]. Chichester, United Kingdom: John Wiley \& sons, Ltd. 
Hong, T. (2006). Contributing factors to the use of health-related websites. Journal of Health Communication, 11, 149-165.

Houben, K., \& Wiers, R. W. (2006). Assessing implicit alcohol associations with the Implicit Association Test: Fact or artifact? Addictive Behaviors, 31, 1346-1362.

Houben, K., \& Wiers, R. W. (2007). Are drinkers implicitly positive about drinking alcohol? Personalizing the alcohol-IAT to reduce negative extrapersonal contamination. Alcohol \& Alcoholism, 42, 301-307.

IJsselsteijn, W. A., De Kort, Y. A. W., Westerink, J., De Jager, M., \& Bonants, R. (2006). Virtual fitness: stimulating exercise behavior through media technology. Presence: Teleoperators \& Virtual Environments, 15, 688-698.

Internet World Stats. (2008a). Countries with highest Internet penetration rates. Retrieved August 5, 2008, from http://www.internetworldstats.com/top25.htm.

Internet World Stats. (2008b). Internet usage statistics: The Internet big picture. Retrieved July 28, 2008, from http://www.internetworldstats.com/stats.htm.

Jackson, L. A., Von Eye, A., Biocca, F., Barbatsis, G., Zhao, Y., \& Fitzgerald, H. (2005). Instructional set and Internet use by lowincome adults. CyberPsychology \& Behavior, 8, 465-472.

Jago, R., Baranowski, T., Baranowski, J. C., Thompson, D., Cullen, K. W., Watson, K., et al. (2006). Fit for Life Boy Scout badge: outcome evaluation of a troop and Internet intervention. Preventive Medicine, 42, 181-187.

Johnston, M., \& Dixon, D. (2008). Current issues and new directions in psychology and health: What happened to behaviour in the decade of behaviour? Psychology \& Health, 23, 509 - 513.

Jones, J., \& Hunter, D. (1995). Consensus methods for medical and health services research. British Medical Journal, 311, 376-380.

Kamel Boulos, M. N., Hetherington, L., \& Wheeler, S. (2007). Second Life: an overview of the potential of 3-D virtual worlds in medical and health education. Health Information and Libraries Journal, 24, 233-245.

Katz, E., \& Lazarfeld, P. F. (1955). Personal Influence. Glencoe, IL: Free Press.

Kelder, S. H., Perry, C. L., Klepp, K. I., \& Lytle, L. L. (1994). Longitudinal tracking of adolescent smoking, physical activity, and food choice behaviors. American Journal of Public Health, 84, 1121-1126.

Kerr, C., Murray, E., Stevenson, F., Gore, C., \& Nazareth, I. (2006). Internet interventions for long-term conditions: patient and caregiver quality criteria. Journal of Medical Internet Research, 8 , e13.

Kok, G., Harterink, P., Vriens, P., De Zwart, O., \& Hospers, H. J. (2006). The Gay Cruise: developing a theory- and evidence-based 
Internet HIV-prevention intervention. Sexuality Research \& Social Policy, 3, 52-67.

Kokko, S., Kannas, L., \& Villberg, J. (2006). The health promoting sports club in Finland: a challenge for the settings-based approach. Health Promotion International, 21, 219-229.

Kools, M., Ruiter, R. A. C., Van de Wiel, M. W. J., \& Kok, G. (2007). Testing the usability of access structures in a health education brochure British Journal of Health Psychology, 12, 525-541.

Koyani, S. J., Bailey, R. W., \& Nall, J. R. (2006). Research-based web design \& usability guidelines. Washington, DC: US Department of Health \& Human Services.

Kremers, S. P. J., De Bruijn, G. J., Schaalma, H., \& Brug, J. (2004). Clustering of energy balance-related behaviours and their intrapersonal determinants. Psychology \& Health, 19, 595-606.

Kremers, S. P. J., De Vries, H., Mudde, A. N., \& Candel, M. J. J. M. (2004). Motivational stages of adolescent smoking initiation: predictive validity and predictors of transitions. Addictive Behaviors, 29, 781-789.

Kreuter, M. W., \& Strecher, V. J. (1996). Do tailored behavior change messages enhance the effectiveness of health risk appraisal: results from a randomized trial. Health Education Research, 11, 97-105.

Kypri, K., \& McAnally, H. M. (2005). Randomized controlled trials of a web-based primary care intervention for multiple health risk behaviors. Preventive Medicine, 41, 761-766.

Lawrence, D., \& Tavakol, S. (2006). Balanced Website Design: Optimising Aesthetics, Usability and Purpose (1st ed.). New York, NY: Springer.

Lee, J., Lim, Y., Graham, S. J., Kim, G., Wiederhold, B. K., Wiederhold, M. D., et al. (2004). Nicotine craving and cue exposure therapy by using virtual environments. CyberPsychology \& Behavior, 7, 705-713.

Lenert, L., Munoz, R. F., Stoddard, J., Delucchi, K., Bansod, A., Skoczen, S., et al. (2003). Design and pilot evaluation of an internet smoking cessation program. Journal of the American Medical Informatics Association, 10, 16-20.

Lenhart, A., \& Madden, M. (2007). Social networking websites and teens: an overview. Washington: Pew Internet \& American life project.

Lessig, L. (1999). Code and other laws of cyberspace. New York, NY: Basic books.

Leung, L. (2003). Impacts of Net-generation attributes, seductive properties of the Internet, and gratifications-obtained on Internet use. Telematics and Informatics, 20, 107-129.

Lillie, S. E. (2008). Diffusion of innovation in the age of YouTube. American Journal of Preventive Medicine, 34, 267. 
Lin, Y., Zhang, W. J., Koubek, R. J., \& Mourant, R. R. (2006). On integration of interface design methods: Can debates be resolved? Interacting with Computers, 18, 709-722.

Lindgaard, G., Fernandes, G., Dudek, C., \& Browñ, J. (2006). Attention web designers: you have 50 milliseconds to make a good first impression! Behaviour \& Information Technology, 25, 115-126.

Linstone, H. A., \& Turoff, M. (1975). The Delphi method: techniques and applications. Reading, MA: Addison-Wesley.

Long, J. D., Armstrong, M. L., Amos, E., Shriver, B., Roman-Shriver, C., Feng, D., et al. (2006). Pilot using World Wide Web to prevent diabetes in adolescents. Clinical Nursing Research, 15, 67-79.

Lou, C. H., Zhao, Q., Gao, E. S., \& Shah, I. H. (2006). Can the Internet be used effectively to provide sex education to young people in China? Journal of Adolescent Health, 39, 720-728.

Macdonald, I. (1999). Overview of the health issues related to alcohol consumption. In I. Macdonald (Ed.), Health issues related to alcohol consumption (2nd ed.). Washington/Brussels: Blackwell sciences ltd.

Maibach, E. W., Van Duyn, M. A. S., \& Bloodgood, B. (2006). A marketing perspective on disseminating evidence-based approaches to disease prevention and health promotion. Preventing Chronic Disease, 3, 1-11.

Mangunkusumo, R. T., Brug, J., De Koning, H. J., Van der Lei, J., \& Raat, H. (2007). School-based Internet-tailored fruit and vegetable education combined with brief counseling increases children's awareness of intake levels. Public Health Nutrition, 10, 273-279.

Marketing Online. (2007). Europese standaard voor meten online bereik in de maak [European standard for measuring online reach in preparation]. Retrieved August 1, 2008, from http://www.marketingonline.nl/nieuws/ModuleItem52230.html

Markow, D. (2006). Friendships in the age of social networking websites. Trends \& Tudes, 5, 1-5.

Marks, J. T., Campbell, M. K., Ward, D. S., Ribisl, K. M., Wildemuth, B. M., \& Symons, M. J. (2006). A comparison of web and print media for physical activity promotion among adolescent girls. Journal of Adolescent Health, 39, 96-104.

Martens, M., Wind, M., Van Assema, P., \& Brug, J. (2002). De (on)mogelijkheden van voedingsvoorlichting aan twaalf- tot veertienjarige jongeren [Opportunities and pitfalls of nutrition education for adolescents aged 12-14]. Nederlands Tijdschrift voor Diëtisten, 57, 71-77.

Martijn, C., Alberts, H., Sheeran, P., Peters, G.-J. Y., Mikolajczak, J., \& De Vries, N. K. (2008). Blocked goals, persistent action: implementation intentions engender tenacious goal striving. Journal of Experimental Social Psychology, 44, 1137-1143. 
Maxwell, K. A. (2002). Friends: The role of peer influence across adolescent risk behaviors. Journal of Youth and Adolescence, 31, 267-277.

McGuire, W. J. (1985). Attitudes and attitude change. In M. Lindsay \& E. Aronson (Eds.), The handbook of social psychology (pp. 233346). New York, New York: Random House.

McQuail, D. (1994). Mass communication: an introduction (3rd ed.). London, Thousand Oaks, New Delhi: Sage publications.

Meijer, A. W. M. (1991). Plaats en functies van de Nederlandse G.G.D.-en [Location and functions of Dutch Community Health Services]. In E. De Leeuw (Ed.), Gezonde steden [Healthy cities] (pp. 109131). Assen/Maastricht: Van Gorcum.

Mermelstein, R., \& Turner, L. (2006). Web-based support as an adjunct to group-based smoking cessation for adolescents. Nicotine \& Tobacco Research, 8, S69-S76.

Michaud, P.-A., \& Colom, P. (2003). Implementation and evaluation of an Internet health site for adolescents in Switzerland. Journal of Adolescent Health, 33, 287-290.

Miller, W. R., \& Rollnick, S. (2002). Motivational interviewing: preparing people for change (2nd ed.). New York, NY: The Guilford press.

Morgan, D. L., \& Kreuger, R. A. (1998). The focusgroup kit. Thousand Oaks, CA: Sage.

Murray, K. B., \& Häubl, G. (2002). The fiction of no friction: A user skills approach to cognitive lock-in. Advances in Consumer Research, 29, 8-10.

Murry, J. P., Stam, A., \& Lastovicka, J. L. (1993). Evaluating an antidrinking and driving advertising campaign with a sample survey and time series intervention analysis. Journal of the American Statistical Association, 88, 50-56.

Neuhauser, L., \& Kreps, G. L. (2003). Rethinking communication in the e-health era. Journal of Health Psychology, 8, 7-23.

Noar, S. M., Clark, A., Cole, C., \& Lustria, M. L. (2006). Review of interactive safer sex web sites: practice and potential. Health Communication, 20, 233-241.

Norman, A. T., \& Russell, C. A. (2006). The pass-along effect: investigating word-of-mouth effects on online survey procedures. Journal of Computer-Mediated Communication, 11, 1085-1103.

Obermayer, J. L., Riley, W. T., Asif, O., \& Jean-Mary, J. (2004). College smoking-cessation using cell phone text messaging. Journal of American College Health, 53, 71-78.

Oenema, A., Brug, J., Dijkstra, A., De Weerdt, I., \& De Vries, H. (2008). Efficacy and use of an Internet-delivered computer-tailored lifestyle intervention, targeting saturated fat intake, physical activity and smoking cessation: a randomized controlled trial. Annals of Behavioral Medicine, 35, 125-135. 
Pan, B., Hembrooke, H. A., Gay, G. K., Granka, L. A., Feusner, M. K., \& Newman, J. K. (2004). The determinants of web page viewing behavior: an eye-tracking study. In Proceedings of the 2004 symposium on eye tracking research \& applications (pp. 147154). New York, NY: ACM press.

Paperny, D. M., Aono, J. Y., Lehman, R. M., Hammar, S. L., \& Risser, J. (1990). Computer-assisted detection and intervention in adolescent high-risk health behaviors. The Journal of Pediatrics, 116, 456-462.

Paswan, A. K., \& Ganesh, G. (2003). Familiarity and interest: in a learning center service context. Journal of Services Marketing, 17, 393-419.

Patten, C. A., Croghan, I. T., Meis, T. M., Decker, P. A., Pingree, S., Colligan, R. C., et al. (2006). Randomized clinical trial of an Internet-based versus brief office intervention for adolescent smoking cessation. Patient Education and Counseling, 64, 249258.

Patten, C. A., Rock, E., Meis, T. M., Decker, P. A., Colligan, R. C., Pingree, S., et al. (2007). Frequency and type of use of a home-based, Internet intervention for adolescent smoking cessation. Journal of Adolescent Health, 41, 437-443.

Pérez-Rodrigo, C., Wind, M., Hildonen, C., Bjelland, M., Aranceta, J., Klepp, K. I., et al. (2005). The Pro Children intervention: applying the Intervention Mapping protocol to develop a schoolbased fruit and vegetable promotion programme. Annals of Nutrition \& Metabolism, 49, 267-277.

Perry, C. L. (2000). Preadolescent and adolescent influences on health. In B. D. Smedley \& S. L. Syme (Eds.), Promoting health: intervention strategies from social and behavioral research (pp. 217-253). Washington, DC: National Academy press.

Peters, L. W. H., Wiefferink, C. H., Hoekstra, F., Buijs, G. J., Ten Dam, G. T. M., \& Paulussen, T. G. W. M. (2008). A review of similarities between domain-specific determinants of four health behaviors among adolescents. Health Education Research, doi:10.1093/her/cyn1013.

Peterson, G., Aslani, P., \& Williams, K. A. (2003). How do consumers search for and appraise information on medicines on the Internet? A qualitative study using focus groups. Journal of Medical Internet Research, 5, e33.

Pettifor, A. E., Kleinschmidt, I., Levin, J., Rees, H. V., MacPhail, C., Madikizela-Hlongwa, L., et al. (2005). A community-based study to examine the effect of a youth HIV prevention intervention on young people aged 15-24 in South Africa: results of the baseline survey. Tropical Medicine \& International Health, 10, 971 - 980.

Petty, R. E., \& Cacioppo, J. T. (1986). Communication and persuasion: central and peripheral routes to attitude change. New York, NY: Springer-Verlag. 
Petty, R. E., Cacioppo, J. T., \& Schumann, D. (1983). Central and peripheral routes to advertising effectiveness: the moderating role of involvement. The Journal of Consumer Research, 10, 135146.

Phelps, J. E., Lewis, R., Mobilio, L., Perry, D., \& Raman, N. (2004). Viral marketing or electronic word-of-mouth advertising: Examining consumer responses and motivations to pass along email. Journal of Advertising Research, 45, 333-348.

Quick, R. (2007). Web Design in Easy Steps (4th ed.). Warwickshire: Computer Step.

Reinaerts, E., De Nooijer, J., \& De Vries, N. K. (2007). Fruit \& vegetable distribution program versus a multi component program to increase $\mathrm{F} \& \mathrm{~V}$ consumption: which should be recommended for implementation? Journal of School Health, 77, 679-686.

Reinaerts, E., De Nooijer, J., \& De Vries, N. K. (2008). Using intervention mapping for systematic development of two schoolbased interventions aimed at increasing children's fruit and vegetable intake. Health Education, 108, 301 - 320.

Reisch, L. A., \& Bietz, S. (2007). How to convince the unconvincibles? A mass mediated approach to communicate sustainable lifestyles to a low-interest target group. International Journal of Innovation and Sustainable Development, 2, 192-200.

Resnicow, K., Jackson, A., Wang, T., De, A. K., McCarty, F., Dudley, W. $\mathrm{N}$., et al. (2001). A motivational interviewing intervention to increase fruit and vegetable intake through Black churches: results of the Eat for Life trial. American Journal of Public Health, 91, 1686-1693.

Rhee, H., Wyatt, T. H., \& Wenzel, J. A. (2006). Adolescents with asthma: learning needs and internet use assessment. Respiratory Care, $51,1441-1449$.

Rice, R. E. (2006). Influences, usage, and outcomes of Internet health information searching: multivariate results from the Pew surveys. International Journal of Medical Informatics, 75, 8-28.

Rimmer, J. (2004). Improving software environments through usability and interaction design. Journal of Visual Communication in Medicine, 27, 6-10.

Roberto, A. J., Zimmerman, R. S., Carlyle, K. E., \& Abner, E. L. (2007). A computer-based approach to preventing pregnancy, STD, and HIV in rural adolescents. Journal of Health Communication, 12, 53-76.

Robinson, T. N., Patrick, K., Eng, T. R., \& Gustafson, D. (1998). An evidence-based approach to interactive health communication: a challenge to medicine in the information age. Journal of the American Medical Association, 280, 1264-1269.

Rochlen, A. B., Zack, J. S., \& Speyer, C. (2004). Online therapy: review of relevant definitions, debates, and current empirical support. Journal of Clinical Psychology, 6o, 269-283. 
Rogers, E. M. (2003). Diffusion of innovations. New York, NY: The free press.

Rogers, E. M., \& Hart, W. B. (2002). New communication technology and the changing nature of conversation. In E. William \& N. Paul (Eds.), The changing conversation in America (pp. 91-117). Thousand Oaks, CA: Sage.

Rothman, A. K., \& Salovey, P. (1997). Shaping perceptions to motivate healthy behavior: the role of message framing. Psychological Bulletin, 121, 3-19.

Ruggiero, T. (2000). Uses and gratifications theory in the 21st century. Mass Communicatino \& Society, 3, 3-37.

Saitz, R., Palfai, T. P., Freedner, N., Winter, M. R., MacDonald, A., Lu, J., et al. (2007). Screening and brief intervention online for college students: the iHealth study. Alcohol and Alcoholism, 42, 28-36.

Sargent, R. P., Shepard, R. M., \& Glantz, S. A. (2004). Reduced incidence of admissions for myocardial infarction associated with public smoking ban: before and after study. British Medical Journal, 328, 977-980.

Saunders, J. B., Aasland, O. G., Babor, T. F., De la Fuente, J. R., \& Grant, M. (1993). Development of the Alcohol Use Disorders Identification Test (AUDIT): World Health Organisations Collaborative Project on early detection of persons with harmful alcohol consumption - II. Addiction, 88, 791-804.

Scheier, M. F., \& Carver, C. S. (2003). Goals and confidence as selfregulatory elements underlying health and illness behavior. In L. Cameron \& H. Leventhal (Eds.), The self-regulation of health and illness behavior (pp. 17-41). New York, NY: Routledge.

Senecal, S., \& Nantel, J. (2004). The influence of online product recommendations on consumers' online choices. Journal of Retailing, 8o, 159-169.

Sillence, E., Briggs, P., Harris, P., \& Fishwick, L. (2006). A framework for understanding trust factors in web-based health advice. International Journal of Human-Computer Studies, 64, 697713 .

Silverman, G. (2001). The secrets of word-of-mouth marketing. New York, NY: American Management Association.

Smahel, D., \& Subrahmanyam, K. (2007). "Any girls want to chat press 911": partner selection in monitored and unmonitored teen chat rooms. CyberPsychology \& Behavior, 10, 346-353.

Smerecnik, C. M. R., \& Mesters, I. (2007). Validating the Medical Data Interpretation Test in a Dutch population. Patient Education and Counseling, 68, 287-290.

Sobell, L. C., \& Sobell, M. B. (1990). Self-report issues in alcohol abuse: State of the art and future directions. Behavioral Assessment, 12, 77-90. 
Stauss, B. (2000). Using new media for customer interaction: a challenge for relationship marketing. In T. Hennig-Thurau \& U. Hansen (Eds.), Relationship Marketing (pp. 233-253). Berlin: Springer.

Steele, R. M., Mummery, W. K., \& Dwyer, T. (2007). Examination of program exposure across intervention delivery modes: face-toface versus internet. International Journal of Behavioral Nutrition and Physical Activity, 4, 7.

STIVORO. (2007). Jaarverslag 2006 [Annual report 2006]. Den Haag: STIVORO.

STIVORO. (2008). Roken Jeugd Monitor [Smoking Youth Monitor]. Den Haag: STIVORO.

Stoddard, J. L., Augustson, E. M., \& Mabry, P. L. (2006). The importance of usability testing in the development of an internet-based smoking cessation treatment resource. Nicotine \& Tobacco Research, 8, S87-S93.

Story, M., \& French, S. (2004). Food advertising and marketing directed at children and adolescents in the US. International Journal of Behavioral Nutrition and Physical Activity, 1, 3.

Street, R. L., \& Rimal, R. N. (1997). Health promotion and interactive technology: a conceptual foundation. In R. L. Street, D. T. Gold \& T. Manning (Eds.), Health promotion and interactive technology: theoretical applications and future directions (Vol. 1-18). Mahwah: Lawrence Erlbaum associates.

Subramani, M. R., \& Rajagopalan, B. (2003). Knowledge-sharing and influence in online social networks via viral marketing. Communications of the ACM, 46, 300-307.

Suminski, R. R., \& Petosa, R. (2006). Web-assisted instruction for changing social cognitive variables related to physical activity. Journal of American College Health, 54, 219-225.

Sun, T., Youn, S., Wu, G., \& Kuntaraporn, M. (2006). Online word-ofmouth (or mouse): an exploration of its antecedents and consequences. Journal of Computer-Mediated Communication, 11, 1104-1127.

Swanborn, P. G. (1987). Methoden van sociaal-wetenschappelijk onderzoek [Research methods in social science]. Amsterdam: Boom.

Tapscott, D. (1998). Growing up digital: the rise of the net generation. New York, NY: McGraw-Hill.

Te Velde, S. J., Twisk, J. W. R., \& Brug, J. (2007). Tracking of fruit and vegetable consumption from adolescence into adulthood and its longitudinal association with overweight. British Journal of Nutrition, 98, 431-438.

Tercyak, K. P., Britto, M. T., Hanna, K. M., Hollen, P. J., \& Hudson, M. M. (2008). Prevention of tobacco use among medically at-risk children and adolescents: clinical and research opportunities in the interest of public health. Journal of Pediatric Psychology, $33,119-132$. 
Thombs, D. L., Olds, R. S., Osborn, C. J., Casseday, S., Glavin, K., \& Berkowitz, A. D. (2007). Outcomes of a technology-based social norms intervention to deter alcohol use in freshman residence halls. Journal of American College Health, 55, 325-332.

Thompson, D., Baranowski, T., Cullen, K., Watson, K., Canada, A., Bhatt, R., et al. (2008). Food, fun and fitness Internet program for girls: influencing log-on rate. Health Education Research, 23, 228237.

Thornburg, H. D. (1981). Adolescent sources of information on sex. Journal of School Health, 51, 274-277.

Van Assema, P., Mesters, I., \& Kok, G. (1992). Het focusgroep-interview: een stappenplan [The focus group interview: a step-by-step plan]. Tijdschrift Sociale Gezondheidszorg, 70, 431-437.

Van den Berg, M. H., Schoones, J. W., \& Vliet Vlieland, T. P. M. (2007). Internet-based physical activity interventions: a systematic review of the literature. Journal of Medical Internet Research, 9, e26.

Van den Eijnden, R., \& Vermulst, A. (2006). Online communicatie, compulsief internetgebruik en het psychosociale welbevinden van jongeren [Online communication, compulsive Internet use and the psycho-social welfare of young people]. In J. De Haan \& C. Van 't Hof (Eds.), Jaarboek ICT en samenleving: De digitale generatie [Yearbook ICT and society: The digital generation] (pp. 25-46). Amsterdam: Boom.

Van Dijck, D., \& Knibbe, R. A. (2005). De prevalentie van probleemdrinken in Nederland: een algemeen bevolkingsonderzoek [The prevalence of problem drinking in the Netherlands: a general public survey]. Maastricht: Maastricht University.

Van Dorst, A. G., \& Crone, M. R. (2006). Actie FF niet: de ontwikkeling en pilot van een niet-roken wedstrijd voor jongeren vanaf 14 jaar [the development and pilot of a non-smoking competition for young people from 14 years]. Leiden: TNO Kwaliteit van Leven [TNO Quality of Life].

Vandelanotte, C., Spathonis, K. M., Eakin, E. G., \& Owen, N. (2007). Website-delivered physical activity interventions: a review of the literature. American Journal of Preventive Medicine, 33, 54-64.

Verheijden, M. W., Jans, M. P., Hildebrandt, V. H., \& Hopman-Rock, M. (2007). Rates and determinants of repeated participation in a web-based behaviour change program for healthy body weight and healthy lifestyle. Journal of Medical Internet Research, 9, e1.

Walters, S. T., Vader, A. M., \& Harris, T. R. (2007). A controlled trial of web-based feedback for heavy drinking college students. Prevention Science, 8, 83-88. 
Weinstein, N. D., \& Sandman, P. M. (1992). A model of the precaution adoption process: evidence from homeradon testing. Health Psychology, 11, 170-180.

White, M. A., Martin, P. D., Newton, R. L., Walden, H. M., York-Crowe, E. E., Gordon, S. T., et al. (2004). Mediators of weight loss in a family-based intervention presented over the Internet. Obesity Research, 12, 1050-1059.

Williamson, D. A., Martin, P. D., White, M. A., Newton, R., Walden, H., York-Crowe, E., et al. (2005). Efficacy of an internet-based behavioral weight loss program for overweight adolescent African-American girls. Eating and Weight Disorders, 1O, 193203.

Williamson, D. A., Walden, H. M., White, M. A., York-Crowe, E., Newton, R. L., Alfonso, A., et al. (2006). Two-year Internet-based randomized controlled trial for weight loss in African-American girls. Obesity, 14, 1231-1243.

Wilson, F. L., Brown, D. L., \& Stephens-Ferris, M. (2006). Can easy-toread immunization information increase knowledge in urban low-income mothers? Journal of Pediatric Nursing, 21, 4-12.

Woodruff, S. I., Conway, T. L., \& Edwards, C. C. (2008). Sociodemographic and smoking-related psychosocial predictors of smoking behavior change among high school smokers. Addictive Behaviors, 33, 354-358.

Woodruff, S. I., Conway, T. L., Edwards, C. C., Elliott, S. P., \& Crittenden, J. (2007). Evaluation of an Internet virtual world chat room for adolescent smoking cessation. Addictive Behaviors, 32, 17691786.

Yanovitzky, I., Stewart, L. P., \& Lederman, L. C. (2006). Social distance, perceived drinking by peers, and alcohol use by college students. Health Communication, 19, 1-10.

Ybarra, M. L., Mitchell, K. J., Wolak, J., \& Finkelhor, D. (2006). Examining characteristics and associated distress related to Internet harassment: findings from the second Youth Internet Safety survey. Pediatrics, 118, e1169-e1177.

Yee, N., Bailenson, J. N., Urbanek, M., Chang, F., \& Merget, D. (2007). The unbearable likeness of being digital: the persistence of nonverbal social norms in online virtual environments. CyberPsychology \& Behavior, 10, 115-121.

Zebrack, J. R., Mitchell, J. L., Davids, S. L., \& Simpson, D. E. (2005). Web-based curriculum. A practical and effective strategy for teaching women's health. Journal of General Internal Medicine, $20,68-74$. 


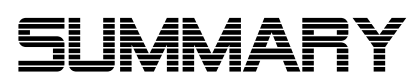

The Internet is thought to have great potential as a communication channel that can combine a high reach with tailored or targeted health promotion. From evidence of efficacy trials, it appears that in practice exposure to Internet-delivered behaviour change interventions is quite low, and this may be even lower when these interventions are implemented in real life. The studies presented in this dissertation aim to understand dissemination of and exposure to Internet-delivered behaviour change interventions and therewith provide opportunities to improve this.

Successful dissemination of an Internet-delivered intervention is required before participants can be exposed to the intervention.

Exposure is a prerequisite to establish desired behaviour change and can be distinguished in three different aspects regarding Internet-delivered interventions: (1) accessing the intervention website, i.e. a first visit, (2) staying on the intervention website long enough to use and process the information and (3) revisiting the intervention website.

The studies presented in this dissertation focus on adolescents while (1) many health risk behaviours are acquired during adolescence, (2) they grew up with the Internet and are more open towards new possibilities offered by this medium, and (3) they are not likely to be internally motivated to invest time in behaviour change interventions in the domain of health promotion.

Chapters 1, 2 and 3 describe explorative research and consist of three studies, covering the literature, experts, and potential users of Internet-delivered interventions.

A systematic review to determine which methods and strategies are effective in facilitating exposure is described in Chapter 1. Potentially relevant articles were retrieved from the PubMED, PsycINFO and Web of Science databases. A study was eligible for inclusion in the review when describing an Internet-delivered intervention aimed at primary prevention of physical chronic diseases through behaviour change and targeted at adolescents or young adults. Several methods and strategies were identified, including e-mail support, tailored feedback, and use of interactive elements and reminders, but their effect on exposure was insufficiently measured. Number of unique visitors was mostly registered, but exposure measures with regard to frequency, duration and activity during visits were often lacking. Most studies used a combination of several methods and strategies, but direct practical application makes it hard to dismantle the effectiveness of single methods and strategies. Effective patterns could be observed, however, such as the combination of tailored communication, the use of reminders to visit or revisit or invitations to participate, and the use of incentives.

Chapter 2 describes a three-round Delphi study to identify factors associated with dissemination and exposure, as well as the extent 
to which experts agree on the importance of these factors. Results showed that there was a high rate of consensus among experts from several disciplines regarding the importance of factors like word of mouth (WOM) recommendation, the attractiveness interface of the intervention at first sight and utilisation of features provided by the Internet (e.g. interactivity). Experts did not agree, however, on a gold standard for successful dissemination. Overall, the results of this exploration serve as a handle for the formation of further research questions to be tested and answered in research among adolescents.

Subsequently, semi-structured focus group interviews were conducted (and described in Chapter 3) with five groups of adolescents. Several factors that are likely to improve exposure were identified, such as the use of WOM marketing, comparison of own behaviour with friends and the use of reminders. Nevertheless, focus group interviews are only a first step in the generation of ideas and opinions. A next step would be to conduct observational and experimental studies to test if and how these factors improve exposure. These studies are described in Chapters 5, 6 and 7.

A conceptual framework for understanding and improving adolescents' exposure to Internet-delivered interventions is proposed in Chapter 4. Although this framework relates to website design in general, it is applied to Internet-delivered behaviour change interventions and results from Chapters 2 and 3 are contextualised. This framework can serve as a tool for health promoters on the one hand, and technical and design staff on the other hand.

As mentioned above, Chapters 5, 6 and 7 of this dissertation consist of experimental and observational studies regarding Internetdelivered interventions which are applied in real-life settings.

In Chapter 5, an Internet-delivered intervention aimed at changing implicit attitudes related to alcohol (http://www.impliciet.eu) was used as an experimental playground to investigate the effect of online WOM on exposure. This strategy was derived from Chapters 2 and 3 and tested in two experiments. The results of the first experiment showed that an invitation by e-mail from a friend was more effective than an invitation from an institution to attract young adults to the intervention website. A 2x2 design was used in the second experiment to test manipulations of argument strength and the use of peripheral cues in invitations. Results showed that strong arguments were more effective to attract young adults to the intervention website if an incentive was mentioned, while weak arguments were more effective when there was no rather than there was an incentive mentioned. These results need to be taken into account when using online WOM as a strategy to improve exposure to Internet-delivered interventions. Although the results of the second experiment could be explained by the elaboration likelihood model (ELM), the possibility of a double role for certain variables (peripheral cue and motivator) is also a limitation of the ELM making falsification of the model impossible. 
Chapter 6 focuses on the relationship between adolescents' intention to change their behaviour and the use of an Internet-delivered lifestyle intervention aimed at multiple health risk behaviours (EMOVO). By means of multilevel analyses, the relationship between intention to change behaviour and adolescents' exposure to E-MOVO's functionalities was investigated. There was a clustering of intention to change risk taking behaviours in an unhealthy way and energy balancerelated behaviours in a healthy way which was associated with the use of E-MOVO's functionalities.

In Chapter 7, the potential of tracking multiple exposure measures was explored, using an Internet-delivered intervention aimed at smoking behaviour as an example (ActieFFniet). Different exposure measures provided insight into different patterns of exposure for subgroups based on educational level. More insight into exposure can be gained by linking exposure measures to variables at the individual level. This offers the opportunity to study potentially mediating effects of exposure on interventions' outcome measures. Exposure measures can also be useful during process evaluation to provide insight into where participants either leave the intervention website or have come to a standstill. This information can be used to adapt interventions and therewith increase exposure rates and probability of behaviour change.

The results of the presented studies are discussed and integrated in the general discussion, and implications for practice and future research are offered. 


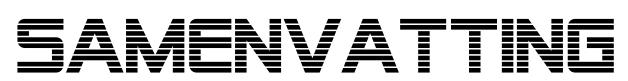

Internet wordt gezien als een communicatiekanaal met groot potentieel, aangezien het een hoog bereik kan combineren met

gezondheidsbevordering-op-maat of gezondheidsbevordering gericht op een specifieke doelgroep. Uit bewijs van doelmatigheidstesten bleek dat de blootstelling aan gedragsveranderingsinterventies via internet in de praktijk behoorlijk laag is en dit zou nog lager kunnen worden wanneer deze interventies daadwerkelijk geïmplementeerd worden. De studies die gepresenteerd worden in deze dissertatie hebben als doel om verspreiding van en blootstelling aan gedragsveranderingsinterventies via internet te begrijpen en daarmee mogelijkheden te bieden om dit te verbeteren.

Succesvolle verspreiding van een internetinterventie is vereist alvorens deelnemers blootgesteld kunnen worden aan de interventie. Blootstelling is vereist om gewenste gedragsverandering te bewerkstelligen en kan onderverdeeld worden in drie verschillende aspecten met betrekking tot internetinterventies: (1) toegang tot de interventiewebsite, i.e. een eerste bezoek, (2) lang genoeg op de interventiewebsite blijven om er gebruik van te maken en de aangeboden informatie te verwerken en (3) het herbezoeken van de interventiewebsite.

De studies die gepresenteerd worden in deze dissertatie richten zich op adolescenten aangezien (1) veel gezondheidsrisicogedragingen aangeleerd worden tijdens de adolescentie, (2) zij opgroeiden met internet en opener staan tegenover nieuwe mogelijkheden die dit medium biedt en (3) zij waarschijnlijk niet intrinsiek gemotiveerd zijn om tijd te investeren in gedragsveranderingsinterventies binnen het domein van gezondheidsbevordering.

Hoofdstukken 1, 2 en 3 beschrijven exploratief onderzoek en bestaan uit drie studies, welke de literatuur, experts en potentiële gebruikers van internetinterventies omvatten.

Een systematisch overzicht om te bepalen welke methoden en strategieën effectief zijn in het faciliteren van blootstelling is beschreven in Hoofdstuk 1. Potentieel relevante artikelen werden verkregen middels de gegevensbestanden PubMED, PsycINFO en Web of Science. Een studie kwam in aanmerking om in het overzicht geïncludeerd te worden wanneer deze een internetinterventie beschreef met als doel primaire preventie van fysieke chronische ziekten door middel van gedragsverandering en gericht was op adolescenten of jongvolwassenen. Verschillende methoden en strategieën werden geïdentificeerd, inclusief e-mail ondersteuning, feedback-op-maat en het gebruik van interactive elementen en reminders, maar het effect hiervan op blootstelling werd onvoldoende gemeten. Het aantal unieke bezoekers werd meestal geregistreerd, maar het ontbrak vaak aan blootstellingsmaten met betrekking tot de frequentie, duur en actviteit gedurende de bezoeken. 
De meeste studies gebruikten een combinatie van verschillende methoden en strategieën, maar direct praktische toepassing hiervan bemoeilijkte ontmanteling van de effectiviteit van losstaande methoden en strategieën. Effectieve patronen, zoals de combinatie van communicatie-op-maat, het gebruik van reminders om te bezoeken of herbezoeken of uitnodigingen om deel te nemen en het gebruik van incentives, konden wel geobserveerd worden.

Hoofdstuk 2 beschrijft een Delphistudie, bestaande uit drie rondes, om te identificeren welke factoren geassocieerd zijn met verspreiding en blootstelling evenals de mate waarin experts overeenstemmen met het belang van deze factoren. Resultaten tonen aan dat er een hoge mate van consensus tussen experts van verschillende disciplines was met betrekking tot het belang van factoren zoals mondtot-mond aanbevelingen, de aantrekkelijkheid van de interface van de interventie op het eerste gezicht en het gebruik maken van kenmerken die geboden worden door internet (e.g. interactiviteit). Experts kwamen echter geen gouden standaard voor succesvolle verspreiding overeen. Als geheel dienen de resultaten van deze exploratie als handvatten voor het opstellen van verdere onderzoekensvragen die getest en beantwoord moeten worden in onderzoek onder adolescenten.

Vervolgens werden semi-gestructureerde focusgroepinterviews uitgevoerd (en beschreven in Hoofdstuk 3) met vijf groepen van adolescenten. Verschillende factoren die blootstelling waarschijnlijk verbeteren werden geidentificeerd, zoals het gebruik van mond-tot-mond marketing, het vergelijken van het eigen gedrag met dat van vrienden en het gebruik van reminders. Focusgroepinterviews zijn niettemin slechts een eerste stap in het genereren van ideeën en meningen. Een volgende stap zou het uitvoeren van observationele en experimentele studies zijn, om te testen of en hoe deze factoren blootstelling verbeteren. Deze studies zijn beschreven in de Hoofdstukken 5, 6 en 7 .

Een conceptueel kader voor het begrijpen en verbeteren van de blootstelling van adolescenten aan internetinterventies is voorgesteld in Hoofdstuk 4. Ondanks dat dit kader relateert aan websitedesign in het algemeen, is het toegepast op gedragsveranderinginterventies via internet en zijn de resultaten van de Hoofdstukken 2 en 3 gecontextualiseerd. Dit kader kan als een hulpmiddel dienen voor gezondheidsbevorderaars enerzijds en technisch en design personeel anderzijds.

Zoals hierboven vermeld, bestaan de Hoofdstukken 5, 6 en 7 van deze disseratie uit experimentele en observationele studies met betrekking tot internetinterventies die zijn toegepast in vivo.

In Hoofdstuk 5 werd een internetinterventie gericht op het veranderen van impliciete attitudes gerelateerd aan alcohol (http://www.impliciet.eu) gebruikt als een experimentele speeltuin voor het onderzoeken van het effect van online mond-tot-mond op blootstelling. Deze strategie werd ontleend aan de Hoofdstukken 2 en 3 en getest in twee experimenten. De resultaten van het eerste experiment 
lieten zien dat een uitnodiging via een e-mail van een vriend effectiever was om jongvolwassenen tot een interventiewebsite aan te trekken dan een uitnodiging van een instelling. Een 2x2 design werd gebruikt in het tweede experiment om manipulaties van argumentsterkte en het gebruik van perifere cues in uitnodigingen te testen. Resultaten lieten zien dat sterke argumenten effectiever waren om jongvolwassenen tot een interventiewebsite aan te trekken wanneer een incentive genoemd werd, terwijl zwakke argumenten effectiever waren wanneer er geen incentive genoemd werd. Deze resultaten moeten in ogenschouw genomen worden wanneer online mond-tot-mond als een strategie gebruikt wordt om blootstelling aan internetinterventies te verbeteren. Ondanks dat de resultaten van het tweede experiment verklaard kunnen worden door het uitweidingswaarschijlijkheid-model (ELM), is de mogelijkheid tot een dubbelrol van bepaalde variabelen (als perifere cue en motivator) ook een beperking van het ELM die falsificatie van het model onmogelijk maakt.

Hoofdstuk 6 richt zich op de relatie tussen de intentie van adolescenten om hun gedrag te veranderen en het gebruik van een online leefstijlinterventie gericht op meerdere gezondheidsrisicogedragingen (E-MOVO). Door middel van multilevel-analyses werd de relatie tussen intentie tot gedragsverandering en het gebruik van E-MOVO's functionaliteiten door adolescenten onderzocht. Er was een clustering van intentie tot gedragsverandering van risiconemende gedragingen op een ongezonde manier en energiebalans-gerelateerde gedragen op een gezonde manier die geassocieerd was met het gebruik van E-MOVO's functionaliteiten.

In Hoofdstuk 7 werd het potentieel van het traceren van meerdere blootstellingsmating geëxploreerd, hierbij als voorbeeld gebruikmakend van een internetinterventie gericht op rookgedrag (ActieFFniet). Verschillende blootstellingsmaten boden inzicht in verschillende patronen van blootstelling voor subgroepen gebaseerd op onderwijsniveau. Meer inzicht in blootstelling kan verkregen worden door het koppelen van blootstellingsmaten aan variabelen op het individuele niveau. Dit biedt de mogelijkheid om potentieel mediërende effecten van blootstelling op de uitkomstmaten van interventies te bestuderen. Blootstellingsmaten kunnen ook gedurende de procesevaluatie bruikbaar zijn om inzicht te bieden in waar deelnemers de interventiewebsite verlaten of blijven hangen. Deze informatie kan gebruikt worden om interventies aan te passen en daarmee de mate van blootstelling te verhogen.

De resultaten van de gepresenteerde studies zijn bediscussieerd en geïntegreerd in de algemene discussie en implicaties voor de praktijk en verder onderzoek worden gegeven. 


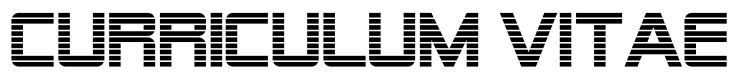

Rik Crutzen grew up happily in the most southern part of the Netherlands. He started studying psychology at Maastricht University in 2000. During his studies, he went abroad to Bond University (Australia) to focus on communication and advertising. After his return to the Netherlands, he started his internship at Noterik Multimedia, Amsterdam. He graduated as a cognitive psychologist in 2004 and moved to Belgium to start studying e-communication at the University of Leuven. He graduated with distinction in 2005. Subsequently, he was employed at the research group of Quantitative Psychology and Individual Differences, also at the University of Leuven, to teach statistics. In June 2006, he returned to the Netherlands, more specifically the department of Health Promotion at Maastricht University, to conduct the studies presented in this dissertation. As of January 2009, he is employed as a post-doctoral researcher at that same department and supported by the School for Public Health and Primary Care (Caphri). Furthermore, he has been appointed as co-editor of The European Health Psychologist. 


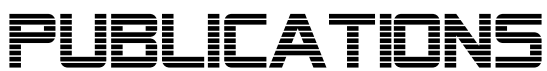

\author{
d.d. 27.11.2008
}

\section{Published}

1. Brouwer, W., Oenema, A., Crutzen, R., De Nooijer, J., De Vries, N. K., \& Brug, J. (2008). An exploration of factors related to dissemination of and exposure to Internet-delivered behavior change interventions aimed at adults: a Delphi study approach. Journal of Medical Internet Research, 10 , e10.

2. Crutzen, R., Brouwer, W., Brug, J., De Vries, N. K., Oenema, A., \& De Nooijer, J. (2008). Gezondheidsbevorderende interventies via internet: onderzoek naar mogelijkheden voor effectievere verspreiding en blootstelling [Health promotion interventions through the Internet: research on possibilities for more effective dissemination and exposure]. Maastricht: Maastricht University.

3. Crutzen, R., De Nooijer, J., Brouwer, W., Oenema, A., Brug, J., \& De Vries, N. K. (2008). Internet-delivered interventions aimed at adolescents: a Delphi study on dissemination and exposure. Health Education Research, 23, 427-439.

4. Crutzen, R., De Nooijer, J., Brouwer, W., Oenema, A., Brug, J., \& De Vries, N. K. (2008). Qualitative assessment of adolescents' views about improving exposure to Internet-delivered interventions. Health Education, 108, 105-116.

5. Crutzen, R., De Nooijer, J., Brouwer, W., Oenema, A., Brug, J., \& De Vries, N. K. (e-pub ahead of print). Effectiveness of online word of mouth on exposure to an Internet-delivered intervention. Psychology \& Health.

6. Crutzen, R., De Nooijer, J., Candel, M. J. J. M., \& De Vries, N. K. (2008). Adolescents who intend to change multiple health behaviours choose greater exposure to an Internet-delivered intervention. Journal of Health Psychology, 13, 898-903.

7. Crutzen, R., De Nooijer, J., \& De Vries, N. K. (2008). How to reach a target group with Internet-delivered interventions? The European Health Psychologist, 10.

8. Reinaerts, E., Crutzen, R., Candel, M. J. J. M., De Vries, N. K., \& De Nooijer, J. (2008). Increasing fruit \& vegetable intake among children: comparing long-term effects of a free distribution and a multi-component program. Health Education Research, 23, 987996.

\section{Submitted}

9. Brouwer, W., Oenema, A., Crutzen, R., De Nooijer, J., De Vries, N. K., \& Brug, J.

What makes people decide to visit and use an Internet-delivered behavior change intervention? A qualitative study among adults. 
10. Crutzen, R., De Nooijer, J., Brouwer, W., Oenema, A., Brug, J., \& De Vries, N. K.

A conceptual framework for understanding and improving adolescents' exposure to Internet- delivered interventions.

11. Crutzen, R., De Nooijer, J., Brouwer, W., Oenema, A., Brug, J., \& De Vries, N. K.

How to facilitate exposure to Internet-delivered health behaviour change interventions aimed at adolescents or young adults? A systematic review on methods, strategies and outcomes.

12. Crutzen, R., De Nooijer, J., Van Dorst, A. G., Crone, M. R., Brouwer, W., Oenema, A., Brug, J., \& De Vries, N. K.

Utilizing exposure measures of Internet interventions: a commendable example on smoking behaviour. 
The problems raised by alcohol and tobacco cannot, it goes without saying, be solved by prohibition. The universal and ever-present urge to self transcendence is not to be abolished by slamming the currently popular Doors in the Wall. The only reasonable policy is to open other, better doors in the hope of inducing men and women to exchange their old bad habits for new and less harmful ones. Some of these other, better doors will be social and technological in nature, others religious or psychological, others dietetic, educational, athletic.

Aldous Huxley, 1954 The Doors of Perception 
